\title{
Gadolinium Concentration Analysis in a Brain Phantom by X-Ray Fluorescence
}

\author{
A thesis submitted in partial fulfilment of the \\ requirements for the degree of Doctor of Philosophy in \\ Medical Physics
}

\section{MUSAED ALIE OTHMAN ALMALKI}
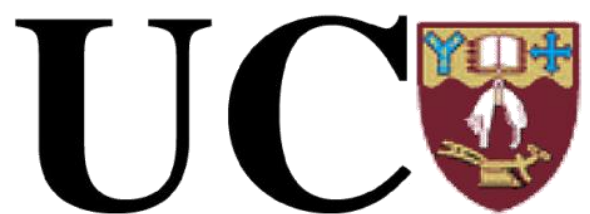

UNIVERSITY OF CANTERBURY

Te Whare Wänanga o Waitaha CHRISTCHURCH NEW ZEALAND

Department of Physics and Astronomy

University of Canterbury

Christchurch, New Zealand

2009

Supervisor: Professor Lou Reinisch PhD 


\section{ACKNOWLEDGEMENT}

The author wishes to express his profound gratitude to Assoc. Prof. Dr. Lou Reinisch, Director of Medical Physics, Department of Physics and Astronomy, University of Canterbury for his kind supervision, cooperation, illuminating discussions, stimulating suggestions, and for his unique exertion in carrying out this research work. The author would like to express his deepest gratitude to Prof. Dr. Samir Abdul-Majid Alzaidi, Department of Nuclear Engineering, King Abdulaziz University, for his valuable advice, thoughtful suggestions, kind co-supervision, and indescribable help. I would like to express my special thanks to Prof. Dr. Phil Butler for his advice, generous co-supervision, continuous encouragement and cooperation. I extend my thanks also to Mr. Wayne Smith, head of mechanical services, Department of Physics and Astronomy, University of Canterbury, and to Engineer Zahoor Alhasan Khan, faculty of Engineering, King Abdulaziz University for their cooperation. I would like to acknowledge Dr. Wael Ghorab, Product Manager, Bayer Schering Pharmacy, for his support and supply of Magnevist contrast medium. The author is obliged to the chairman and faculty members of the Department of Nuclear Engineering, King Abdulaziz University for their support and cooperation for this research work. I would like to express my gratitude to the Ministry of Health in Saudi Arabia for the generous financial support in the form of the scholarship. I also acknowledge the support, and the help from the Saudi cultural offices in Pakistan and Australia. Finally, I am grateful to my parents, my wife and my children for their love, help and encouragement. 


\begin{abstract}
The study was conducted to develop a technique that measures the amount of gadolinium based contrast agent accumulated in a head tumour by x-ray fluorescence, while a patient is exposed to neutrons or during external beam radiotherapy planning. In this research, measurements of the gadolinium concentration in a vessel simulating a brain tumour located inside a head phantom, by the x-ray fluorescence method were taken, where the Magnevist contrast medium which has gadolinium atom, in the tumour vessel, was excited by a $36 \mathrm{GBq}(0.97 \mathrm{Ci}){ }^{241} \mathrm{Am}$ source that emits gamma rays of $59.54 \mathrm{keV}$, in $35.7 \%$ of it's decays, resulting the emission of characteristic fluorescence of gadolinium at $42.98 \mathrm{keV}$ that appeared in the X-ray fluorescence spectrum.
\end{abstract}

A Cadmium Telluride (CdTe) detector was used to evaluate and make an analysis of the gadolinium concentration. Determinations of the gadolinium content were obtained directly from the detector measurements of XRF from gadolinium in the exposed tumour vessel. The intensity measured by the detector was proportional to the gadolinium concentration in the tumour vessel. These concentrations of gadolinium were evaluated for dose assessment.

The positioning of the head phantom was selected to be in the lateral and vertex positions for different sizes of tumour vessels. Spherical tumour vessels of $1.0,2.0,3.0 \mathrm{~cm}$ and an oval tumour vessel of $2.0 \mathrm{~cm}$ diameter and $4.0 \mathrm{~cm}$ length, containing the gadolinium agent, contained concentration between 5.62 to 78.63 
$\mathrm{mg} / \mathrm{ml}$. They were placed at different depths inside a head phantom at different positions in front of the detector and the source for the measurements. These depths ranged from $0.5 \mathrm{~cm}$ to $5.5 \mathrm{~cm}$ between the center of the tumour and interior wall of the head phantom surface.

The total number of measurements in all four sizes of the tumour vessel was $478 ; 78$ examinations of a $1.0 \mathrm{~cm}$ spherical tumour vessel, 110 examinations of a $2.0 \mathrm{~cm}$ spherical tumour vessel, 150 examinations of a $3.0 \mathrm{~cm}$ spherical tumour vessel and 140 examinations of a 2.0 x $4.0 \mathrm{~cm}$ ellipsoid tumour vessel.

To measure the size and the shape of the tumour by the alternative radiographic method, a general x-ray machine with radiograph film was used. Based on that, the appropriate shape of concentration could be selected for therapy. The differences of optical density in the x-ray films showed that the noise was increased with low concentration of the Gd. Because radiographic film may be subjected to different chemical processes where the darkness will be affected, these measurements would be very hard to be quantitative. Accordingly it is difficult to use the film for Gd concentrations. The obtained data show that the method works very well for such measurements. 


\section{TABLE OF CONTENTS}

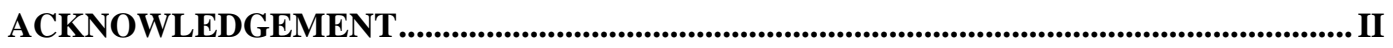

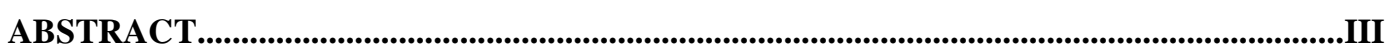

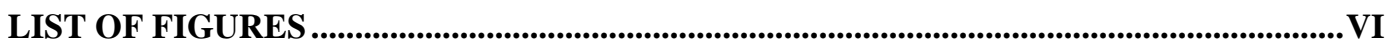

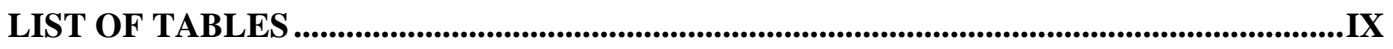

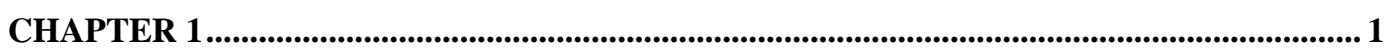

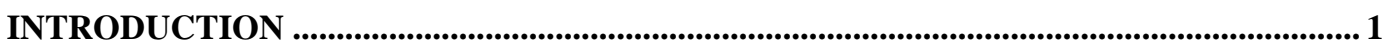

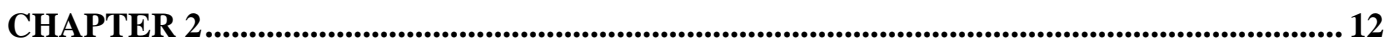

GADOLINIUM CONCENTRATION ANALYSIS IN BRAIN PHANTOM .......................... 12

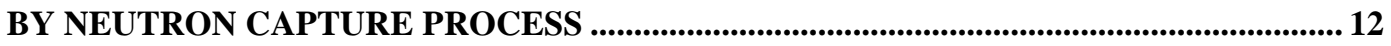

2.1 ATTEMPT TO MEASURE GD CONCENTRATION FROM (N, Г) REACTION ......................... 12

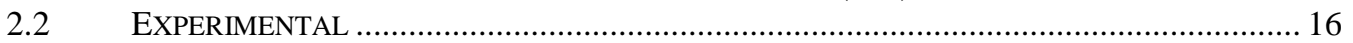

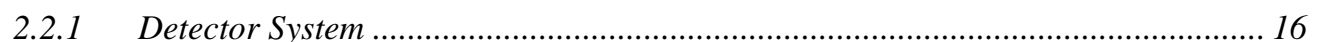

2.2.2 Radiation Source .............................................................................................. 17

2.2.3 Gadolinium Compounds ................................................................................... 18

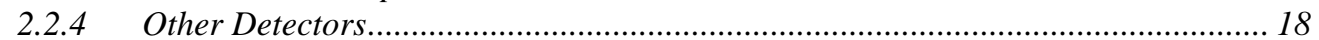

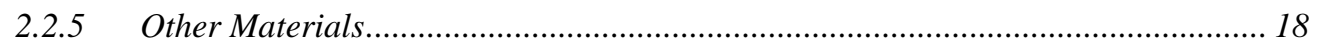

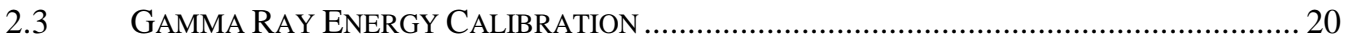

2.4 PROCEDURE TO DESIGN OPTIMUM GEOMETRY FOR GD EXPERIMENT ........................... 22

2.4.1 Gamma ray measured by using ionisation chamber ............................................. 22

2.4.2 Neutron flux measured by using neutron proportional counters ........................... 24

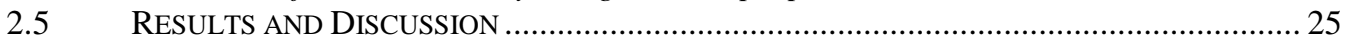

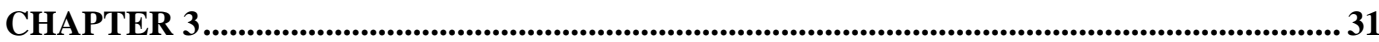

MATERIALS AND METHODS OF THE GADOLINIUM CONCENTRATION ANALYSIS

\begin{tabular}{|c|c|}
\hline 3.1 & 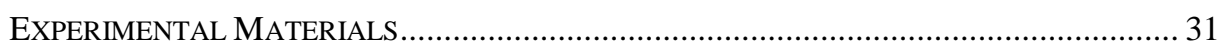 \\
\hline 3.1 .1 & 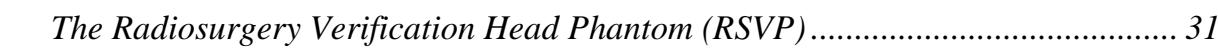 \\
\hline 3.1 .2 & Alignment System \\
\hline 3.1 .3 & 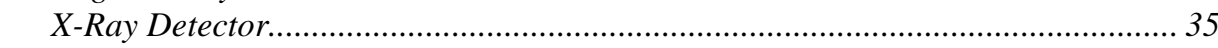 \\
\hline 3.1 .4 & 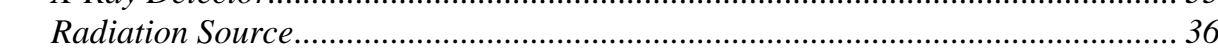 \\
\hline 3.1 .5 & Contrast Examination ................ \\
\hline 3.1 .6 & Other Materials............................... \\
\hline 3.2 & EXPERIMENTAL METHOD ............... \\
\hline 3.2 .1 & X-Ray Energy Calibration ......... \\
\hline 3.3 & PROCEDURE OF MEASURING GD CONCENTRATION \\
\hline
\end{tabular}

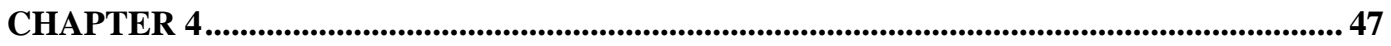

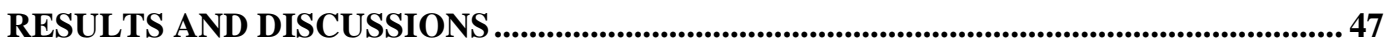

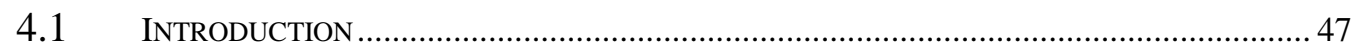

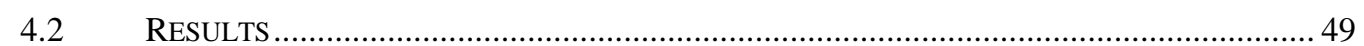

4.2.1 Measurements of $G d$ concentration on lateral position:.......................................... 49

4.2.2 Measurements of $G d$ concentration on vertex position .......................................... 72

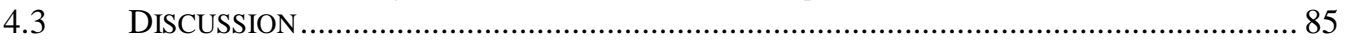

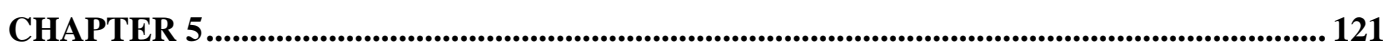

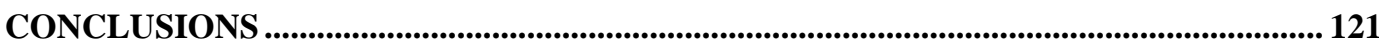

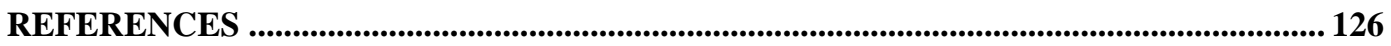




\section{LIST OF FIGURES}

FIGURE 1.1: BRAIN TUMOUR IN RADIOGRAPHIC IMAGE[1] .................................................... 5

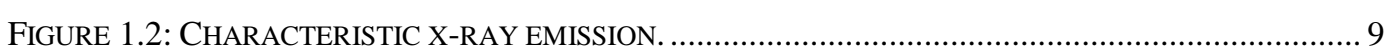

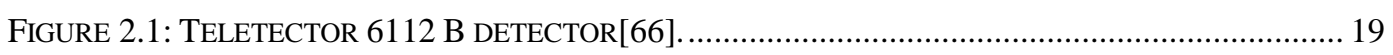

Figure 2.2: NEUTRON DOSIMETER DETECTOR (NM2B), SERIAL No. 433[67]. .............................. 19

FIGURE 2.3: ENERGY CALIBRATION CHART OF THE HPGE DETECTOR........................................... 21

FIGURE 2.4: GAMMA RAYS MEASURED BY USING IONISATION CHAMBER TO DESIGN OPTIMUM GEOMETRY FOR NEUTRON CAPTURE EXPERIMENT. ............................................... 23

FIGURE 2.5: LATERAL VIEW OF SCHEMATIC THAT REPRESENTS THE OPTIMUM GEOMETRY TO MEASURE GD CONCENTRATION........................................................................ 28

FIGURE 2.6: NEUTRON CAPTURE GAMMA RAY SPECTRUM OF BORON. ....................................... 29

FIGURE 2.7: NEUTRON CAPTURE GAMMA RAY SPECTRUM OF GD. ................................................. 30

FIGURE 3.1: COMPONENTS OF THE RADIOSURGERY VERIFICATION HEAD PHANTOM....................... 33

FIGURE 3.2: RADIOSURGERY VERIFICATION HEAD PHANTOM IN AN UPRIGHT POSITION [69]. .......... 33

FIGURE 3.3: ALIGNMENT OF TUMOUR VESSEL SCALE WITH LASER BEAM POINTER. ........................ 34

FIGURE 3.4: XR-100T-CDTE DETECTOR WITH POWER SUPPLY AND AMPLIFIER [70]..................... 35

FIGURE 3.5: SCHEMATIC REPRESENTATION OF THE HEAD PHANTOM CONTAIN TUMOUR VESSEL IN THE LATERAL POSITION. THE SOURCE AND DETECTOR ARE ALSO SHOWN AS A LIGHTER IMAGE IN THE VERTEX POSITION.

FIGURE 3.6: ENERGY CALIBRATION OF SPECTROSCOPY SYSTEM USING KNOWN CHARACTERISTICS

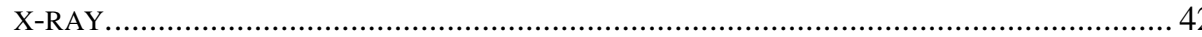

FIGURE 3.7: ENERGY CALIBRATION CURVE OF XR-100T-CDTE DETECTOR................................... 43

FIGURE 4.1: SPECTRUM OF THE CHARACTERISTIC X-RAY OF THE GD OBTAINED FROM A 3 CM DIAMETER TUMOUR VESSEL, WHICH CONTAINED 50.55 MG/ML OF GD AT A DEPTH OF $1.0 \mathrm{CM}$ IN THE LATERAL POSITION.................................................................... 48

FIGURE 4.2: HEAD PHANTOMS CONTAIN TUMOUR VESSEL IN THE LATERAL POSITION. .................... 50

FIGURE 4.3: COUNTS VERSUS CONCENTRATION OF GD AT DIFFERENT DEPTHS OF A 1.0 CM DIAMETER TUMOUR INSIDE A HEAD PHANTOM IN THE LATERAL POSITION. THE LINES ARE DRAWN TO GUIDE THE EYE.

FIGURE 4.4: COUNTS VERSUS CONCENTRATION OF GD AT DIFFERENT DEPTHS OF A 2.0 CM DIAMETER TUMOUR INSIDE A HEAD PHANTOM WITH AND WITHOUT WATER IN THE LATERAL POSITION. THE LINES ARE DRAWN TO GUIDE THE EYE.

FIGURE 4.5: COUNTS VERSUS CONCENTRATION OF GD AT DIFFERENT DEPTHS OF A 3.0 CM DIAMETER TUMOUR INSIDE A HEAD PHANTOM WITH AND WITHOUT WATER IN THE LATERAL POSITION. THE LINES ARE DRAWN TO GUIDE THE EYE.

FIGURE 4.6: COUNTS VERSUS CONCENTRATION OF GD AT DIFFERENT DEPTHS OF 2.0 X $4.0 \mathrm{CM}$ DIAMETER TUMOUR INSIDE A HEAD PHANTOM WITH AND WITHOUT WATER IN THE LATERAL POSITION. THE LINES ARE DRAWN TO GUIDE THE EYE.

FIGURE 4.7: COUNTS VERSUS TUMOUR VESSEL DEPTH AT DIFFERENT CONCENTRATIONS OF GD ON A 1.0 CM DIAMETER TUMOUR, INSIDE HEAD PHANTOM, IN THE LATERAL POSITION.

FIGURE 4.8: COUNTS VERSUS TUMOUR VESSEL DEPTH AT DIFFERENT CONCENTRATIONS OF GD OF A 2.0 CM DIAMETER TUMOUR INSIDE A HEAD PHANTOM WITH AND WITHOUT WATER IN THE LATERAL POSITION. 
FIGURE 4.9: COUNTS VERSUS TUMOUR VESSEL DEPTH AT DIFFERENT CONCENTRATIONS OF GD OF A 3.0 CM DIAMETER TUMOUR INSIDE A HEAD PHANTOM WITH AND WITHOUT WATER IN THE LATERAL POSITION.

FIGURE 4.10: COUNTS VERSUS TUMOUR VESSEL DEPTH AT DIFFERENT CONCENTRATIONS OF GD OF A 2.0 X 4.0 CM DIAMETER TUMOUR INSIDE A HEAD PHANTOM WITH AND WITHOUT WATER IN THE LATERAL POSITION

FiguRE 4.11: CALCULATED ATTENUATION COMPARED WITH MEASURED ATTENUATION AT DIFFERENT DISTANCE (CM) AND DIFFERENT CONCENTRATIONS OF GD ON A $2.0 \mathrm{CM}$, 3.0 CM AND $2.0 \times 4.0$ CM DIAMETER TUMOUR, INSIDE HEAD PHANTOM WATER, IN THE LATERAL POSITION.

FIGURE 4.12: COUNTS VERSUS TOTAL AMOUNT OF GD IN DIFFERENT TUMOUR SIZES IN THE HEAD PHANTOM WITHOUT WATER AT A DEPTH OF 1.5 CM FOR ALL SIZES IN THE LATERAL POSITION.

FIGURE 4.13: RADIOGRAPH OF THE 3 CM TUMOUR VESSEL WHICH CONTAINS 0.56 MG/ML OF GD CONCENTRATION INSIDE THE HEAD PHANTOM TAKEN AT 73KVP, 20 MAS, AND AT 105 CM SFD.

FIGURE 4.14: RADIOGRAPH OF THE 3 CM TUMOUR VESSEL WHICH CONTAINS 2.81 MG/ML OF GD CONCENTRATION INSIDE THE HEAD PHANTOM TAKEN AT 73KVP, 20 MAS, AND AT 105 CM SFD.

FIGURE 4.15: RADIOGRAPH OF THE 3 CM TUMOUR VESSEL WHICH CONTAINS 5.62 MG/ML OF GD CONCENTRATION INSIDE THE HEAD PHANTOM TAKEN AT 73KVP, 20 MAS, AND AT 105 CM SFD.

FIGURE 4.16: RADIOGRAPH OF THE 3 CM TUMOUR VESSEL WHICH CONTAINS 16.85 MG/ML OF GD CONCENTRATION INSIDE THE HEAD PHANTOM TAKEN AT 73KVP, 20 MAS, AND AT 105 CM SFD.

FIGURE 4.17: RADIOGRAPH OF THE 3 CM TUMOUR VESSEL WHICH CONTAINS 28.08 MG/ML OF GD CONCENTRATION INSIDE THE HEAD PHANTOM TAKEN AT 73KVP, 20 MAS, AND AT 105 CM SFD.

FIGURE 4.18: RADIOGRAPH OF THE 3 CM TUMOUR VESSEL WHICH CONTAINS 39.32 MG/ML OF GD CONCENTRATION INSIDE THE HEAD PHANTOM TAKEN AT 73KVP, 20 MAS, AND AT $105 \mathrm{CM}$ SFD.

FIGURE 4.19: RADIOGRAPH OF THE 3 CM TUMOUR VESSEL WHICH CONTAINS 50.55 MG/ML OF GD CONCENTRATION INSIDE THE HEAD PHANTOM TAKEN AT 73KVP, 20 MAS, AND AT 105 CM SFD.

FIGURE 4.20: RADIOGRAPH OF THE 3 CM TUMOUR VESSEL WHICH CONTAINS 78.63 MG/ML OF GD CONCENTRATION INSIDE THE HEAD PHANTOM TAKEN AT 73KVP, 20 MAS, AND AT 105 CM SFD.

FIGURE 4.21: DIFFERENCE OF OPTICAL DENSITY VERSUS CONCENTRATION OF GD IN A 3.0 CM DIAMETER TUMOUR VESSEL, AT 1.5 CM DEPTH INSIDE THE HEAD PHANTOM, IN THE LATERAL POSITION.

FIGURE 4.22: HEAD PHANTOMS CONTAIN TUMOUR VESSEL IN THE VERTEX POSITION.

FIGURE 4.23: COUNTS VERSUS CONCENTRATIONS OF GD AT DIFFERENT DEPTHS OF A 1.0 CM DIAMETER TUMOUR, INSIDE THE HEAD PHANTOM IN THE VERTEX POSITION.

FIGURE 4.24: COUNTS VERSUS CONCENTRATIONS OF GD AT DIFFERENT DEPTHS OF A 2.0 CM DIAMETER TUMOUR, INSIDE THE HEAD PHANTOM WITH AND WITHOUT WATER, IN THE VERTEX POSITION

FIGURE 4.25: COUNTS VERSUS CONCENTRATIONS OF GD AT DIFFERENT DEPTHS OF A 3.0 CM DIAMETER TUMOUR, INSIDE THE HEAD PHANTOM WITH AND WITHOUT WATER, IN THE VERTEX POSITION. 
FIGURE 4.26: COUNTS VERSUS CONCENTRATIONS OF GD AT DIFFERENT DEPTHS OF A 2.0 X 4.0 CM DIAMETER TUMOUR, INSIDE THE HEAD PHANTOM WITH AND WITHOUT WATER, IN THE VERTEX POSITION.

FIGURE 4.27: COUNTS VERSUS TUMOUR VESSEL DEPTH AT DIFFERENT CONCENTRATIONS OF GD IN A 1.0 CM DIAMETER TUMOUR, INSIDE THE HEAD PHANTOM IN THE VERTEX POSITION.

FIGURE 4.28: COUNTS VERSUS TUMOUR VESSEL DEPTH AT DIFFERENT CONCENTRATIONS OF GD IN A 2.0 CM DIAMETER TUMOUR, INSIDE THE HEAD PHANTOM WITH AND WITHOUT WATER, IN THE VERTEX POSITION.

FIGURE 4.29: COUNTS VERSUS TUMOUR VESSEL DEPTH AT DIFFERENT CONCENTRATIONS OF GD ON A 3.0 CM DIAMETER TUMOUR, INSIDE THE HEAD PHANTOM WITH AND WITHOUT WATER, IN THE VERTEX POSITION.

FIGURE 4.30: COUNTS VERSUS TUMOUR VESSEL DEPTH AT DIFFERENT CONCENTRATIONS OF GD ON A 2.0 X 4.0 CM DIAMETER TUMOUR, INSIDE THE HEAD PHANTOM WITH AND WITHOUT WATER, IN THE VERTEX POSITION.

Figure 4.31: CALCULATED ATTENUATION COMPARE WITH MEASURED ATTENUATION AT DIFFERENT DISTANCE (CM) AND DIFFERENT CONCENTRATIONS OF GD ON A $2.0 \mathrm{CM}$, 3.0 CM AND $2.0 \times 4.0 \mathrm{CM}$ DIAMETER TUMOUR, INSIDE HEAD PHANTOM, IN THE VERTEX POSITION.

FIGURE 4.32: COUNTS VERSUS TOTAL AMOUNT OF GD IN DIFFERENT TUMOUR SIZES IN THE HEAD PHANTOM WITHOUT WATER, AT A DEPTH OF $2.0 \mathrm{CM}$, FOR ALL SIZES IN THE VERTEX POSITION.

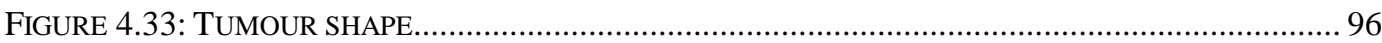

FIGURE 4.34: SCHEMATIC OF RADIATION INTERACTION INSIDE HEAD PHANTOM.......................... 102

FIGURE 4.35: SCHEMATIC OF AFFECT OF SCATTERED RADIATION INSIDE HEAD PHANTOM............. 102

FIGURE 4.36: CONSTANT VALUE OF A PARAMETER VERSUS DEPTHS. .......................................... 109

FIGURE 4.37: CONSTANT VALUE OF B PARAMETER VERSUS DEPTHS........................................... 109 


\section{LIST OF TABLES}

TABLE 2.1: DIFFERENT TYPE OF ISOTOPE SOURCES USED FOR THE RESEARCH. ............................... 17

TABLE 2.2: CAPTURE GAMMA RAYS ENERGY OF GD ATOMS...................................................... 21

TABLE 2.3: SLOW NEUTRON FLUX MEASURED BY USING THE $\mathrm{BF}_{3}$ COUNTER TO DESIGN FOR OPTIMUM GEOMETRY FOR NEUTRON CAPTURE EXPERIMENT. .................................... 24

TABLE 3.1: CHARACTERISTICS X-RAYS ENERGY CALIBRATION OF SPECTROSCOPY SYSTEM USING KNOWN ELEMENT.

TABLE 4.1: COUNTS FOR 30 MIN OF GD CHARACTERISTICS X-RAY AT DIFFERENT CONCENTRATIONS OF GD AND DIFFERENT DEPTHS INSIDE THE HEAD PHANTOM OF A 1.0 CM DIAMETER TUMOUR IN THE LATERAL POSITION............................................. 106

TABLE 4.2: LIST OF A \& B CONSTANT VALUES..................................................................... 108

TABLE 4.3: LIST OF GENERAL EQUATION FOR EACH TUMOUR CASE. ............................................ 112

TABLE 4.4: LOGG AND COUNTS MEASUREMENT AT DIFFERENT CONCENTRATIONS AND DEPTHS ... 115

TABLE 4.5: LIST OF GD CONCENTRATION EQUATIONS FOR EACH TUMOUR CASE USING MINITAB SOFTWARE. 


\section{CHAPTER 1}

\section{INTRODUCTION}

The human body is composed of a huge number of cells, which have the ability to divide and reproduce. This is required for body growth and to replace cells that die during physiological function or as a result of diseases. This division is normally under a control system, but for any reason, if cell reproduction becomes independent or autonomous, in a way that does not serve a specific need, then a tumour will occur.

A brain tumour is defined as any intracranial mass formed as a result of uncontrolled cellular growth as shown in Figure 1.1. Clinically, brain tumours can be classified as malignant or benign according to their pathological behaviour. Malignant tumours are either primary (i.e., originating from the brain itself) or secondary (i.e., originating from other locations, metastatic tumours). Primary brain tumours can originate from neurons, glial cells (astrocyts, oligodendrocytes, and ependymal cells), lymphatics, blood vessels, nerves, brain envelope (meninges) and skull.

Symptoms of brain tumours vary, depending on the type, size and location of the tumour. Benign tumours are usually slow growing while malignant tumours are fast growing with rapidly progressive symptoms. Large tumours can present symptoms of elevated intracranial pressure such as headache, vomiting and altered levels of consciousness. Focal neurological signs are not uncommon in brain tumours. These may include weakness or paralysis, sensory loss, visual 
impairment, behavioural impairments, imbalance, personality changes and seizures.

Imaging plays a crucial role in the diagnosis of brain tumours. Noninvasive high resolution imaging modalities such as computed tomography (CT) and magnetic resonance imaging (MRI) have replaced older invasive methods such as pneumoencephalography and cerebral angiography and other techniques that provide a geometrical reconstruction and a three-dimensional space visualisation for the recognised brain tumour region. Definitive diagnosis can only be confirmed by histological examination of the tumour tissue, obtained either by means of open surgery or biopsy[1, 2].

The 1997 Central Brain Tumour Registry of the United States shows more than 14 people were diagnosed with primary brain tumours per 100,000 population [3]. Radiation therapy plays a major role in the treatment planning by using ionising radiation. This is a form of energy whose absorption in tissues leads to a chain of physical and chemical events. These events result in the induction of biological damage to nucleic acids in chromosomes which are vital constituents of living cells.

Nucleic acids are the main constituents of genes and carry the code for the genetically determined characters of the living cell. However, when repairing the induced damage, errors may occur. This may have two consequences. Firstly: the structure of the gene may change at the site of damage, which can lead to a genetic mutation with the appearance of new genetic characters. Most new characters are harmful and can lead to the occurrence of hereditable defects. Alternatively, it may lead to a long chain of alterations that result in the 
transformation of the cell into a malignant one: a process that is called carcinogenesis. Secondly: if the damage occurs in a cell capable of division, the cell may not be able to complete the division cycle and may die during the division process. This will stop or slow down the process of production of new cells. This particularly influences tissues whose cells are short lived and require a high rate of production of new cells to replace those that are lost under normal physiological condition. Stoppage or slowing down of production of new cells would then lead to a rapid reduction in the number of tissue cells.

Continuation of tumour growth depends on the activity of the tumour stem cells that have an unlimited capacity for division. In tumours, cell production exceeds cell production in the surrounding healthy tissue. This can occur as a result of nourishment or a lack of host resistance that will result in increasing the size of the tumour. The success of radiotherapy depends on the probability of killing all tumour stem cells. Consequently, we need to deliver a large dose to the tumour. This always involves the delivery of a large radiation dose to the normal tissues in the neighbourhood, and this produces various degrees of normal tissue damage resulting in the stoppage or slowing down of the division of normal tissue stem cells[4].

It is the task of the radiotherapist to plan an optimum treatment that can achieve maximal damage within the tumour and the least damage in the surrounding normal tissue. These treatments include neutron therapy that has been used since 1930 and is very effective compared with the conventional radiotherapy. It has the ability to deliver the maximum dose of the radiation to the tumour cells with minimum dose to the normal tissue around the tumour. 
In lower energy electron and photon radiation, the damage will happen because the atomic interactions with low linear energy transfer (low LET). With the fast neutrons however, the energy will be higher (high LET) and the damage will be from nuclear interactions. The advantage of neutron therapy is the ability of the neutron to deposit up to 100 times of the energy per unit intensity to the tumour compare with conventional high energy x-rays from linear accelerator radiation. This is because, following neutron interaction, charged particles like alpha or conversion electrons emitted following a neutron absorption deposit all their energy in the tumour, while high energy x-rays deposit only a small fraction of their energy. Moreover the cross sections of interaction of neutrons with Gadolinium or Boron are much higher than that of x-rays. Also, the biological advantages of the neutron over conventional radiation, is that neutron has a higher probability of creating a double strand breakage of the deoxyribonucleic acid (DNA).

The biological effectiveness is not affected by the growth stage of tumour cells and unlike low LET radiation does not depend on the presence of oxygen to be effective [5-7]. 


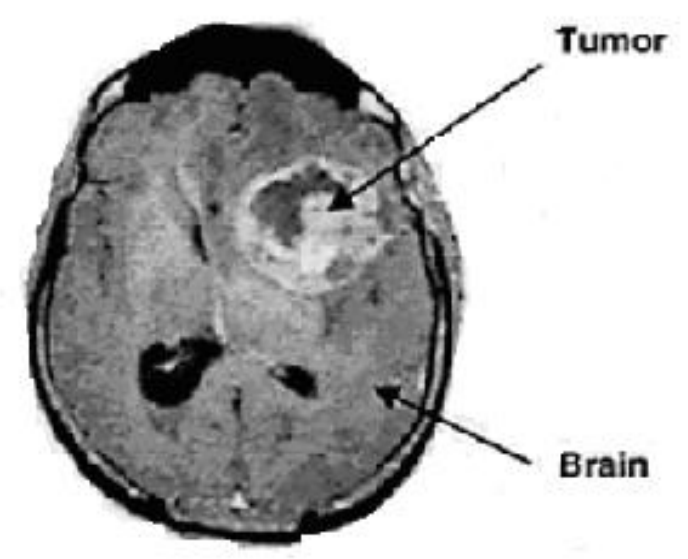

Figure 1.1: Brain tumour a radiographic image[1].

Neutron radiotherapy can be used as external beam therapy or as neutron capture therapy (NCT). Neutron capture treatment is an effective means in tumour therapy where the dose is delivered mainly to the tumour, leaving a negligible dose to the surrounding healthy tissue. This is unlike other radiation treatment methods, such as treatment with an incident external beam from a linear accelerator. In this case healthy tissue, in the path of the incident beam, is exposed during treatment. In NCT, stable therapeutic agents are delivered to the tumour and then exposed to neutrons. Stable agents in the tumour emit different radiation patterns following neutron capture, depending on the type of therapeutic agent.

Most often gadolinium (Gd) and boron compounds are injected into the body and concentrate in the tumour. The dose delivered to the tumour is of prime interest to the therapists. Because the Gd compounds gradually build up in the tumour, followed by elimination, it is important to know the time when the highest concentration is reached, in order to give the most effective treatment. 
The extra cellular Gd agents have been administered safely to over 10 million patients, since gadoteridol was first approved for marketing in the United States in 1992 [8]. Gadolinium-diethylenetriamine penta-acetic acid (Gd-DTPA) is one such agent capable of strong proton relaxation enhancement with relatively high in-vivo tolerance. This hydrophilic complex is rapidly excreted, predominately in the urine. Apparently it does not dissociate in-vivo [9]. The Gd dose used in the irradiation experiments was four times the current accepted high dose in clinical MRI[10].

In recent years the stable element $\mathrm{Gd}$ has received a lot of attention in research with regards to NCT, which is a promising radiation therapy for brain cancer treatment [11-25]. In this type of treatment, a non-radioactive compound that contains $\mathrm{Gd}$, an element with a high thermal neutron absorption cross section for neutron reactions, is introduced into the patient. There is significant accumulation of the agent in the tumour cells. The body is then irradiated from outside with neutrons. Upon absorption of thermal neutrons, the compound is activated and radiation is emitted, giving a highly localised dose to the tumour and a much lower dose to the surrounding healthy tissue. This has distinct advantages over other types of treatment, where healthy tissue may receive significant doses. Boron-10 is known for such treatment but gadolinium-157 radionuclides have a thermal neutron cross section of 255,000 barn and releases $7.9 \mathrm{MeV}$ per neutron absorbed, compared with a 3,838 barn thermal neutron cross section for boron-10 which releases only $2.79 \mathrm{MeV}$. The high thermal neutron cross section for gadolinium-157 may permit a reduced irradiation time and a lower neutron dose delivered to the healthy tissues. 
Moreover, the Gd compound was also developed as a contrast-enhancing agent for MRI. Because Gd emits conversion electrons and several x-rays following neutron absorption, it gives a wider dose distribution than boron-10 which gives a highly localised dose due to producing energetic alpha particles and lithium atoms following neutron absorption, as shown in the equation below:

$$
{ }^{10} \mathrm{~B}+\mathrm{n}_{\mathrm{th}} \rightarrow{ }^{4} \mathrm{He}+{ }^{7} \mathrm{Li}+\gamma \text { 's } \quad \mathrm{Q}_{\text {value }} \approx 2.79 \mathrm{MeV}
$$

Also, boron has poor tumour to blood ratios, poor solubility in aqueous or biological media, and lacks tumour specificity [26-38]. In recent work, [39] the two radionuclides combined were considered for treatment. Each compensates for the other's disadvantages and new compounds are being developed as carrying agents.

In order to evaluate the dose delivered to a patient and to determine the duration of the irradiation, it is important to know the amount of $\mathrm{Gd}$ atoms in the tumour and the reaction rates with neutrons. After each neutron absorption, a fixed amount of energy is released and dissipated in the tissue.

Current methods of measuring Gd distribution in a rat model [40, 41] include MRI for brain scans and neutron autoradiography with gadolinium-157. Neither of these techniques can be used for accurate determination of doses in the clinical setting. Both techniques are time consuming and the time period between imaging and treatment is too long. By the time a patient is imaged and prepared for treatment by neutron irradiation, a significant amount of $\mathrm{Gd}$ is eliminated. This is due to the Gd compound's biological half-life which is approximately 30 minutes [42]. 
Neutron autoradiography is the creation of an image of the target tissue on an X-ray film emulsion due to the radioactive material inserted into the target. This technique has been used on a sliced tissue sample containing Gd, but not for invivo measurements [43]. It is expected to be extremely complicated for in-vivo measurements. Also, MRI is an expensive imaging technique that may or may not be available at the place where neutron irradiation is carried out.

$\mathrm{X}$-ray fluorescence $(\mathrm{XRF})$ is one of the principal techniques used for quantitative analysis of high- $\mathrm{Z}$ materials. It determines the concentration and identity of elements and minerals. It was the first clinical method used for noninvasive measurement of natural iodine in the thyroid gland [44]. Later, this XRF technique was used to measure x-ray contrast agents containing iodine in body tissue [45]. Since then, the technique has been used to study the elemental concentration of different metals such as cadmium in the kidney, mercury, strontium and lead in the bone tissue that are toxic to the human body if present in too high a concentration [46-50]. Minimum detectable lead concentrations in the tibia bone were between $8-35 \mu \mathrm{g} / \mathrm{g}$ of bone mineral, these concentrations were obtained when target material is exposed to radiation sources such as ${ }^{99 \mathrm{~m}} \mathrm{Tc},{ }^{109} \mathrm{Cd}$ or ${ }^{157}$ Co [51-53].

In XRF, the target material is irradiated with a gamma source. A photoelectric effect occurs when the atom is absorbed by the gamma ray and gives all its energy to the electron in the inner shell that is then ejected from the atom and creates a vacancy. These vacancies cause the atom to be unstable. To return to its stable state, electrons from the outer shell move into replace the one removed. They produce a characteristic $\mathrm{x}$-ray with energy equal to the difference between 
the two binding energies of the corresponding shells, Figure 1.2. The energy of the emitted radiation is characteristic of the element.

The characteristic x-ray is termed as $\mathrm{K}, \mathrm{L}$, or M to indicate the shells they originated from. Also, $\mathrm{x}$-rays that originate from the transition of electrons from higher shells is labelled as $\alpha, \beta$, or $\gamma$. So, if the replacing electron originates from the $\mathrm{L}$ shell, it is labelled $\mathrm{K}_{\alpha}$, while the electron which is comes from the $\mathrm{M}$ shell is labelled as $\mathrm{K}_{\beta}$.

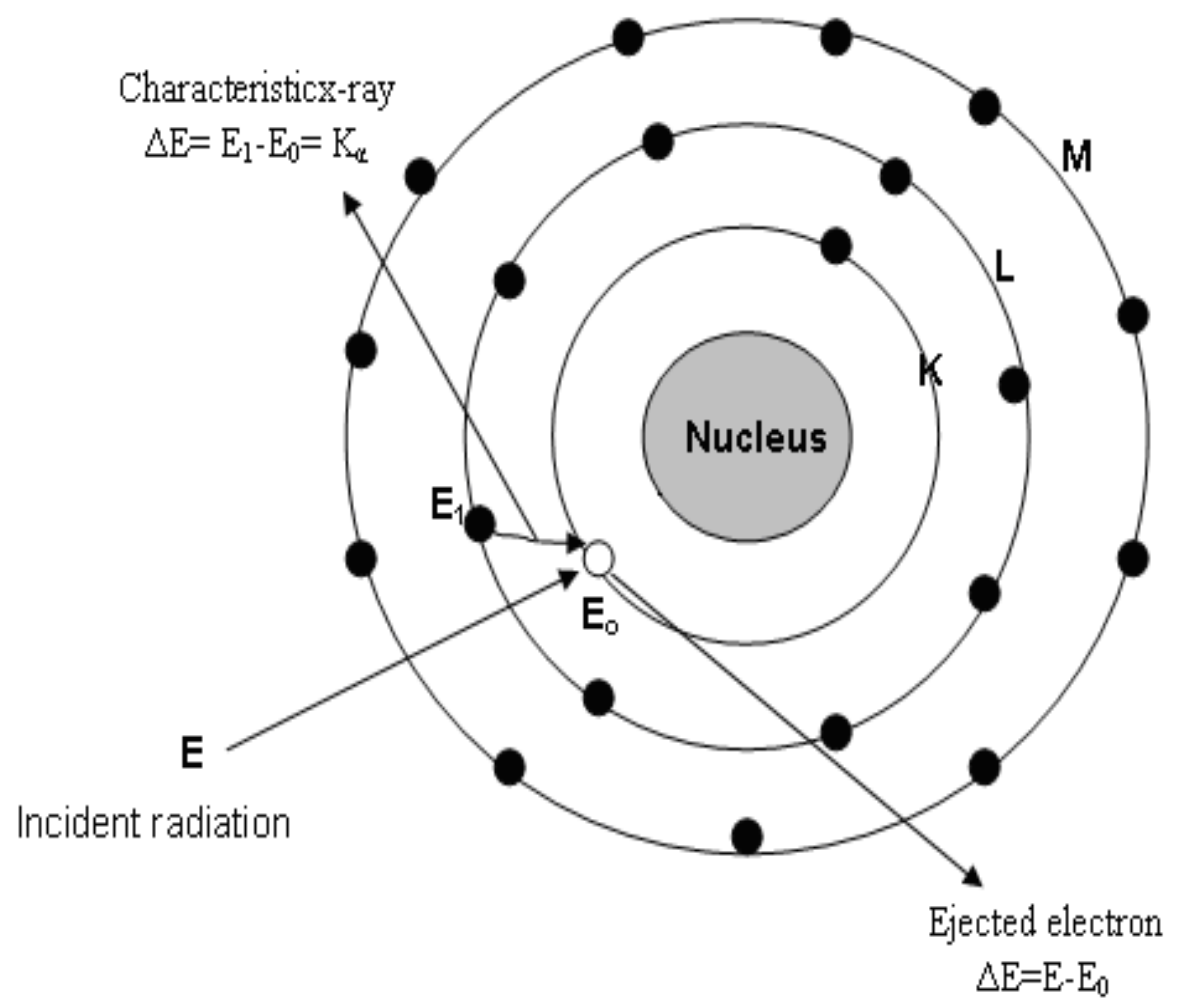

Figure 1.2: Characteristic x-ray emission.

Our study was conducted to start the development of a technique that measures the amount of Gd in a brain tumour vessel by the XRF at the same time a patient is exposed to the neutrons or during external beam radiotherapy 
planning. It is intended to measure Gd concentration in the brain tumour vessel in a head phantom. In this method, gamma rays are allowed to be incident on the organ under investigation. Following the absorption of gamma rays by Gd atoms, characteristic x-rays are emitted and measured by a solid state detector and associated electronics. The intensity measured by the detector is dependent on the $\mathrm{Gd}$ concentration. The amount of $\mathrm{Gd}$ can be evaluated for dose assessment. Variables of this measurement were: tumour vessel size, tumour shape, depth of the tumour vessel, concentration of the Gd solution and position of the head phantom.

Gadolinium atoms in the tumour vessel were excited by a $36 \mathrm{GBq}(0.97$ Ci) americium-241 $\left({ }^{241} \mathrm{Am}\right)$ source $\left(\mathrm{T}_{1 / 2}=432.7\right.$ years $)$, that produces 59.5 $\mathrm{keV}$ gamma rays with a relative probability of 0.357 per disintegration. A cadmium telluride detector measures emitted characteristic fluorescence radiation. Because the energy of the incident radiation is greater than the binding energy of electrons of the $\mathrm{Gd}$ atom, absorption will occur mainly via the photoelectric effect. Characteristic of the Gd, $42.98 \mathrm{keV}$ photons were measured. The observed count rate from x-ray peaks of the Gd was dependent on the amount of Gd present in the brain tumour vessel.

A second method that depends on neutron capture gamma ray was attempted as well. Using this technique, neutrons from a californium-252 $\left({ }^{252} \mathrm{Cf}\right)$ source are allowed to be incident on the tumour vessel that contains Gd inside a head phantom. Following the neutron capture $(n, \gamma)$ reaction, the emitted gamma rays are measured by a high purity germanium (HPGe) detector and associated electronics. 
The intensity of the gamma ray should be proportional to the concentration of Gd in the tumour vessel. Experimental work was performed, but was not entirely successful. The measured data and limitations of this additional method are presented in Chapter 2. 


\section{CHAPTER 2}

\section{Gadolinium Concentration Analysis in a Brain Phantom By a Neutron Capture Process}

This chapter presents attempts to measure concentrations of the Gd in brain tumour vessels using a neutron source. It consists of five sections. The first section describes attempts to measure $\mathrm{Gd}$; the second section presents the experimental method; the third section describes the calibration; the fourth section presents the procedure and the last section is the results and discussion.

\subsection{Attempt to measure $\mathrm{Gd}$ concentration from $(\mathrm{n}, \gamma)$ reaction}

Neutron capture therapy is a radiotherapy technique utilised for brain tumour treatment in which the tumour contains a non-radioactive agent. When exposed to neutron radiation this agent is converted it into a radioactive agent. In this type of therapy, gadolinium-157, which has the highest thermal neutron capture cross section is introduced into the tumour cells through Gd agent molecules such as Gd-DTPA, which were designed to penetrate the cell membrane and then release the Gd atom that can bind to the DNA $[54,55]$.

When the human body is irradiated from the outside by neutrons, gadolinium-157 atoms inside the tumour absorb a slow neutron to become gadolinium-158 as shown in the reaction below. Gadolinium neutron capture 
reactions produce Auger electrons, internal conversion electrons, prompt gamma rays and X-rays.

${ }^{157} \mathrm{Gd}+\mathrm{n}_{\mathrm{th}} \rightarrow{ }^{158} \mathrm{Gd}+\gamma+\mathrm{x}$-rays $+\mathrm{IC}$ e- $+\mathrm{A} \mathrm{e}-, \quad \mathrm{Q} \approx 7.94 \mathrm{MeV}$

where IC e- are the internal conversion electrons, and A e- are the Auger electrons. High energy capture gamma rays can easily escape from the body and be measured by a high-resolution gamma detector such as a HPGe. The new isotope spontaneously decays with $69 \%$ of the nuclear decay yielding internal conversion electrons of energy $45-46 \mathrm{keV}$ with range $60 \mu \mathrm{m}$. These electrons are ejected from the atoms and create a vacancy that is filled by electrons from outer shells, emitting x-rays or Auger electrons with 5-9 keV energies [56]. Gamma rays and conversion electrons released in the gadolinium-157 (n, $\gamma$ ) reaction deliver a dose to the cells in the brain tumour, causing a number of double strand breaks of DNA and cell death.

After gadolinium-157 atom in the tumour cell absorbs slow neutron, it produces gamma rays, conversion electrons and Auger electrons. These electrons, dissipate their energy in the tumour. Gamma rays penetrates the tumour and only a small fraction of its energy is dissipated in it. For $944 \mathrm{keV}$ emitted following a neutron capture, the half-value layer is $10 \mathrm{~cm}$. for a bout $1 \mathrm{~cm}$ diameter tumour the calculated energy deposited will be about $7 \%$ as most of the ray leave the tumour without interaction. On the other hand, the range of Internal Conversion electrons is $60 \mu \mathrm{m}$ and for Auger electrons about $1 \mu \mathrm{m}$, accordingly all their energies are deposited in tumour, causing a double strand break in DNA. 
The long range component photon of $157-\mathrm{Gd}$ is able to increase the dose received by quiescent tumour cells (i.e., cells that do not have strong uptake of the carrying agent) [57]. Studies indicate that concentrations of up to $300 \mu \mathrm{g} / \mathrm{g}$ of tumour can be achieved in a brain tumour with Gd-DTPA and gadoliniumtetraazacyclododecanetetraacetic acid (Gd-DOTA) contrast agents and up to 800 $\mu \mathrm{g} / \mathrm{g}$ of bone tumour with gadolinium-ethylene diamine tetramethylphosphonate (Gd-EDTMP) [58].

The total dose rates from $1000 \mu \mathrm{g} / \mathrm{g}$ of $\mathrm{Gd}$ in tumour were $2 \mathrm{~Gy} / \mathrm{hr}$ of neutrons, $5.5 \mathrm{~Gy} / \mathrm{hr}$ of gamma rays while from the electrons it was $5 \mathrm{~Gy} / \mathrm{hr}$ [59$61]$.

Monte Carlo calculations such as Monte Carlo N-Particle code (MCNP4B) show that Gd NCT provides a high tumour dose. Also, it was used to calculate the total dose distribution from neutrons and prompt gamma emissions for Gd NCT of the brain tumours $[62,63]$.

In early work, the Gd concentration in rare earth ores was determined, using capture gamma rays, from $10-100 \mathrm{mg}$ of each ore sample using a thermal neutron flux of $10^{8} \mathrm{n} / \mathrm{cm}^{2} \mathrm{~s}$ [64].

Gadolinium appears to be a promising alternative to boron as an NCT agent. It has distinct advantages over other types of treatment, where healthy tissue may receive significant doses.

In this technique, neutrons from a ${ }^{252} \mathrm{Cf}$ source are slowed down by water to become thermal neutrons then they incident on the tumour vessel inside the head phantom. Following the neutron capture $(n, \gamma)$ reaction, emitted gamma rays 
are measured by an HPGe detector and the associated electronics. The intensity of the characteristic gamma ray is proportional to the concentration of the Gd. 


\subsection{Experimental}

\subsubsection{Detector System}

The first detector used was a portable HPGe detector, with a relative efficiency of $20 \%$ (Canberra, USA). The genie PC multichannel analyser (MCA) programme supplied by Canberra comprises a power supply, a spectroscopy amplifier and a Pentium computer with a special card and software. The MCA had 8192 channels. The second detector was a standard Tennelec HPGe coaxial detector, a vertical type with a relative efficiency of $20 \%$ and high energy resolution (Tennelec INC, Oak Ridge-USA). The HPGe detectors were supplied with a liquid nitrogen Dewar, and a preamplifier/electronics package which was connected to a single channel analyser, counter/rate meter, computer-based MCA board, computer data analysis and storage and display. 


\subsubsection{Radiation Source}

A number of radiation sources were used for both calibration and the experiment as shown in Table 2.1.

Table 2.1: Different type of isotope sources used for the research.

\begin{tabular}{|c|c|c|c|c|}
\hline Source & Activity & Half-Life & $\gamma(\mathrm{keV})$ & Calibration Date \\
\hline${ }^{252} \mathrm{Cf}$ & $1.4 \mathrm{mCi}$ & 2.64 year & 100.2 & $\begin{array}{l}\text { September } 19 \text {, } \\
2005\end{array}$ \\
\hline${ }^{241} \mathrm{Am}-\mathrm{Be}$ & $3 \mathrm{mCi}$ & 458 year & 59.54 & $\begin{array}{c}\text { December 18, } \\
1981\end{array}$ \\
\hline \multirow[t]{2}{*}{${ }^{137} \mathrm{Cs}$} & $0.962 \mu \mathrm{Ci}$ & 30 year & \multirow[t]{2}{*}{661.66} & $\begin{array}{c}\text { September 01, } \\
1978\end{array}$ \\
\hline & $5 \mu \mathrm{Ci}$ & 30 year & & $\begin{array}{c}\text { September 01, } \\
1978\end{array}$ \\
\hline${ }^{60} \mathrm{Co}$ & $1 \mu \mathrm{Ci}$ & 5.3 year & $\begin{array}{l}1173.24 \\
1332.50\end{array}$ & $\begin{array}{c}\text { December 18, } \\
1981\end{array}$ \\
\hline${ }^{152} \mathbf{E u}$ & $2.37 \mathrm{kBq}$ & 13 year & 121.78 & $\begin{array}{c}\text { December 01, } \\
1987\end{array}$ \\
\hline${ }^{241} \mathrm{Am}$ & $1.04 \mu \mathrm{Ci}$ & 462 year & 59.54 & $\begin{array}{c}\text { September 01, } \\
1978 \\
\end{array}$ \\
\hline $\begin{array}{c}\text { *Multi- } \\
\text { Gamma Ray } \\
\text { contains: }\end{array}$ & $\begin{array}{c}\text { Total } \\
\text { activity } \\
1.13 \mu \mathrm{Ci} \\
\end{array}$ & - & & October 14, 2004 \\
\hline${ }^{155} \mathbf{E u}$ & $0.116 \mu \mathrm{Ci}$ & 4.96 year & 86.54 & October 14,2004 \\
\hline${ }^{57} \mathrm{Co}$ & $0.147 \mu \mathrm{Ci}$ & 271.77 day & 122.06 & October 14,2004 \\
\hline${ }^{133} \mathrm{Sn}$ & $0.305 \mu \mathrm{Ci}$ & 1.47 second & 1096.20 & October 14,2004 \\
\hline${ }^{137} \mathrm{Cs}$ & $0.062 \mu \mathrm{Ci}$ & 30 year & 661.66 & October 14,2004 \\
\hline${ }^{54} \mathrm{Mn}$ & $0.114 \mu \mathrm{Ci}$ & 312.20 day & 834.83 & October 14,2004 \\
\hline${ }^{65} \mathrm{Zn}$ & $0.341 \mu \mathrm{Ci}$ & 244.1 day & 1115.52 & October 14, 2004 \\
\hline${ }^{40} \mathbf{K}$ & $0.017 \mu \mathrm{Ci}$ & $1.2 \times 10^{9}$ year & 1460.83 & October 14,2004 \\
\hline
\end{tabular}

* Multi-Gamma Ray Standard where the total activity was $1.13 \mu \mathrm{Ci}$ on October 14,2004 and

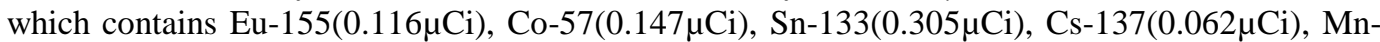
$54(0.114 \mu \mathrm{Ci}), \mathrm{Zn}-65(0.341 \mu \mathrm{Ci})$ and $\mathrm{K}-40(0.017 \mu \mathrm{Ci})$ 


\subsubsection{Gadolinium Compounds}

High purity gadolinium fluoride $\left(\mathrm{GdF}_{3}\right)$ powder was used. Both $\mathrm{GdF}_{3}$ and Magnevist did not show clear gamma peaks because of the low intensity of thermal neutrons (the calculated flux is shown on page 25-28). Magnevist contrast medium was also used where the active substance is gadopentetic acid and it is provided as dimeglumine salt ( $1 \mathrm{ml}$ of aqueous solution containing $469 \mathrm{mg}$ of gadopentetic acid, dimeglumine salt corresponding to $78.63 \mathrm{mg}$ of $\mathrm{Gd}$ ). The $\mathrm{GdF}_{3}$ powder and the Magnevist were exposed to the neutron source to activate the Gd.

\subsubsection{Other Detectors}

1. Cylindrical boron trifluoride $\left(\mathrm{BF}_{3}\right)$ neutron proportional counters, $\mathrm{LND}$ 2022 (LND Inc, Oceanside, New York, USA) for slow neutron measurement[65].

2. Telescope ionisation chamber detector to measure exposure dose, TELETECTOR 6112B, 4 meters long (Automation und Messtechnik, Ladenberg, Germany) for gamma dose measurements (Figure 2.1)[66].

3. Neutron monitors, type NM2B, for neutron dose measurements (NE Technology, United Kingdom) (Figure 2.2)[67].

\subsubsection{Other Materials}

In addition, the following materials were also used in this study.

A block of lead, size $10 \mathrm{~cm} \times 20 \mathrm{~cm}$ and $5 \mathrm{~cm}$ thickness.

Water containers of different thicknesses to thermalise fast neutrons were used. 


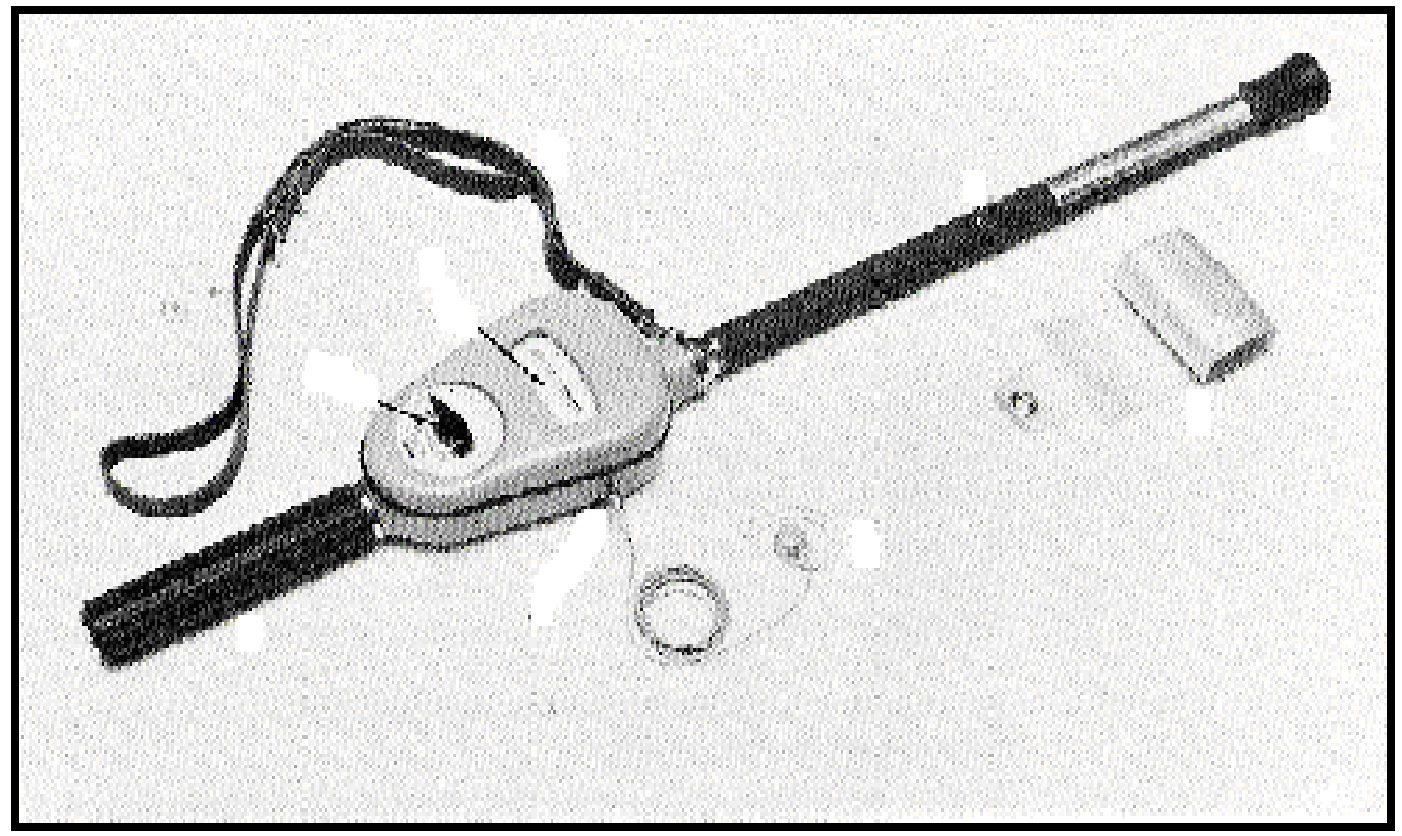

Figure 2.1: Teletector 6112 B detector[66].

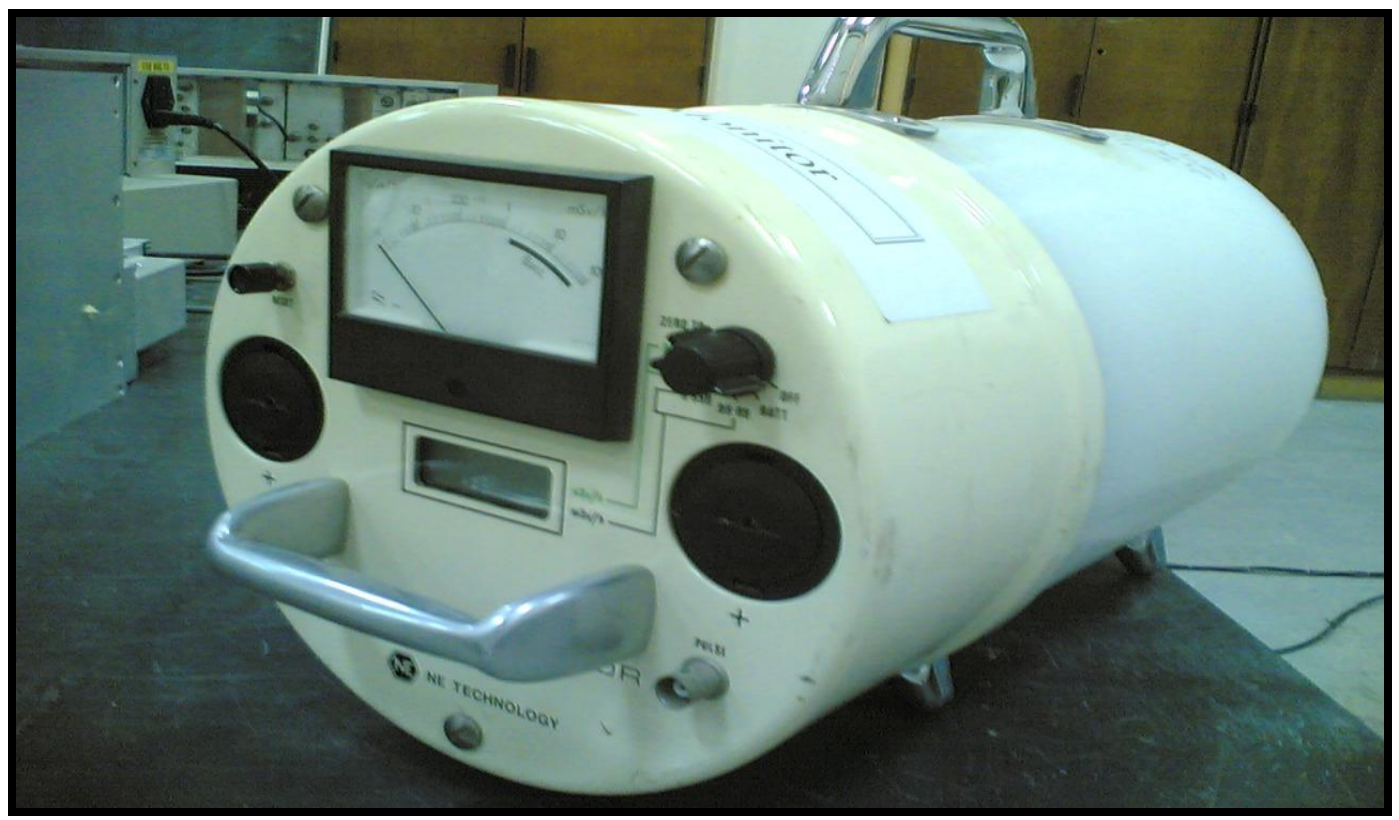

Figure 2.2: Neutron dosimeter detector (NM2B), Serial No. 433[67]. 


\subsection{Gamma Ray Energy Calibration}

To calibrate the measurement system (HPGe detector) different types of sources were used. Firstly, we utilised a combination of two point sources. Cesium-137 source $\left({ }^{137} \mathrm{Cs}\right)$ and cobalt-60 source $\left({ }^{60} \mathrm{Co}\right)$ whose activities were 5 $\mu \mathrm{Ci}$ and $1 \mu \mathrm{Ci}$ respectively, were set and spectra that appeared from the two point sources were determined. We utilised neutron capture gamma rays for calibration as well. A sheet of iron was placed between the neutron source and the HPGe detector and was exposed to neutrons from a $1.4 \mathrm{mCi}{ }^{252} \mathrm{Cf}$ source. Capture gamma rays emitted from the iron were recorded with a HPGe detector. The intensity of gamma rays from each source and material were determined and recorded.

The peak from ${ }^{137} \mathrm{Cs}$ was at $662 \mathrm{keV}$. The $1173 \mathrm{keV}$ and $1332 \mathrm{keV}$ peaks for the ${ }^{60} \mathrm{Co}$ source, and capture gamma rays of iron $6610 \mathrm{keV}, 7121 \mathrm{keV}$ and $7632 \mathrm{keV}$ peaks, were utilised. These peaks were used in the calibration curve to identify the gamma rays of the other elements, particularly Gd atoms, during exposure to neutrons. The energy calibration curve, Figure 2.3, shows a relevant straight line calibration, since we know that the capture gamma ray of Gd atoms is located between $780 \mathrm{keV}$ and $6750 \mathrm{keV}$ (Table 2.2) [68]. 
Table 2.2: Capture gamma rays energy of Gd atoms.

\begin{tabular}{|c|c|c|}
\hline $\begin{array}{c}\text { Channel } \\
\text { Number }\end{array}$ & $\begin{array}{c}\text { Known energy of Gd } \\
\text { capture gamma rays (keV) }\end{array}$ & $\begin{array}{c}\text { Measured energy of Gd } \\
\text { capture gamma ray (keV) }\end{array}$ \\
\hline $\mathbf{5 6 5}$ & 780.1 & 780.5 \\
\hline $\mathbf{6 8 8}$ & 897.6 & 897.4 \\
\hline $\mathbf{7 3 6}$ & 944.1 & 943 \\
\hline $\mathbf{9 0 9}$ & 1107.6 & 1107.3 \\
\hline $\mathbf{9 1 7}$ & 1116.5 & 1114.9 \\
\hline $\mathbf{9 5 4}$ & 1141.4 & 1150 \\
\hline
\end{tabular}

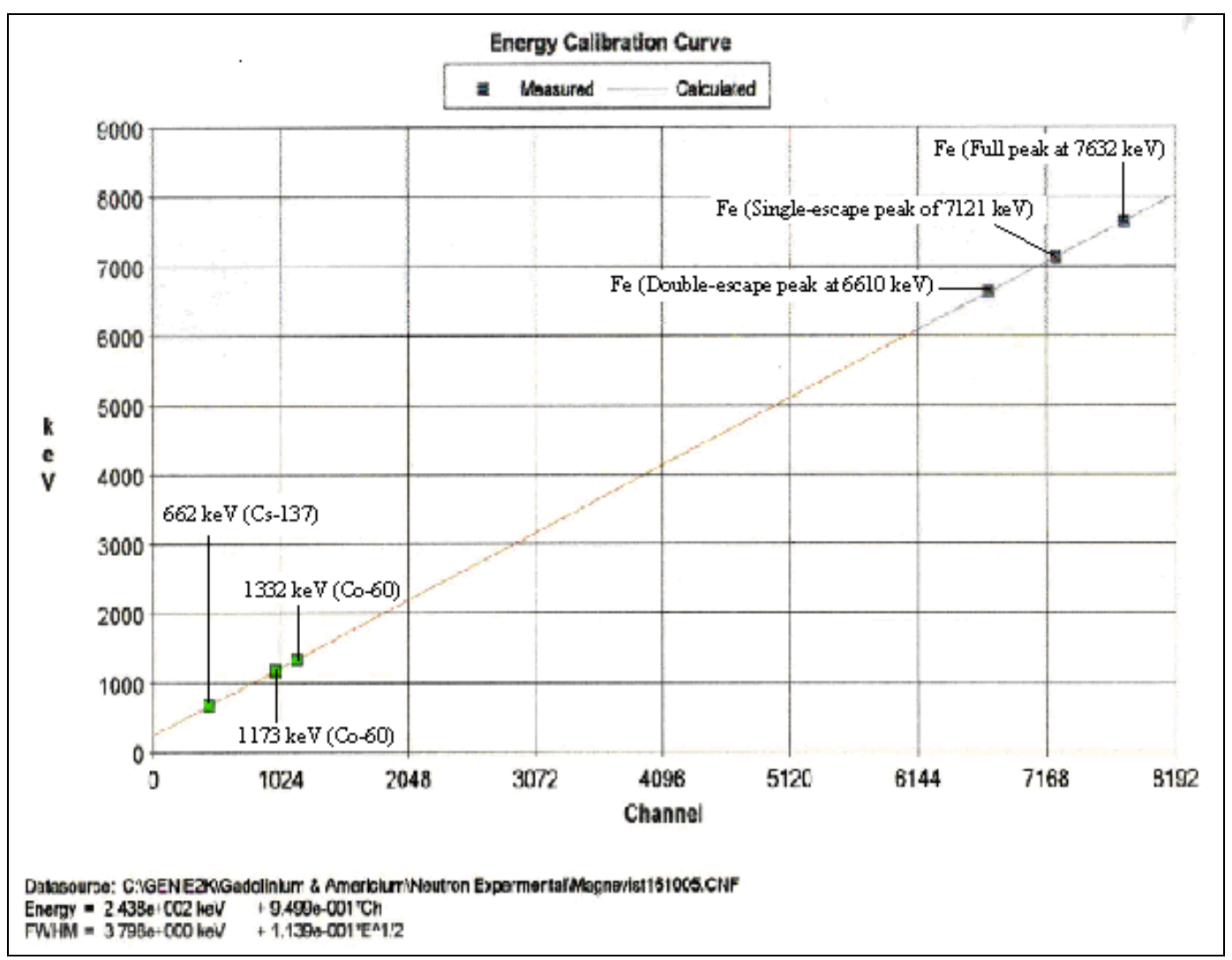

Figure 2.3: Energy calibration chart of the HPGe detector. 


\subsection{Procedure to design optimum geometry for Gd experiment}

\subsubsection{Gamma ray measured by using ionisation chamber}

The aim was to minimise gamma rays coming from a neutron source, as they produce unnecessary counts and saturation in the HPGe detector. The distance between the neutron source and the detector was adjusted to be $40 \mathrm{~cm}$ and then $15 \mathrm{~cm}$ of lead thickness was placed between the source and the detector to reduce the gamma rays coming directly from the neutron source. The background was measured using a telescope gamma detector that measures gamma dose rates. It was found to be $0.04 \mathrm{mR} / \mathrm{hr}$. The dose rates were taken also with the water containers in front and behind the neutron source to slow down fast neutrons, as slow neutrons have a higher cross section for interaction. Because water backscatters gamma rays, the increase in quantity of water increased the gamma exposure. The average dose rate was $2.44 \mathrm{mR} / \mathrm{hr}$ (Figure 2.4). Data were then recorded and analysed. 


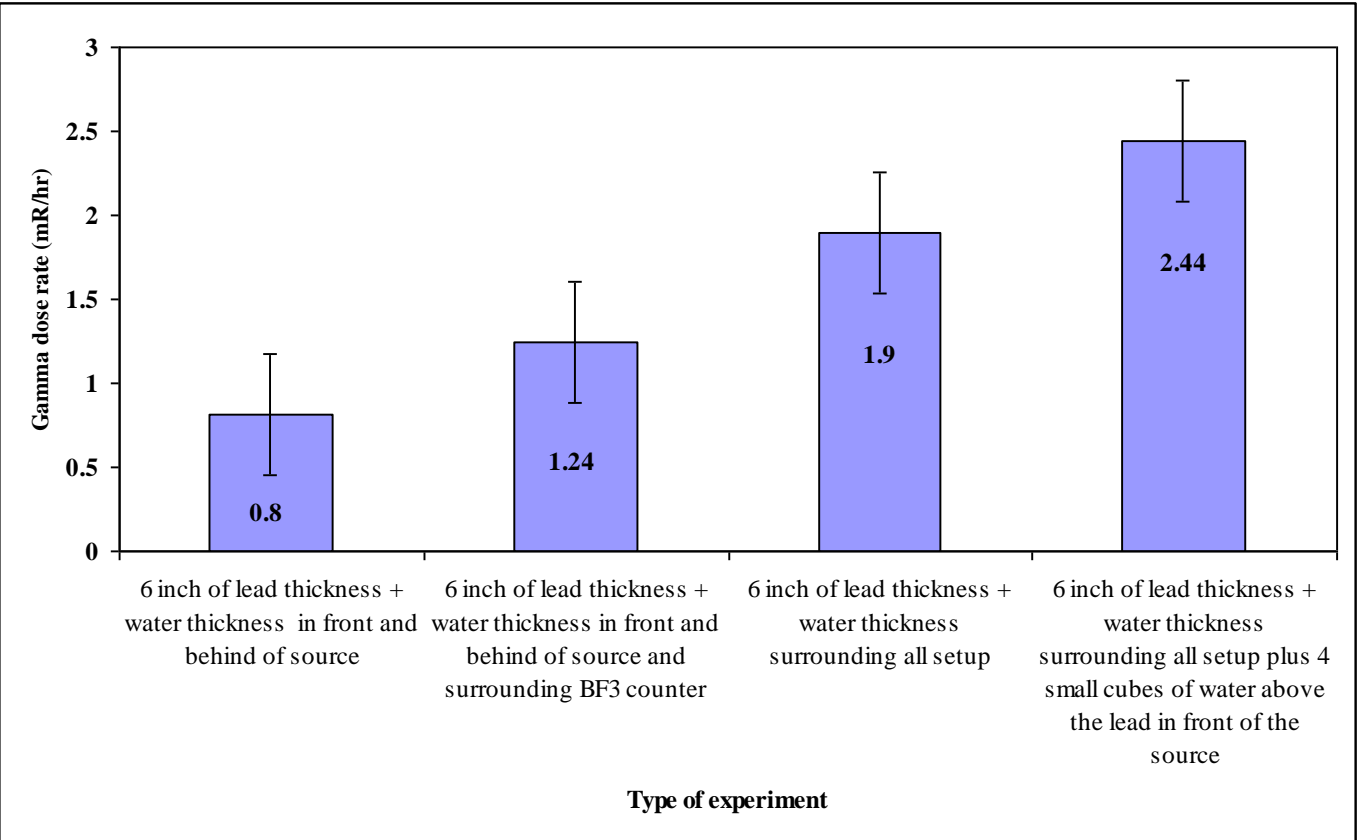

Figure 2.4: Gamma rays measured by using ionisation chamber to design optimum geometry for neutron capture experiment. 


\subsubsection{Neutron flux measured by using neutron proportional counters}

In this procedure we measured slow neutrons that reached the target tumour. Slower neutrons were obtained by increasing the volume of the water moderator. The boron trifluoride proportional counter is a sensitive thermal neutron detector. This $\mathrm{BF}_{3}$ counter was placed $40 \mathrm{~cm}$ from the neutron source and then $15 \mathrm{~cm}$ of lead thickness was placed between the source and the $\mathrm{BF}_{3}$ counter. The exposure time was chosen to be real time and set for 10 minutes. The count rate of the first reading was taken with the water in front and behind the neutron source and showed 81,098 counts per second. As the thickness of water surrounding the setup increased, the count rate increased. Counts rate readings taken with increased water by using the $\mathrm{BF}_{3}$ detector are shown in

Table 2.3. The highest counts rate was 237,989 counts per second. Counts rate data were recorded and analysed. These count rates are proportional to thermal neutron flux; they are not the flux.

Table 2.3: Slow neutron flux measured by using the $\mathrm{BF}_{3}$ counter in an experiment to design the optimum geometry for the neutron capture experiment.

\begin{tabular}{|l|c|}
\hline \multicolumn{1}{|c|}{ Type of experiment } & Counts per second \\
\hline $\begin{array}{l}6 \text { inch of lead thickness + Water thickness in front and } \\
\text { back of source }\end{array}$ & 81098 \\
\hline $\begin{array}{l}6 \text { inch of lead thickness + Water thickness in front and } \\
\text { back of source and surrounding BF3 }\end{array}$ & 204730 \\
\hline $\begin{array}{l}6 \text { inch of lead thickness + Water thickness in front and } \\
\text { back of source and surrounding all geometry }\end{array}$ & 233738 \\
\hline $\begin{array}{l}6 \text { inch of lead thickness + Water thickness in front and } \\
\text { back of source and surrounding all geometry \& 4 small } \\
\text { cubes of water above the lead in front of the source }\end{array}$ & 237989 \\
\hline
\end{tabular}




\subsection{Results and Discussion}

The objective, of studying Gd concentration analysis in the brain phantom by NCT, was to develop a technique that measures the amount of Gd and the neutron reaction rate, at the same time as a patient is exposed to the neutrons emitted by a $1.4 \mathrm{mCi}{ }^{252} \mathrm{Cf}$ source. It was intended to measure gamma ray emission following neutron capture during the irradiation process. However, because the gamma peak observed from the Gd sample in the HPGe detector was very weak, it took a long time to accumulate. A tremendous amount of work was done to improve the geometry of the neutron capture experiment shown in Figure 2.5. First we had to reduce, as much as possible, the gamma rays coming directly from the source that dominated the spectrum. We decreased the gamma ray counts using a telescope detector (see Figure 2.4). Secondly, the slow neutron flux had to be increased. By increasing moderation we could increase the flux of slow neutrons and that was measured by the $\mathrm{BF}_{3}$ neutron proportional counters.

With this "enhanced" flux, the Gd peaks were still very small. We attempted to use another non-portable germanium detector (coaxial germanium detector) to increase the detection efficiency. At this point, we could expose the target materials such as boron-10 and Gd, to the neutron source and were successful in finding the capture gamma rays of $478 \mathrm{keV}$ from the boron-10 (see Figure 2.6), but Gd was still at the smaller end of being measurable. The peak height was slightly above background and was falling within the standard deviation of the background.

An experiment was done using Magnevist contrast medium, which contained Gd, in which we exposed $160 \mathrm{ml}$ of Magnevist $(1 \mathrm{ml}$ of aqueous 
solution containing $469 \mathrm{mg}$ of gadopentetic acid, dimeglumine salt corresponding to $78.63 \mathrm{mg}$ of $\mathrm{Gd}$ ) for 47 hours. The peak was still not high enough (Figure 2.7). As in any neutron capture gamma ray analysis, there are large number of gamma peaks that were coming from all surrounding materials as well as from the capture gamma ray in the HPGe detector. Peaks from lead, aluminium, iron, concrete etc are usually found. Accordingly it is very difficult to analyze the whole spectrum. The very large peak found at $2.22 \mathrm{MeV}$ is that of hydrogen neutron capture; there was large amount of water surrounding the detector used for neutron thermalization.

The method can be successful only if the neutron flux is high. In our work, it took too long time to collect reasonable counts. This is not a very successful practical approach.

To explain the weakness of the counts under the peak that was obtained from the experimental, we calculated the effect of neutron attenuation from the source to the sample in the experiment.

Attenuation of neutrons in the system before reaching the sample that included the effect of the inverse square law, attenuation and scattering in lead and attenuation in water were obtained by

$$
\varphi=\frac{S}{4 \pi r^{2}} e^{\left(-\Sigma_{a P b} d_{1}\right)} e^{\left(-\Sigma_{s P b} d_{1}\right)} e^{\left(-\Sigma_{a w} d_{2}\right)}
$$

Where, in Eq. (3) above, $\varphi$ is the neutron intensity, and $\mathrm{S}$ is the ${ }^{252} \mathrm{Cf}$ neutron source strength. For our measurements, we used $S=2.5 \times 10^{6} \mathrm{n} / \mathrm{s}$. the data were provided by Nuclear Engineering department at King Abdulaziz University. 
$\mathrm{r}$ is the distance from source to the target material (35 $\mathrm{cm}$ for our measurements). $d_{1}$ and $d_{2}$ are the thicknesses of lead and water, respectively. We used $15 \mathrm{~cm}$ of lead and $20 \mathrm{~cm}$ of water. $\sum_{\mathrm{aPb}}, \sum_{\mathrm{sPb}}$, and $\sum_{\mathrm{aw}}$ are the macroscopic cross sections. The $\mathrm{aPb}$ is for the absorption cross section of lead $\left(0.0056 \mathrm{~cm}^{-1}\right)$, the $\mathrm{sPb}$ is for the scattering cross section of lead $\left(0.3757 \mathrm{~cm}^{-1}\right)$ and the aw is for the absorption cross section of water $\left(0.0222 \mathrm{~cm}^{-1}\right)[69]$.

In Eq. (3), we neglected attenuation due to scattering in water as the flux of neutrons was compensated by thermalisation. Using the values given above, we can obtain, $\varphi=0.342 \mathrm{n} / \mathrm{cm}^{2} \mathrm{~s}$.

The attenuation, A, of neutrons in the Magnevist agent $\left(\mathrm{C}_{28} \mathrm{H}_{54} \mathrm{GdN}_{5} \mathrm{O}_{20}\right)$ was obtained by the equation:

$$
\mathrm{A}=e^{-\left(\Sigma_{a M g n} d\right)}
$$

Where $\sum_{\mathrm{aMgn}}$ is the macroscopic absorption cross section of Magnevist whose density is $1.2 \mathrm{~g} \mathrm{~cm}^{-3} . \mathrm{d}$ is the thickness of the Magnevist and we used 0.5 $\mathrm{mm}$ and $1.0 \mathrm{~mm}$ thicknesses. Furthermore, we can write

$$
\Sigma_{a M g n}=N \sigma
$$

Where $\mathrm{N}$ is the number of Gd molecules per $\mathrm{cm}^{3}$, and $\sigma$ is the absorption cross section of Gd (49000 barn)

Using these values we obtain attenuations of 0.15 and 0.023 for $0.5 \mathrm{~mm}$ and $1.0 \mathrm{~mm}$ thickness of Magnevist, respectively. 
The neutron intensity after $1 \mathrm{~mm}$ of Magnevist will be $\left(0.342 \mathrm{n} / \mathrm{cm}^{2} . \mathrm{s}\right) \times(0.023 \mathrm{n} / \mathrm{s})=7.87 \times 10^{-3} \mathrm{n} / \mathrm{cm}^{2} . \mathrm{s}$

Accordingly most of the neutrons are absorbed in the first $1 \mathrm{~mm}$ of the Magnevist contrast medium; therefore the reaction volume is very small.

The neutron spectrum is a fission spectrum. If only $10 \%$ of the neutrons are thermal neutrons, then the slow neutron flux at the sample position will reduce the intensity even much below the above number.

It is clear that the slow neutron flux is very low at the magnevist agent and most of slow neutrons are absorbed in $1 \mathrm{~mm}$ of Magnevist. Therefore, additional Gd will not be useful for increasing count.

The $47 \mathrm{hr}\left(1.69 \times 10^{5} \mathrm{sec}.\right)$, collection time will give a neutron fluence of $1.69 \times 10^{5} \mathrm{sec} \times 7.87 \times 10^{-3} \mathrm{n} / \mathrm{cm}^{2} . \mathrm{s}=1.33 \times 10^{3} \mathrm{n} / \mathrm{cm}^{2}$

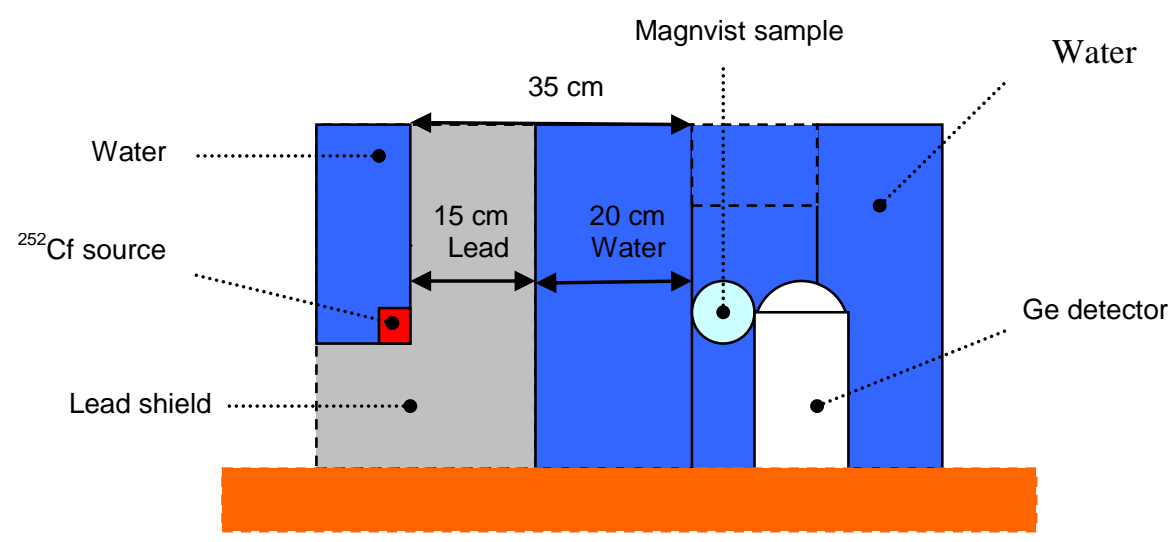

Figure 2.5: Lateral view of schematic that represents the optimum geometry to measure Gd concentration.. 


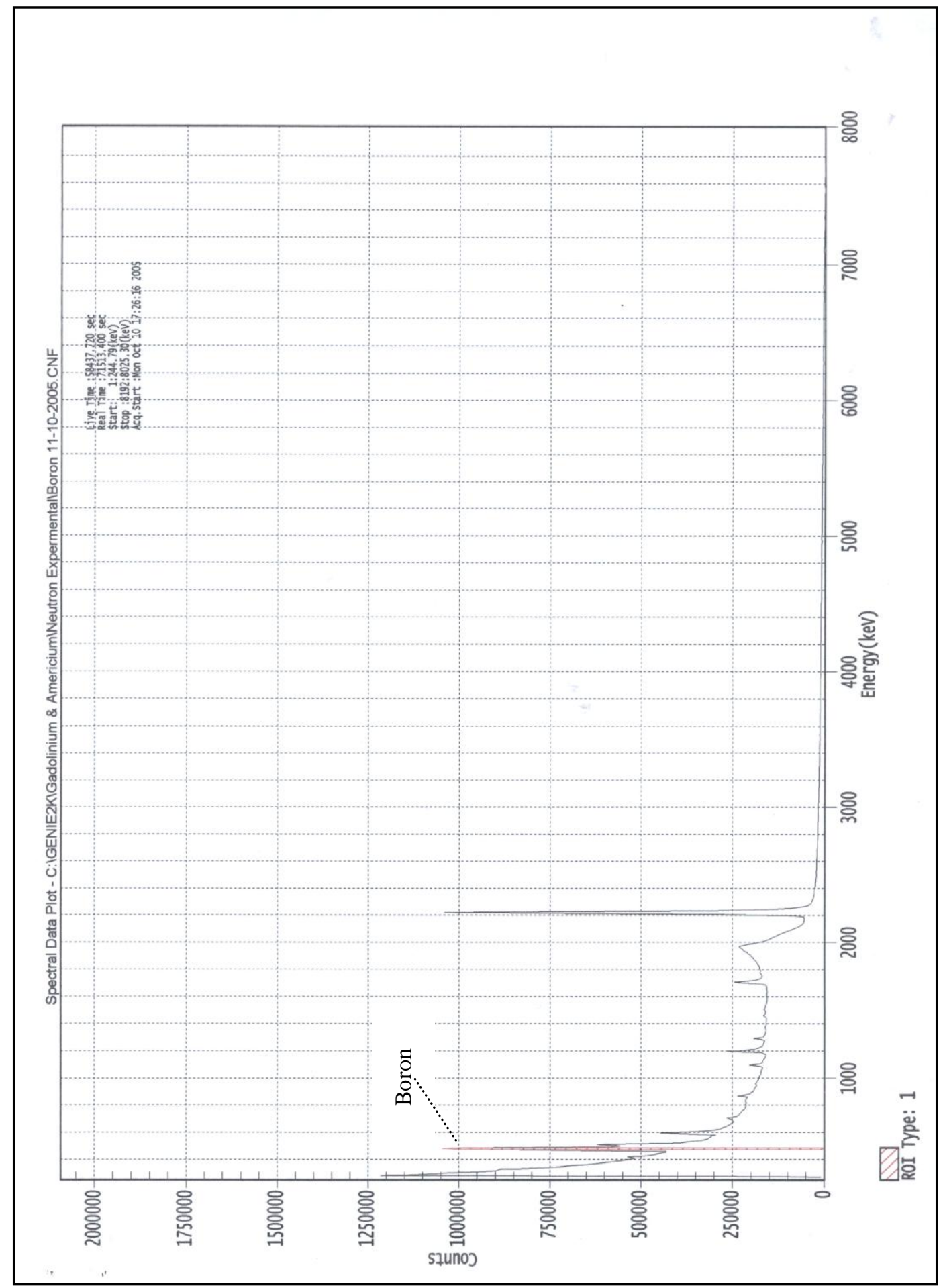

Figure 2.6: Neutron capture gamma ray spectrum of boron. 


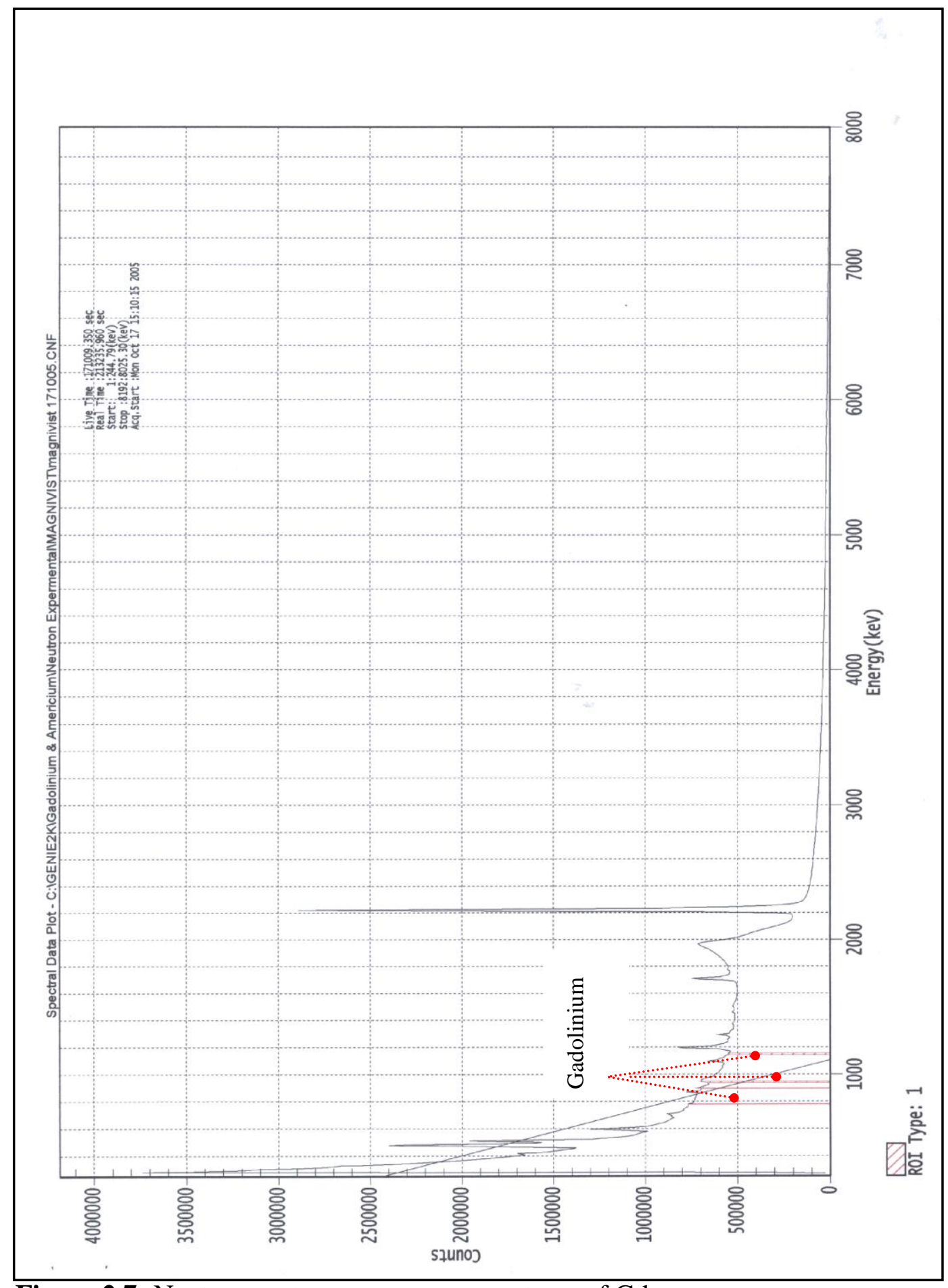

Figure 2.7: Neutron capture gamma ray spectrum of Gd. 
CHAPTER 3

\section{MATERIALS AND METHODS OF THE GADOLINIUM CONCENTRATION ANALYSIS}

\subsection{Experimental Materials}

The experimental materials consisted of

- The radiosurgery verification head phantom

- The alignment system

- The detector

- Radiation source

Each of these will be discussed in more detail below.

\subsubsection{The Radiosurgery Verification Head Phantom (RSVP)}

The radiosurgery verification head phantom (RSVP) is placed on a table in the supine position, facing up to enable the correct simulation of patient-imaging and dose assessment. The shell of the RSVP consists of $3.18 \mathrm{~mm}$ thick cellulose acetate butyrate $(\mathrm{CAB})$, a transparent plastic selected for its strength and low water absorption. The shell is fixed to a durable polycarbonate end plate, which is connected to a cover plate and an assembly that enables the tumour vessel to be turned around and processed. The head case of the radiosurgery system can be screwed directly onto the $\mathrm{CAB}$ plastic [70]. 
The RSVP consists of a tumour vessel, position rod, cover plate O-ring, rotation ball O-ring, rotation ball, lock bolts for position rod, lock nut for rotation ball and cover plate (Figure 3.1).

The position rod was used to hold the tumour vessel by threading it into the connector to close the port of the tumour vessel. The position rod was inserted into the rotation ball that was used to move the position rod in different directions and positions inside the head phantom.

The lock bolts on the position rod were loosened so as to insert it through the rotation ball, until the rod was extended to the desired distance into the head phantom. The lock bolts were tightened when the position rod was in the proper position. The head phantom was filled with water which is equivalent to the brain tissue. The rotation ball, position rod and tumour vessel were reinserted into the head phantom and the rotation ball lock nut was fitted loosely on to the phantom. The ball was rotated until the tumour vessel was in the desired position and the rotation ball lock nut was tightened. The phantom was placed in the face-up position to check for any leaks as shown in Figure 3.1.

The RSVP is able to contain spherical hollow tumour vessels whose diameters are $1.0 \mathrm{~cm}, 2.0 \mathrm{~cm}$, and $3.0 \mathrm{~cm}$. It is also able to contain a hollow oval tumour vessel whose diameter is $2.0 \mathrm{~cm}$ and its length is $4.0 \mathrm{~cm}$ (see Figure 3.2). 


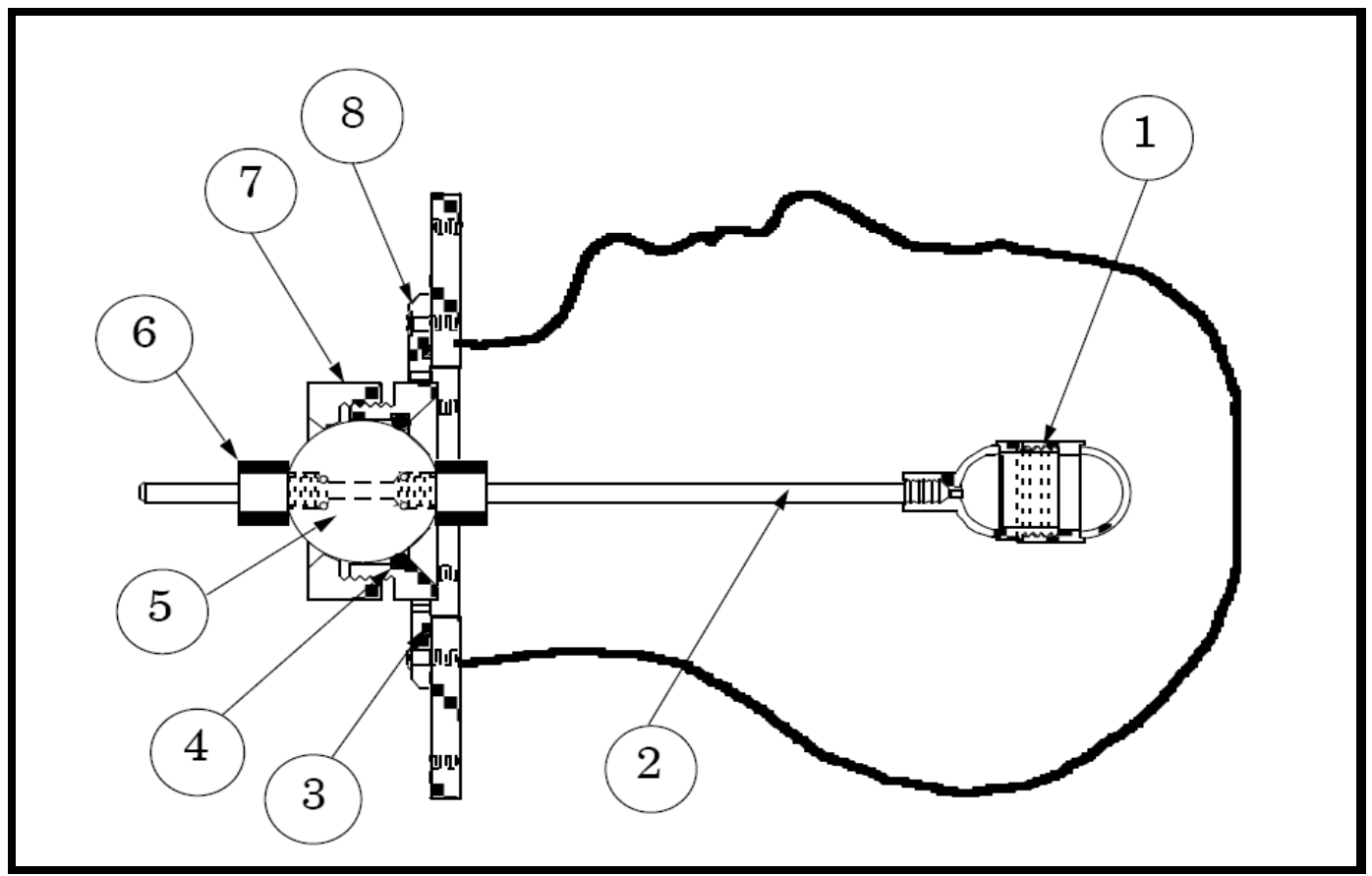

Figure 3.1: Components of the radiosurgery verification head phantom.

1. Tumour vessel 2. Position rod 3. Cover plate O-ring 4. Rotation ball O-ring

5. Rotation ball 6. Lock bolts for position rod 7. Lock nut for rotation ball

8. Cover plate [69].

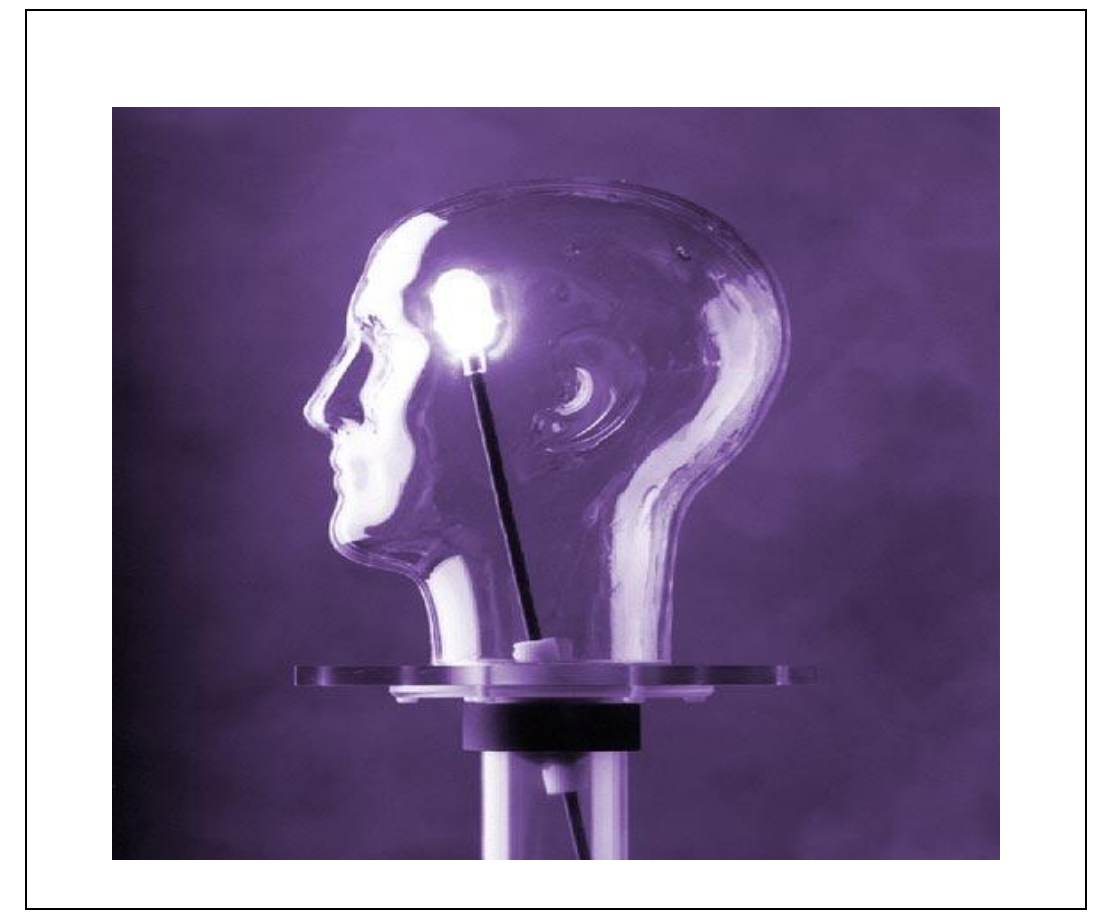

Figure 3.2: Radiosurgery verification head phantom in an upright position [69]. 


\subsubsection{Alignment System}

To determine the position of the tumour vessel inside the head phantom, a measurement system has been created at the University of Canterbury by a technician (Figure 3.3). The alignment system consists of: a head phantom tumour vessel, scale and a laser alignment system.

The head phantom including a tumour vessel is placed on a custom wood platform. Then the position of the tumour vessel, inside the head phantom, was determined along two orthogonal axes by a laser pointer that moves along the orthogonal axes with mm scales. This system can identify the centre of the tumour vessel to $\pm 0.2 \mathrm{~mm}$. The position of the vessel is estimated to be reproducible to \pm $0.5 \mathrm{~mm}$ see Figure 3.1. The anatomical marker of the tumour vessel was chosen to be $5.0 \mathrm{~cm}$ above the left lateral of the external auditory meatus (ear) and $1.0 \mathrm{~cm}$ posterior.

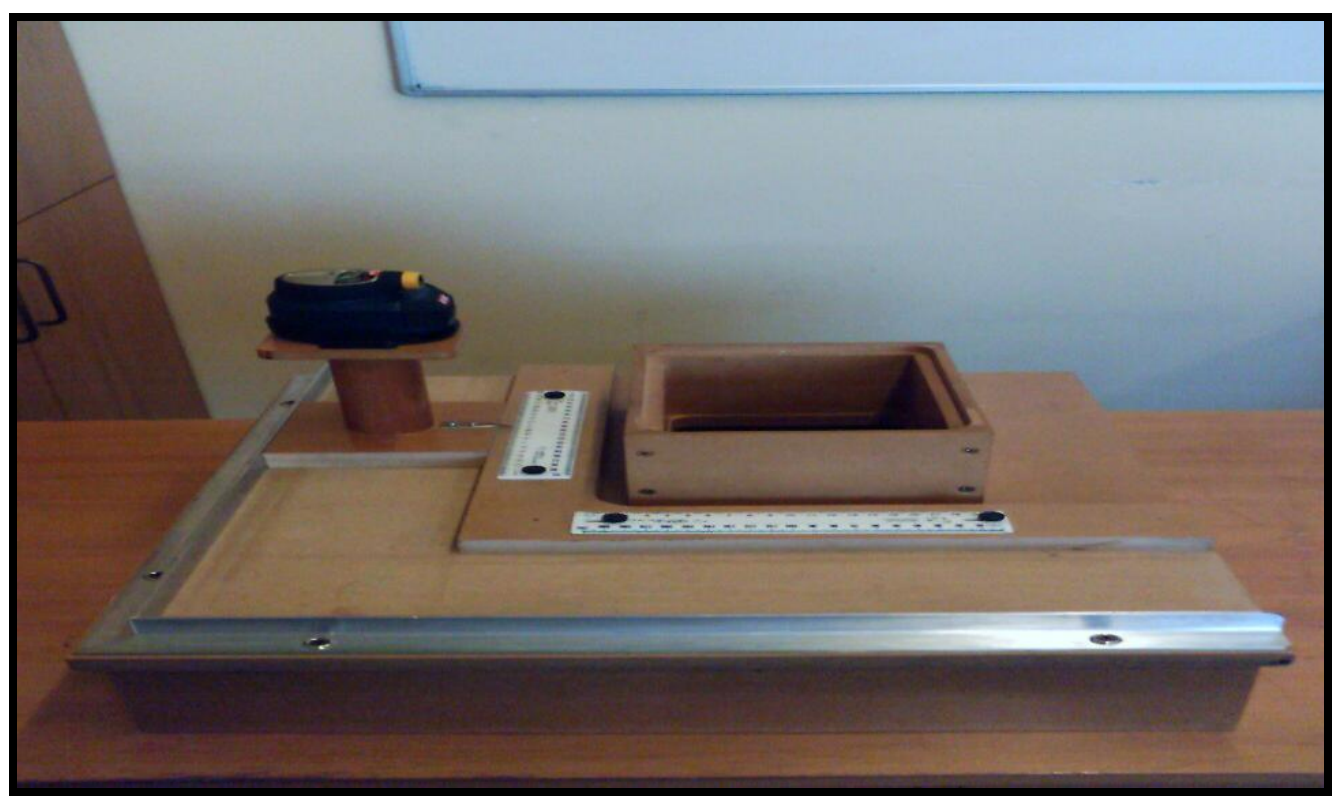

Figure 3.3: Alignment of tumour vessel scale with laser beam pointer. 


\subsubsection{X-Ray Detector}

The X-ray detector system consists of a model, XR-100T-CdTe, (cadmium telluride) counting system and Genie 2000 PC MCA. The counting system consists of $\mathrm{x}$-ray and gamma detectors, preamplifier, and a cooling system (Figure 3.4). The $3 \times 3 \times 1 \mathrm{~mm}^{3}$ cadmium telluride (CdTe) diode detectors are mounted on a thermoelectric cooler. These have an energy resolution $<1.2 \mathrm{keV}$ FWHM, at 122 $\mathrm{keV}$ of ${ }^{57} \mathrm{Co}$ with a beryllium (Be) window, $250 \mu \mathrm{m}$ thick [71]. The MCA is supplied by Canberra Company USA. It has a comprehensive unit for power supply, amplification and a Pentium computer with a special interface card and software. The MCA has 8,192 channels.

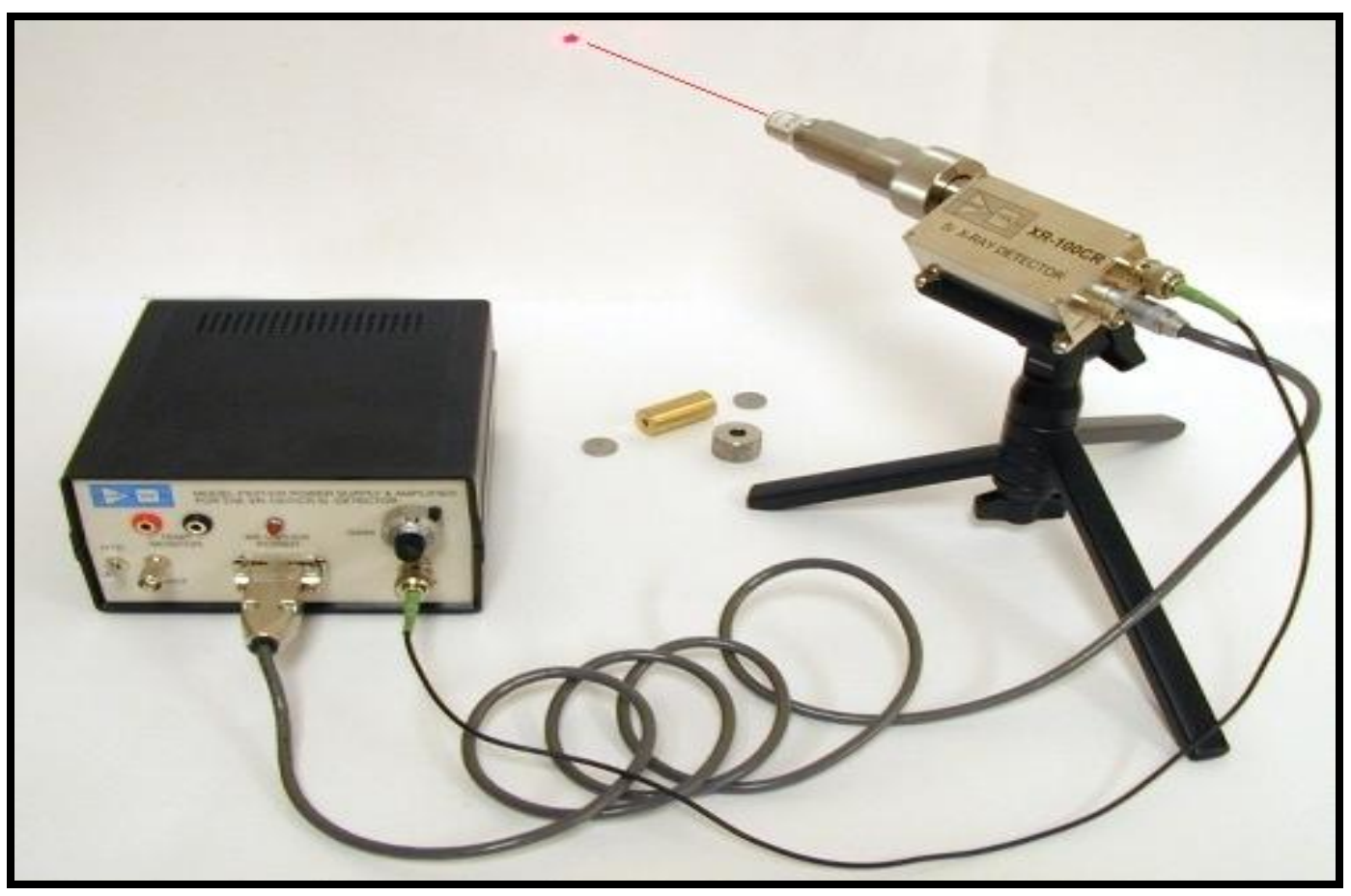

Figure 3.4: XR-100T-CdTe detector with power supply and amplifier [70]. 


\subsubsection{Radiation Source}

Americium is a man-made radioactive source which is produced when plutonium atoms absorb neutrons in nuclear reactors. Americium-241 has many medical and industrial applications and is also used in research. Americium-241 is an unstable isotope that emits alpha particles and gamma rays. The ${ }^{241} \mathrm{Am}$ source, used in this work, had $37 \mathrm{GBq}$ (1 Ci) of activity on February 22, 1989. The halflife of ${ }^{241} \mathrm{Am}$ is about 432.7 years. It produces a $59.5 \mathrm{keV}$ gamma ray with a relative probability of 0.357 per disintegration [72]. By using the radioactive decay law expressed mathematically as:

$$
\mathrm{A}_{\mathrm{t}}=\mathrm{A}_{0} \mathrm{e}^{-\lambda \mathrm{t}}
$$

where $A_{0}$ is the initial quantity of activity, $A_{t}$ is the amount of activity left after time $t, \lambda$ is the radioactive decay constant $\left(0.693 / \mathrm{T}_{1 / 2}\right)[73,74]$.

The calculated amount of activity used for this experiment as calculated from the equation above was $0.97 \mathrm{Ci}(36 \mathrm{GBq})$. The ${ }^{241} \mathrm{Am}$ source is in the form of an oxide pressed into a ceramic cylinder with dimension of $0.3 \mathrm{~cm}$ in diameter and $1 \mathrm{~cm}$ in height. The shape of the source is cylindrical and it is a single encapsulation made of stainless steel and laser seal welded. 


\subsubsection{Contrast Examination}

Gd DTPA is a contrast agent that produces magnetic effects (the commercial name is Magnevist). It is used in combination with MRI to allow blood vessels, and internal organs to be seen more clearly.

"Magnevist Injection is a $0.5-\mathrm{mol} / \mathrm{L}$ solution of 1-deoxy-1-(methylamino)D-glucitol dihydrogen [N,N-bis[2-[bis(carboxymethyl)amino]ethyl]-glycinato(5"-)-]gadolinate(2-)(2:1) with a molecular weight of 938, an empirical formula of $\mathrm{C}_{28} \mathrm{H}_{54} \mathrm{GdN}_{5} \mathrm{O}_{20}, "$ [75].

Gd-DTPA contains the active substance, gadopentetic acid, and dimeglumine salt. One millilitre of aqueous solution contains $469 \mathrm{mg}$ of gadopentetic acid, and dimeglumine salt that corresponds to $78.63 \mathrm{mg}$ of $\mathrm{Gd}$.

Magnetic resonance imaging will be valuable and very effective, when a contrast media, such as Magnevist, which has a paramagnetic ion (Gd) that increases tissue relaxation rate in that magnetic field. Gadolinium is mixed with other chemical metals to reduce the toxicity in its properties. There are several Gd based contrast agents available such as: "gadopentetate dimeglumine (Magnevist), gadodiamide (Omniscan), gadoteridol (ProHance) and gadoversetamide (OptiMARK)". The biological half-lives of these agents are similar, at about half an hour. The common side effects of the contrast agent are nausea, headache, anaphylactic reaction and vomiting.

The Food and Drug Administration has approved the usage of specific dosage volume of this contrast $(0.23$ to 0.31$) \mathrm{ml} / \mathrm{kg}$ for adults; whereas in children, the dose is $0.16 \mathrm{ml} / \mathrm{kg}$ body weight $[76,77]$. 


\subsubsection{Other Materials}

In addition, the following materials were also used in this study.

Densitometer, model 07-443, S/N 107679, Nuclear Associates Division of Victoreen Inc (Phoenix, USA).

Normal saline, $0.9 \% \mathrm{w} / \mathrm{v}$ sodium chloride, intravenous infusion B.P. 500ml ( $\left.\mathrm{Na}^{+} 150 \mathrm{mmole} / \mathrm{L}, \mathrm{Cl}^{-} 150 \mathrm{mmole} / \mathrm{L}\right)$. 


\subsection{Experimental Method}

A tremendous amount of work was done to measure Gd concentration and to improve the geometry of the experiment to reach the optimum result. The purpose was to provide a method for the analysis of the amount of the Gd in the brain tumour. Characteristic x-rays of $\mathrm{Gd} \mathrm{K}_{\alpha 1}=42.98 \mathrm{keV}$, induced by a $36 \mathrm{GBq}$ (0.97 Ci) ${ }^{241}$ Am source, were emitted and measured.

The lateral and the vertex positions of the head phantom were selected, to measure the concentration of the Gd in different sized of the tumour vessels as shown in Figure 3.5. Also, the depths of the tumour were measured from the surface of the head phantom to the centre of the tumour vessel. These depths ranged from $0.5 \mathrm{~cm}$ to $5.5 \mathrm{~cm}$ between the centre of the tumour and interior wall of the head phantom surface. Concentrations from 5.62 to $78.63 \mathrm{mg} / \mathrm{ml}$ of $\mathrm{Gd}$ in the tumour vessel were used and measured.

Tumour movement inside the head phantom is described by defining the sagittal and transverse planes. The sagittal plane is the plane that divides the body to the left side and right side, while the transverse plane is the plane which divides the body to the superior (top side) and inferior (bottom side).

In the lateral position, the tumour vessel moves parallel to the transverse plane is and is perpendicular to the sagittal plane. In other words, the tumour vessel moves from the left to the right side. While in the vertex position, the tumour vessel moves parallel to the sagittal plane and is perpendicular to the transverse plane or the tumour moves from the top end to the bottom end.

An analysis of the results provided information concerning those aspects of radiotherapy-planning that needed attention. 


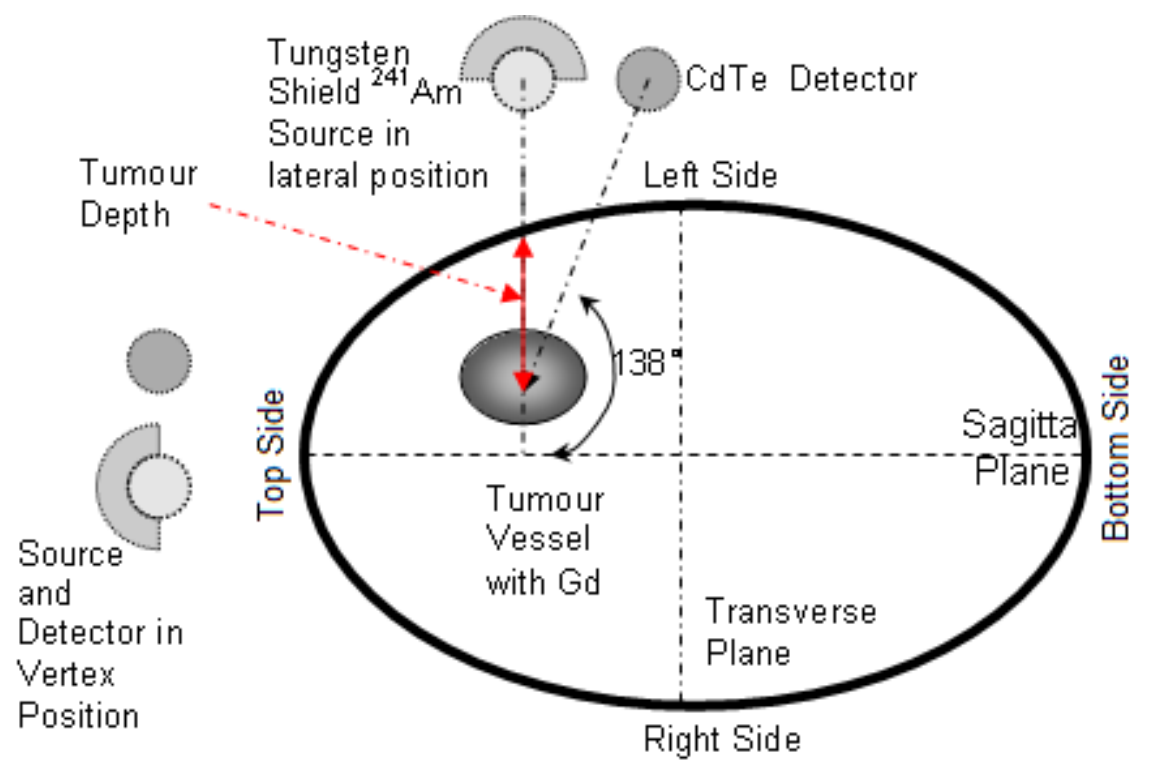

Figure 3.5: Schematic representation of the head phantom contain tumour vessel in the lateral position. The source and detector are also shown as a lighter image in the vertex position. 


\subsubsection{X-Ray Energy Calibration}

Energy calibration was required to guarantee that the cadmium telluride (CdTe) detector was operating correctly to measure the energy of the gamma radiation, which was emitted directly from the source and also, the x-ray energy that was reflected from the target materials. Therefore to calibrate the measurement system (XR-100T-CdTe detector), 500 grams of barium diagnostic agent (100 grams contains 95 grams of barium sulphate), providone-iodine U.S.P $10 \%$, a sheet of cadmium and an iron plate, were used and exposed separately and in combination to a $36 \mathrm{GBq}{ }^{241} \mathrm{Am}$ source to determine the characteristic $\mathrm{x}$-ray $\left(\mathrm{K}_{\alpha}\right)$ emission of the materials. $\mathrm{K}_{\alpha} \mathrm{X}$-ray peaks of $\mathrm{Fe}, \mathrm{Cd}, \mathrm{I}, \mathrm{Ba}$, and the direct energy of the ${ }^{241} \mathrm{Am}$ source in the pulse height distributions are shown respectively in Table 3.1 .

These were used to identify the energy of the characteristics X-ray $\left(\mathrm{K}_{\alpha}\right)$ of each element and to compare it with the characteristics $\mathrm{x}$-ray $\left(\mathrm{K}_{\alpha}\right)$ of the literature of the same element. Figure 3.6 and Figure 3.7 show the energies of the characteristic x-rays that were measured. They were really identical to the energy of the characteristics x-ray from the literature studied [78-80]. Also, the background count was measured by filling the head phantom, including a tumour, with water that simulated the brain tissue, which showed zero count. The positions of the tumour inside the head phantom were determined and adjusted by the tumour scale and the laser alignment system that were made for this purpose in physics department workshop. 
Table 3.1: Characteristics X-rays energy calibration of spectroscopy system using known element.

\begin{tabular}{|c|c|c|c|}
\hline $\begin{array}{c}\text { Calibration } \\
\text { Element }\end{array}$ & $\begin{array}{c}\text { Channel } \\
\text { Number }\end{array}$ & $\begin{array}{c}\text { Ka (keV) } \\
\text { (Literature) }\end{array}$ & $\begin{array}{c}\text { Ka (keV) } \\
\text { (Measured) }\end{array}$ \\
\hline Iron & 465 & 6.40 & 6.4 \\
\hline Cadmium & 2330 & 23.17 & 23.1 \\
\hline Iodine & 2941 & 28.61 & 28.5 \\
\hline Barium & 3343 & 32.19 & 32.1 \\
\hline Americium & 6415 & 59.54 & 59.6 \\
\hline
\end{tabular}

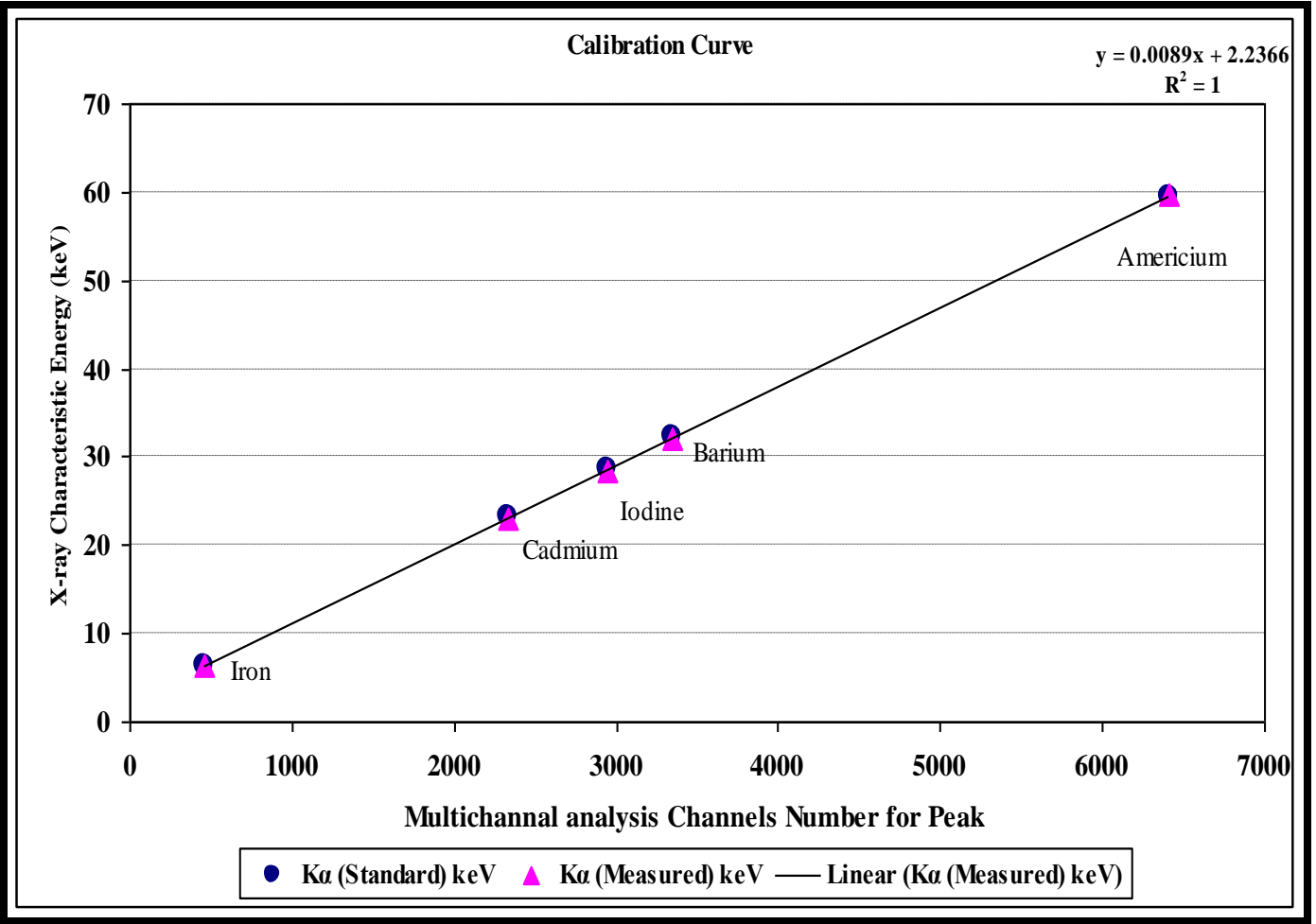

Figure 3.6: Energy calibration of spectroscopy system using known characteristics $\mathrm{x}$-ray. 


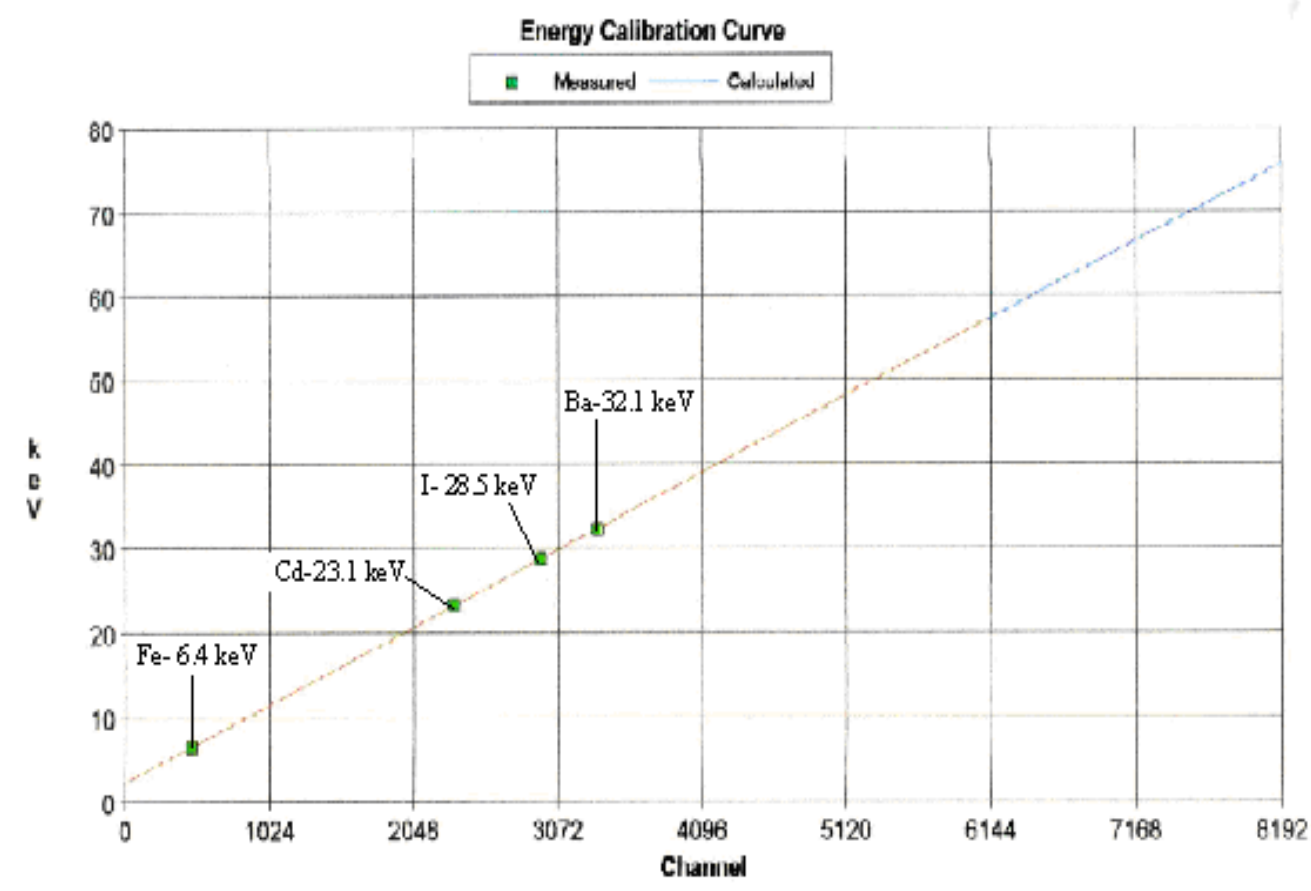

Datesourse: DETO1

Energy $=2.194 e^{+000 ~} \mathrm{kaV}+8.8520-003$ th

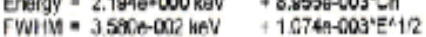

Figure 3.7: Energy calibration curve of XR-100T-CdTe detector. 


\subsection{Procedure for Measuring Gd Concentration}

The concentration of $\mathrm{Gd}(\mathrm{mg} / \mathrm{ml})$ and the total amount of $\mathrm{Gd}$ (mass of $\mathrm{Gd}$ in Magnevist contrast medium (mg)) in the tumour vessel inside the head phantom were calculated. The procedure included several stages which are explained sequentially. First, the level of the table and the head phantom was adjusted using a spirit level. An ${ }^{241}$ Am source beam faced the head phantom which included the tumour vessel. The position of the XR 100T CdTe detector with a standard 3.81 $\mathrm{cm}$ extender collimator was positioned on the top of the table parallel to the ${ }^{241} \mathrm{Am}$ source and toward the tumour vessel. The position of the tumour vessel inside the head phantom was adjusted by using the pointer laser which was placed in the collimator of the detector, before tumour exposure to gamma radiation. The XR $100 \mathrm{~T}$ detector was connected to the Genie 2000 PC MCA. The distance from the

surface of the head phantom to the ${ }^{241} \mathrm{Am}$ source was adjusted to be $6.0 \mathrm{~cm}, 8.3$ $\mathrm{cm}$ to the detector and the exposure time was chosen to be live time and set for 30 minutes, to obtain the maximum count collection.

The different size and shape of the tumour vessels were selected for exposure. These sizes were $1.0 \mathrm{~cm}, 2.0 \mathrm{~cm}, 3.0 \mathrm{~cm}, 2.0 \mathrm{x} 4.0 \mathrm{~cm}$ and the shapes were spherical and oval. The entire tumour vessel was hollow to enable it to be filled with contrast medium. Also, the depths of the tumour were measured from the surface of the head phantom to the centre of the tumour vessel. These depths ranged from $0.5 \mathrm{~cm}$ to $5.5 \mathrm{~cm}$ between the centre of the tumour and interior wall of the head phantom surface.

Different concentrations of the Gd were injected into the tumour vessel through the tumour port at the base of the position rod connector (see Figure 3.1). 
The maximum value of the Gd concentration was limited by its concentration in the Gd-DTPA. Concentrations from 5.62 to $78.63 \mathrm{mg} / \mathrm{ml}$ of $\mathrm{Gd}$ in the tumour vessel were used and measured. Checking for any leaks in the tumour vessel was performed after each filling.

The position rod was threaded into the connector to close the port, and the position rod was inserted into the rotation ball. The lock bolts on the position rod were loosened to insert it through the rotation ball until the rod extended to the desired distance into the head phantom. The lock bolts were tightened when the position rod was in the proper position. The head phantom was filled with water which is equivalent to the brain tissue. The rotation ball, position rod, and tumour vessel were reinserted into the head phantom and the rotation ball lock nut was fitted loosely on to the phantom. The ball was rotated until the tumour vessel was in the desired position and the rotation ball lock nut was tightened. Again there was a check for any leaks in the head phantom.

The position of the tumour vessel was adjusted inside the head phantom by using the tumour scale and the laser alignment system (see Figure 3.3) where the anatomical marker of the tumour vessel inside the head phantom was chosen to be $5.0 \mathrm{~cm}$ above the left lateral of the external auditory meatus (ear) and $1.0 \mathrm{~cm}$ posterior. Lateral and vertex positions were selected to measure the concentration of the Gd in the tumour vessel. In the lateral position the head phantom was placed in the supine position on the table (facing up) with the left lateral of the external auditory meatus (left ear) toward the ${ }^{241}$ Am source and XR 100T CdTe detector (see Figure 3.5). In the vertex position, the head phantom, faced up and 
the vertex landmark (top side) was placed toward both the source and the detector. An exposure was made for 30 minutes and the data collected and analysed. 


\section{CHAPTER 4}

\section{RESULTS AND DISCUSSIONS}

This chapter presents the results and the discussion in three sections describing the dependence of the total count of the characteristics $\mathrm{x}$-ray on the concentration of $\mathrm{Gd}(\mathrm{mg} / \mathrm{ml})$, the total amount of $\mathrm{Gd}(\mathrm{mg})$; tumour depth, the tumour size and the positioning of the head phantom. The first section provides an introduction; the second section presents the results; the third section is a discussion of the results.

\subsection{Introduction}

The head phantom, containing Gd contrast medium in the tumour vessel, was placed in front of an ${ }^{241} \mathrm{Am}$ source. The counts of the characteristic $\mathrm{x}$-ray in the lateral and vertex positions of the head phantom were taken. Almost adjacent to the source, the x-ray detector was positioned as shown in Figure 4.2 and Figure 4.22. A gamma ray from the source penetrated the head phantom and interacted with the $\mathrm{Gd}$ atoms inside the tumour vessel. Following the interaction, a characteristic x-rays of Gd were emitted in all directions. some reached the $\mathrm{CdTe}$ detector where they were detected and measured. The energy of the characteristics x-ray emitted was measured at $42.98 \mathrm{keV}$. The detector also measured scattered radiation. The energy of the scattered photons was calculated by using the following equation for Compton scattering: 


$$
E^{\prime}=\frac{E}{1+\left(E / m_{0} c^{2}\right)(1-\cos \theta)}
$$

Where $\mathrm{E}$ is the energy of the incident photon, E' the energy of the scattered photons, $\mathrm{m}_{0} \mathrm{c}^{2}$ is the rest mass energy of electron $(511 \mathrm{keV})$, and $\theta$ is the scattering angle for the scattered photons $[81,82]$. At 138 degrees of scattering, between the incident radiation from the source and the scattered radiation reaching the detector, the scattered photons give a broad Compton peak at $49 \mathrm{keV}$.

The characteristic x-ray peak of the $\mathrm{Gd}$ atoms $(42.98 \mathrm{keV})$ was clear and easily separated from the scattered photon peak (49 keV) as shown in Figure 4.1.

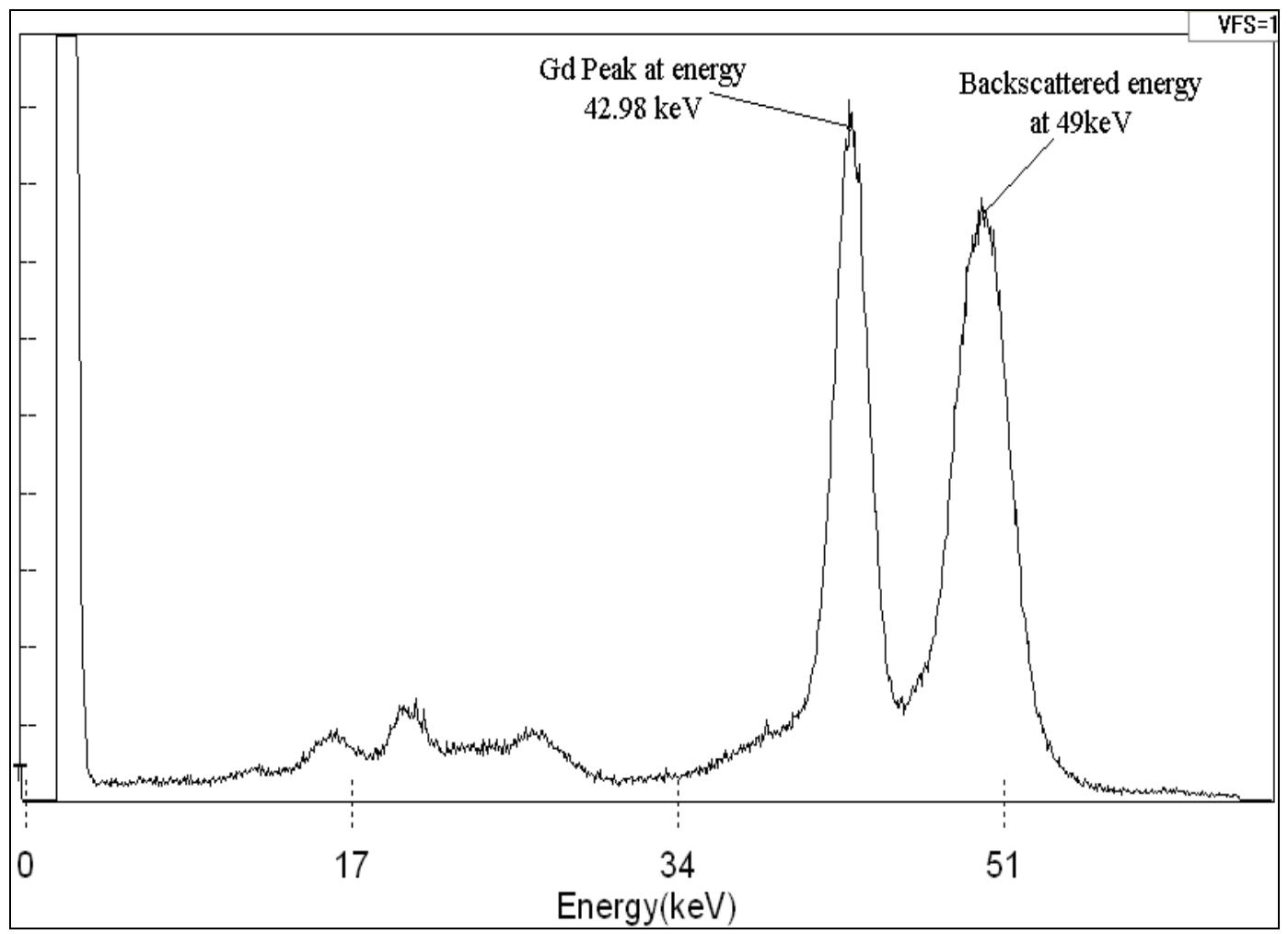

Figure 4.1: Spectrum of the characteristic x-rays of Gd obtained from a $3 \mathrm{~cm}$ diameter tumour vessel, which contained $50.55 \mathrm{mg} / \mathrm{ml}$ of $\mathrm{Gd}$ at a depth of $1.0 \mathrm{~cm}$ in the lateral position. 


\subsection{Results}

This section presents the results of the dependence of the total counts on the Gd concentration. The measurements were taken for the phantom head in the lateral and vertex positions. For each of the positions, the dependence of the total counts on the Gd concentration was measured regarding the tumour size, tumour depth and the presence of water inside the head phantom. The following two subsections present the results of each phantom position.

\subsubsection{Measurements of Gd concentration on lateral position:}

The tumour containing the contrast agent (Magnevist) was placed at different depths inside a head phantom in the lateral position in front of the CdTe detector and the ${ }^{241} \mathrm{Am}$ source, for measurements, as described in chapter 3 section 3.3. A photograph of the experimental setup for the lateral position is presented in Figure 4.2. The results of the dependence of the total counts of the Gd characteristics x-ray for 30 minutes counting time on $\mathrm{Gd}$ concentration as a function of the tumour depth are shown in Figure 4.3 to Figure 4.12 as explained below. The results of the experiments show that the required Gd concentrations were obtained by using the correct contrast agent (Magnevist) to the water ratio. The purpose of the water ratio is to achieve optimum homogeneous distribution of Magnevist contrast medium inside the tumour vessel. 


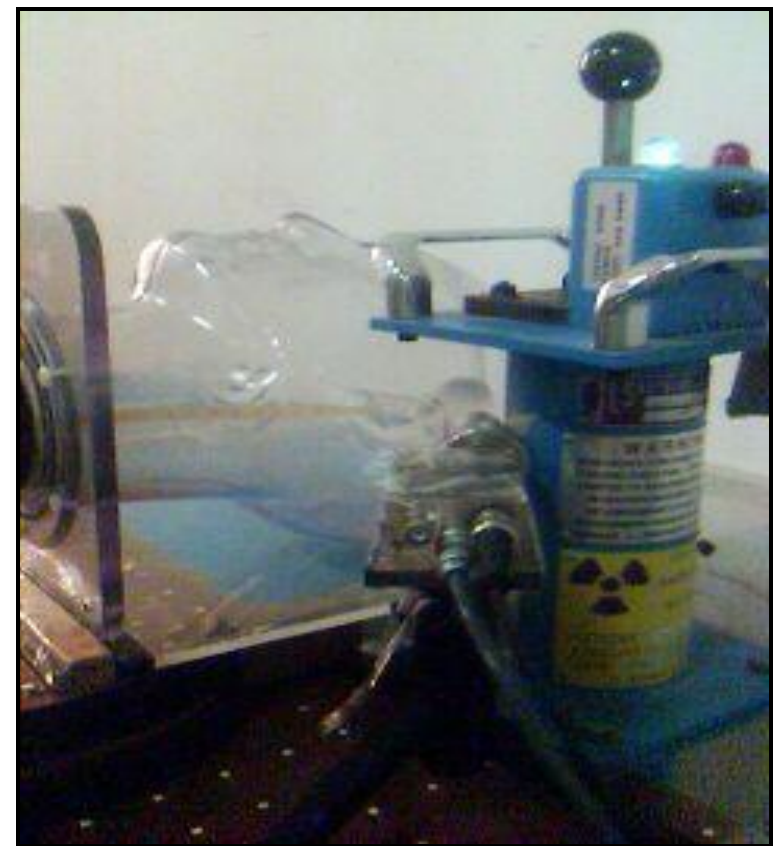

Figure 4.2: Head phantom containing the tumour vessel in the lateral position. 
The dependence of the total count on the Gd concentration as a function of the tumour depth for the tumours of the following sizes: $1.0 \mathrm{~cm}, 2.0 \mathrm{~cm}, 3.0 \mathrm{~cm}$, and $2.0 \times 4.0 \mathrm{~cm}$ is shown in Figure 4.3 to Figure 4.6. For each tumour, data are presented for the tumour with water and without water. However, data are presented for the $1.0 \mathrm{~cm}$ tumour only without water as shown in Figure 4.3. As the diameter of the tumour was small, it was difficult to measure the characteristic $\mathrm{x}$ rays that were emitted from the tumour containing $\mathrm{Gd}$ in the head phantom filled with water to mimic biological tissue. So, all the experiments for the $1.0 \mathrm{~cm}$ tumour were conducted in an empty head phantom. All the Figures (Figure 4.3 to Figure 4.6) show that the total count increased as the Gd concentration increased. They also show that the total count decreased as the tumour depth increased.

Comparisons of the dependence of the total counts on the $\mathrm{Gd}$ concentration for the head phantom with and without water are shown in Figure 4.3 to Figure 4.6. for example, the measurements that were taken at depths of 1.0 $\mathrm{cm}$ and $2.0 \mathrm{~cm}$ for a tumour vessel size $2.0 \mathrm{~cm}$; at depths of $1.5 \mathrm{~cm}$ and $4.5 \mathrm{~cm}$ for a $3.0 \mathrm{~cm}$ diameter tumour; and at depths of $1.0 \mathrm{~cm}$ and $3.5 \mathrm{~cm}$ for the $2.0 \mathrm{x} 4.0 \mathrm{~cm}$ tumour, show the total counts increase as the concentration increases and they are higher for the phantom head without water for each tumour depth as discussed in the next section. 


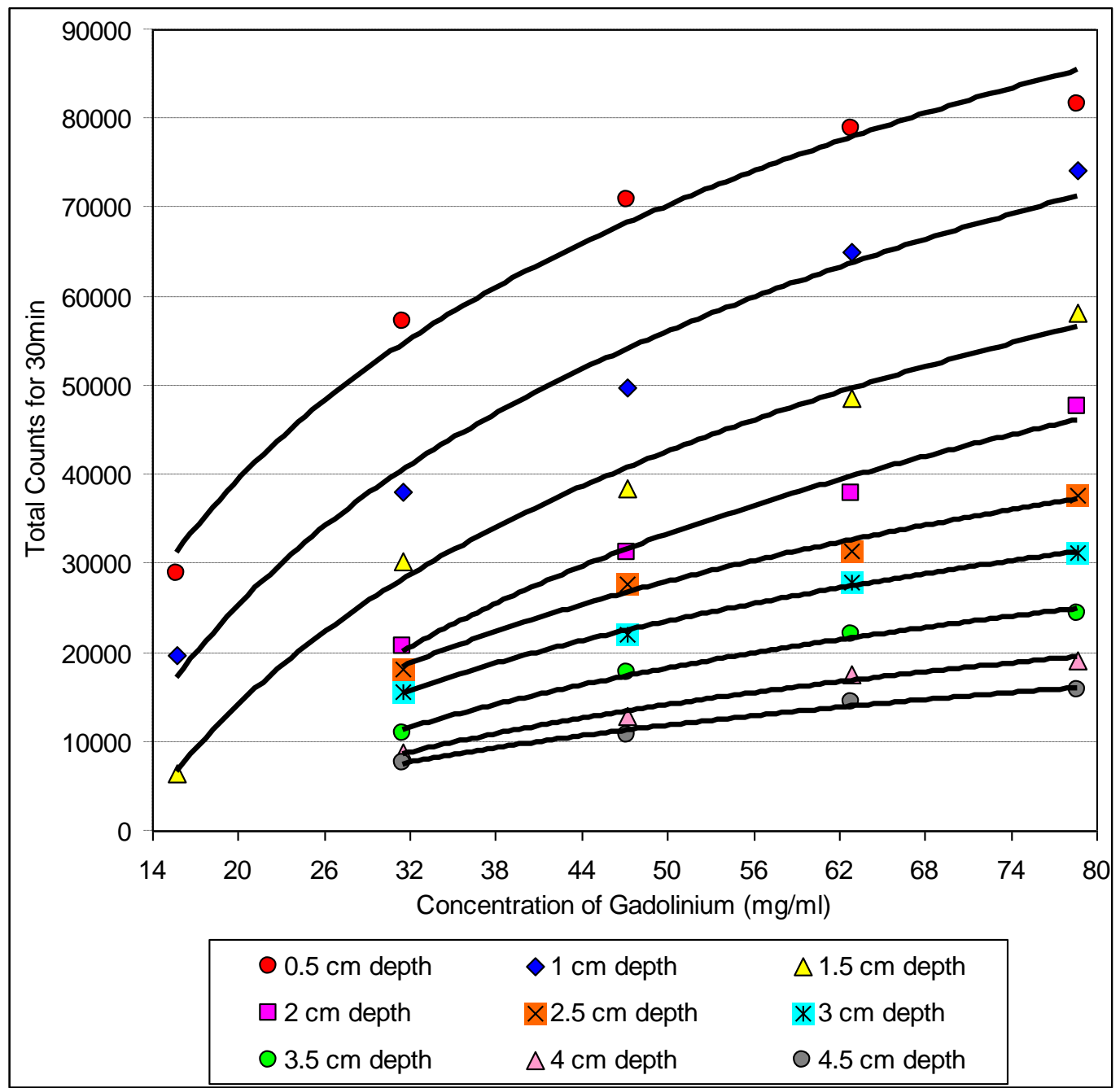

Figure 4.3: Counts versus concentration of $\mathrm{Gd}$ at different depths for a $1.0 \mathrm{~cm}$ diameter tumour inside a head phantom in the lateral position. The lines are drawn to guide the eye. 


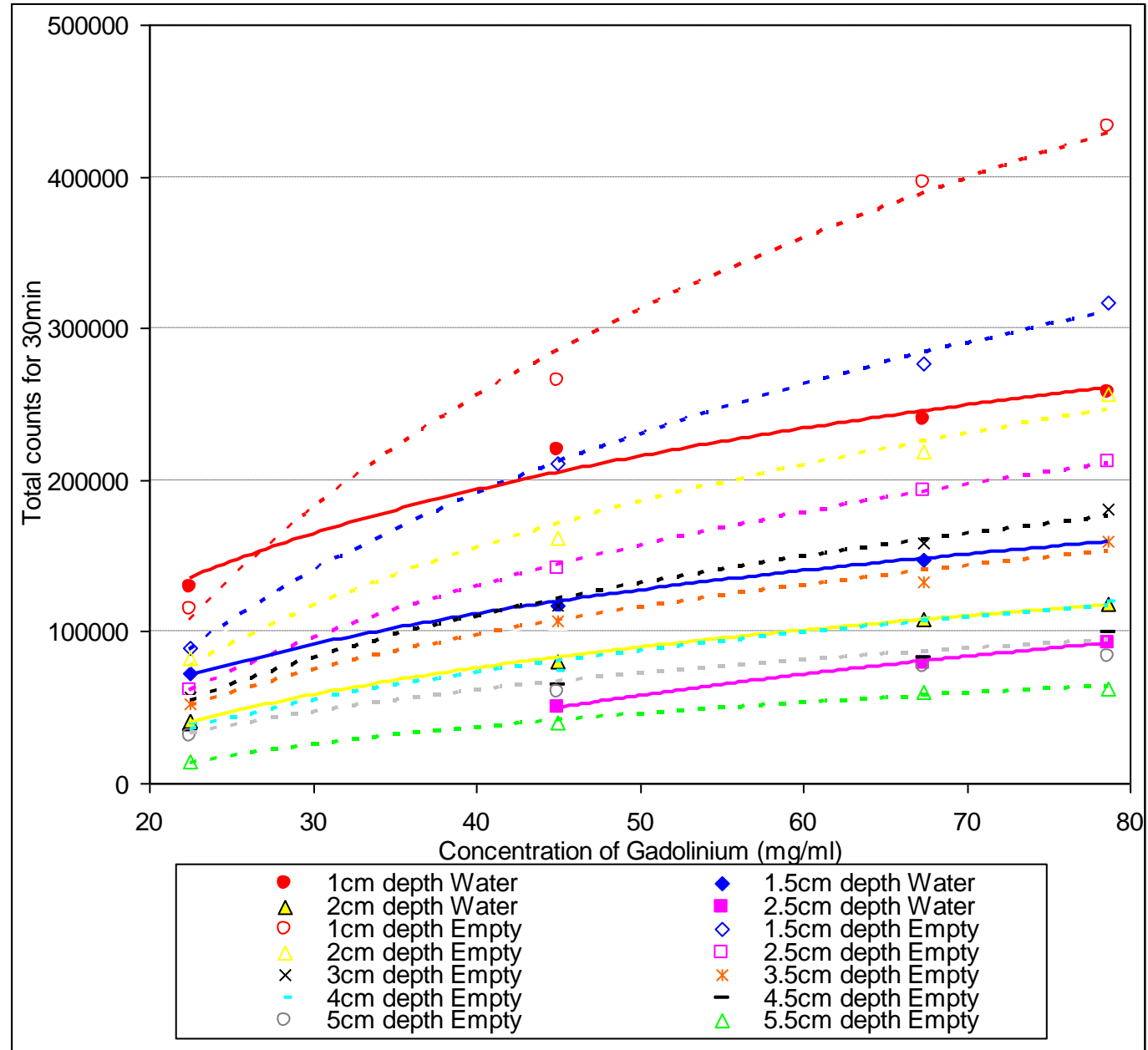

Figure 4.4: Counts versus concentration of $\mathrm{Gd}$ at different depths for a $2.0 \mathrm{~cm}$ diameter tumour inside a head phantom with and without water in the lateral position. The lines are drawn to guide the eye. 


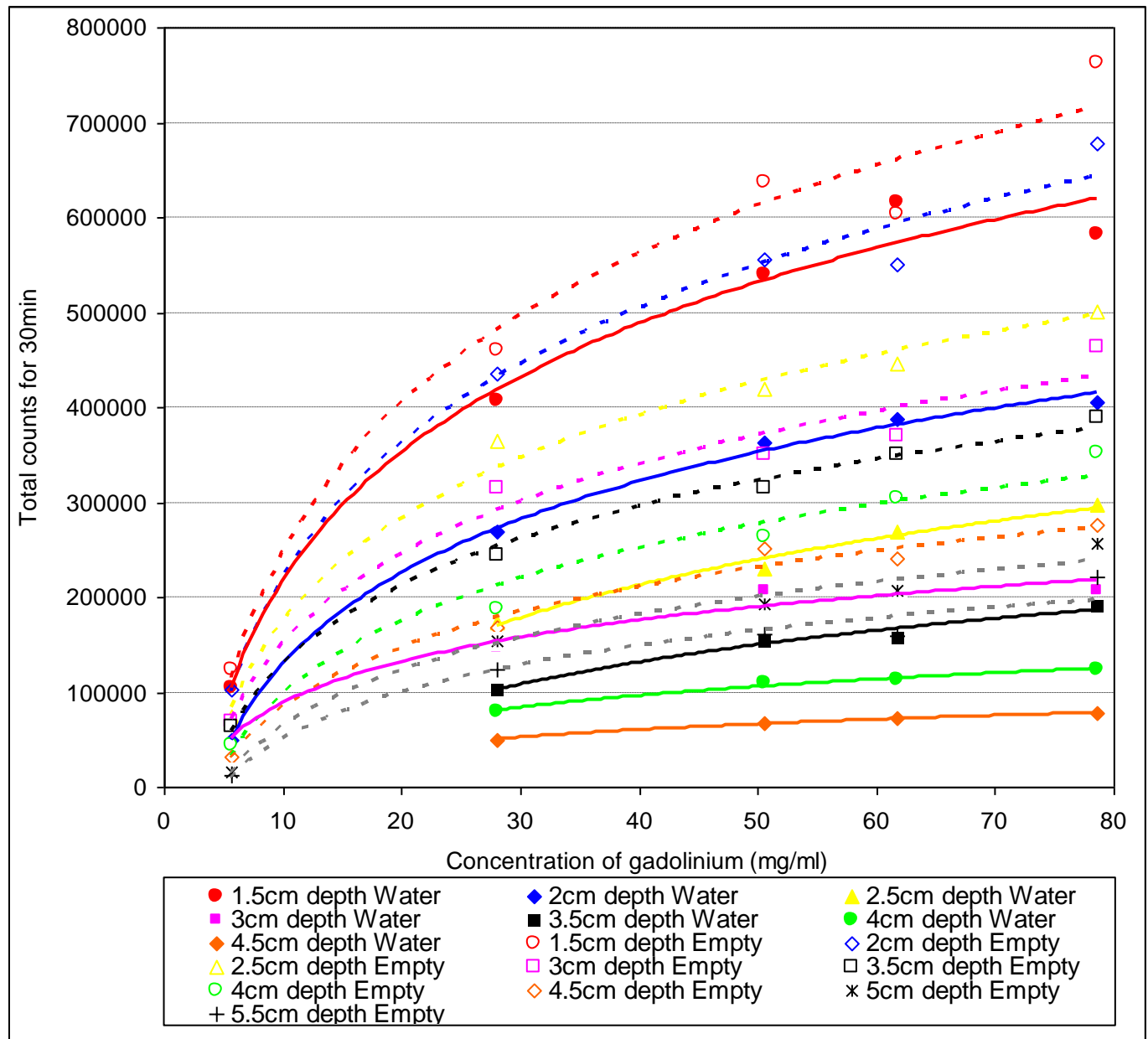

Figure 4.5: Counts versus concentration of $\mathrm{Gd}$ at different depths for a $3.0 \mathrm{~cm}$ diameter tumour inside a head phantom with and without water in the lateral position. The lines are drawn to guide the eye. 


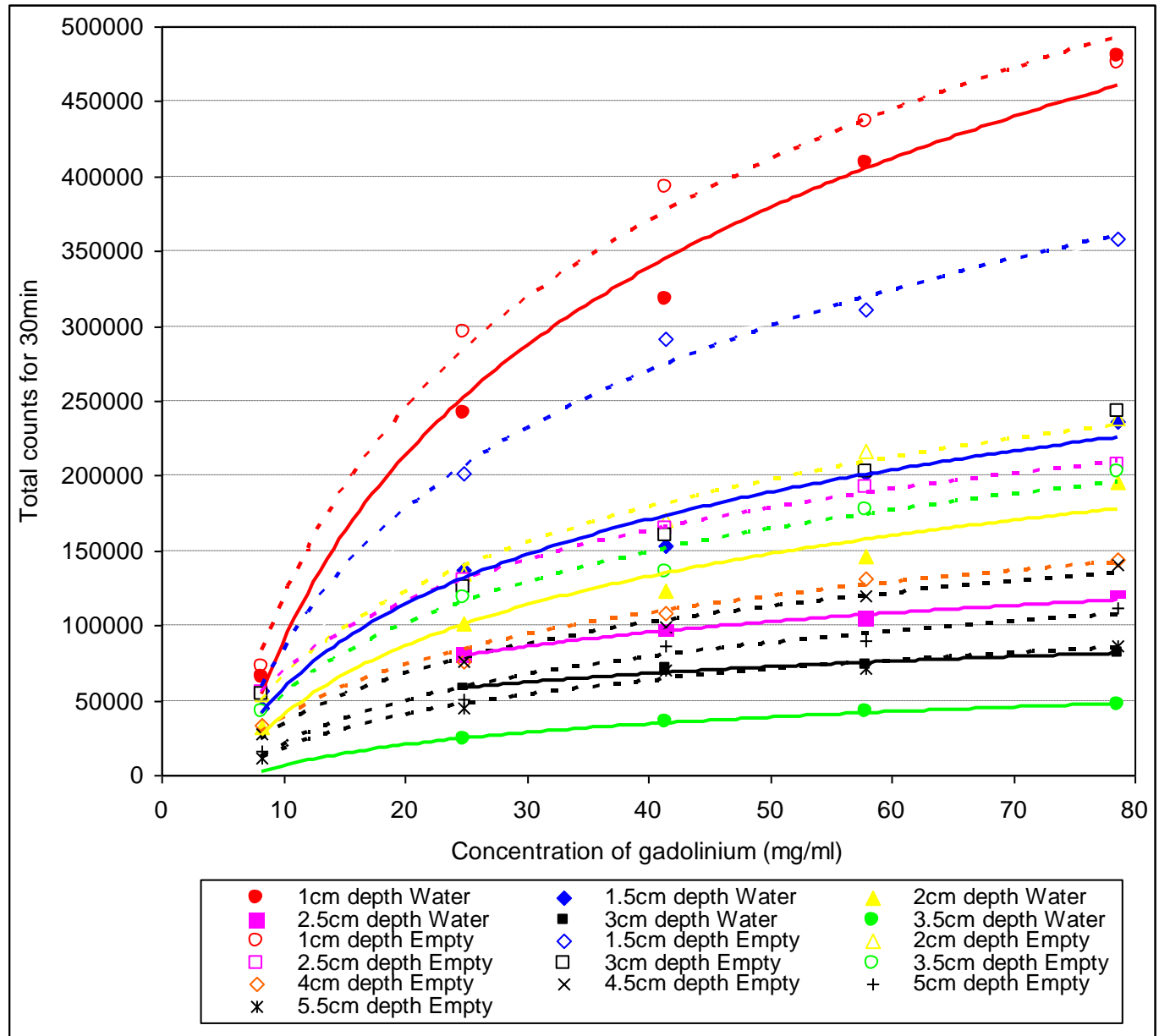

Figure 4.6: Counts versus concentration of Gd at different depths for a $2.0 \times 4.0$ $\mathrm{cm}$ diameter tumour inside a head phantom with and without water in the lateral position. The lines are drawn to guide the eye. 
The dependence of the total count on the tumour depth, as a function of the Gd concentration for the tumours of the sizes of $1.0 \mathrm{~cm}, 2.0 \mathrm{~cm}, 3.0 \mathrm{~cm}$, and $2.0 \times 4.0 \mathrm{~cm}$ are shown in Figure 4.7 to Figure 4.10. The depth of the tumour was measured from the surface of the head phantom to the centre of the tumour vessel. These depths were $0.5,1.0,1.5,2.0,2.5,3.0,3.5,4.0,4.5,5.0$ and $5.5 \mathrm{~cm}$. Figures are presented for each tumour: one with water and one without (except for the tumour size $1.0 \mathrm{~cm}$ ) as explained above.

These figures show that the total counts decreased as the tumour depth increased inside the head phantom. The figures also show that the total count increased, as the Gd concentration increased. 


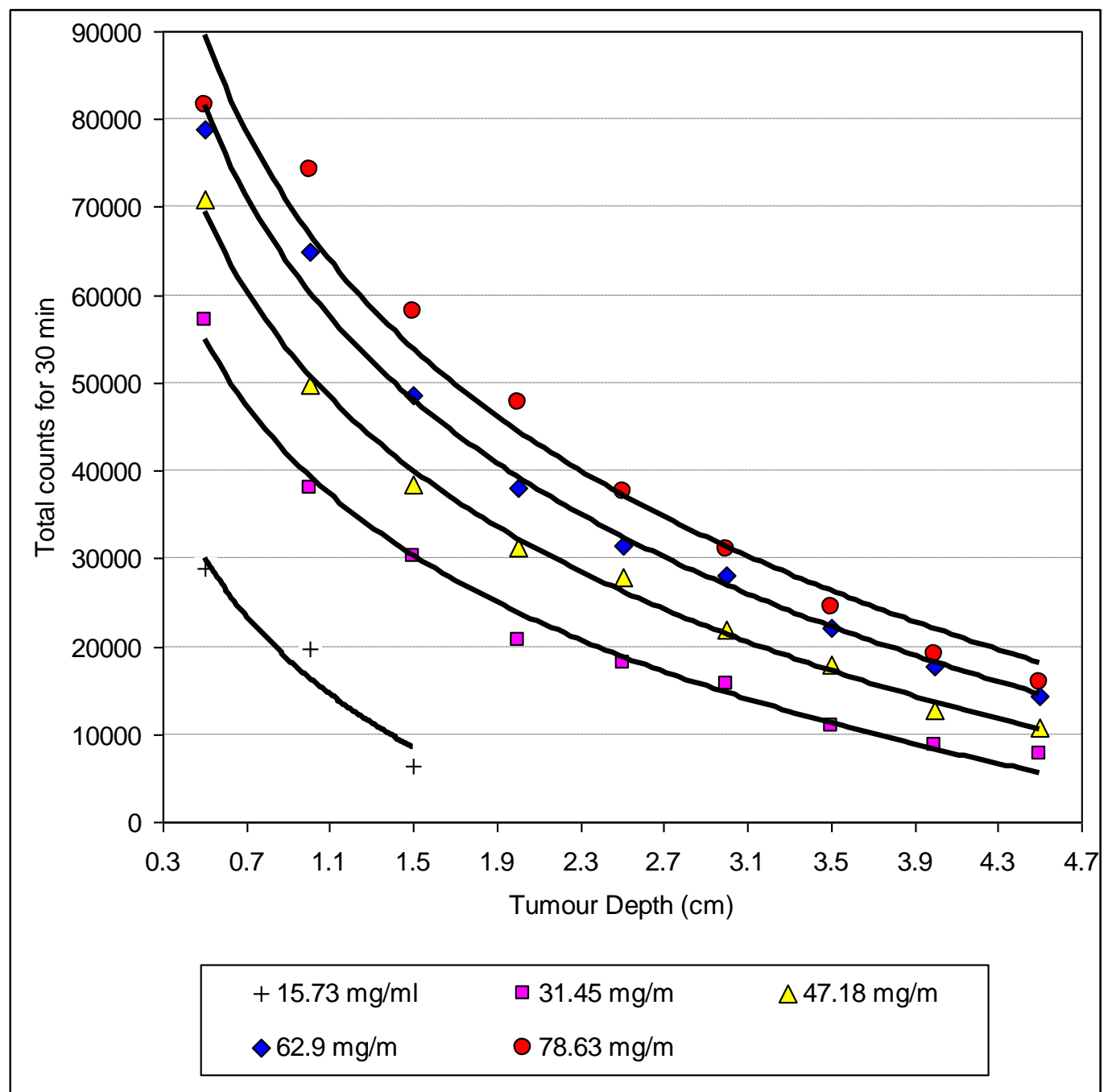

Figure 4.7: Counts versus tumour vessel depth at different concentrations of $\mathrm{Gd}$ for a $1.0 \mathrm{~cm}$ diameter tumour, inside head phantom, in the lateral position. 


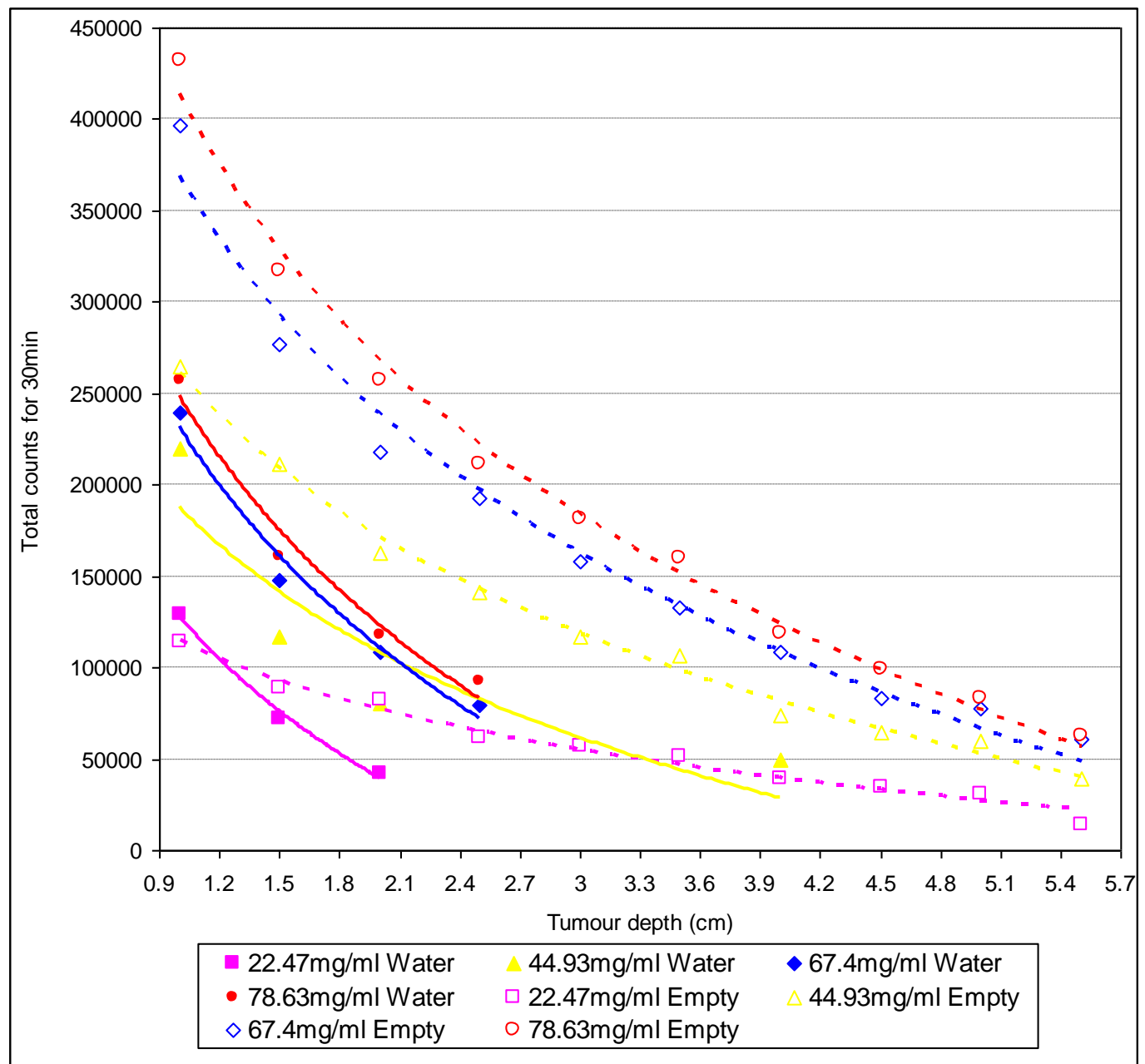

Figure 4.8: Counts versus tumour vessel depth at different concentrations of $\mathrm{Gd}$ for a $2.0 \mathrm{~cm}$ diameter tumour inside a head phantom with and without water in the lateral position. 


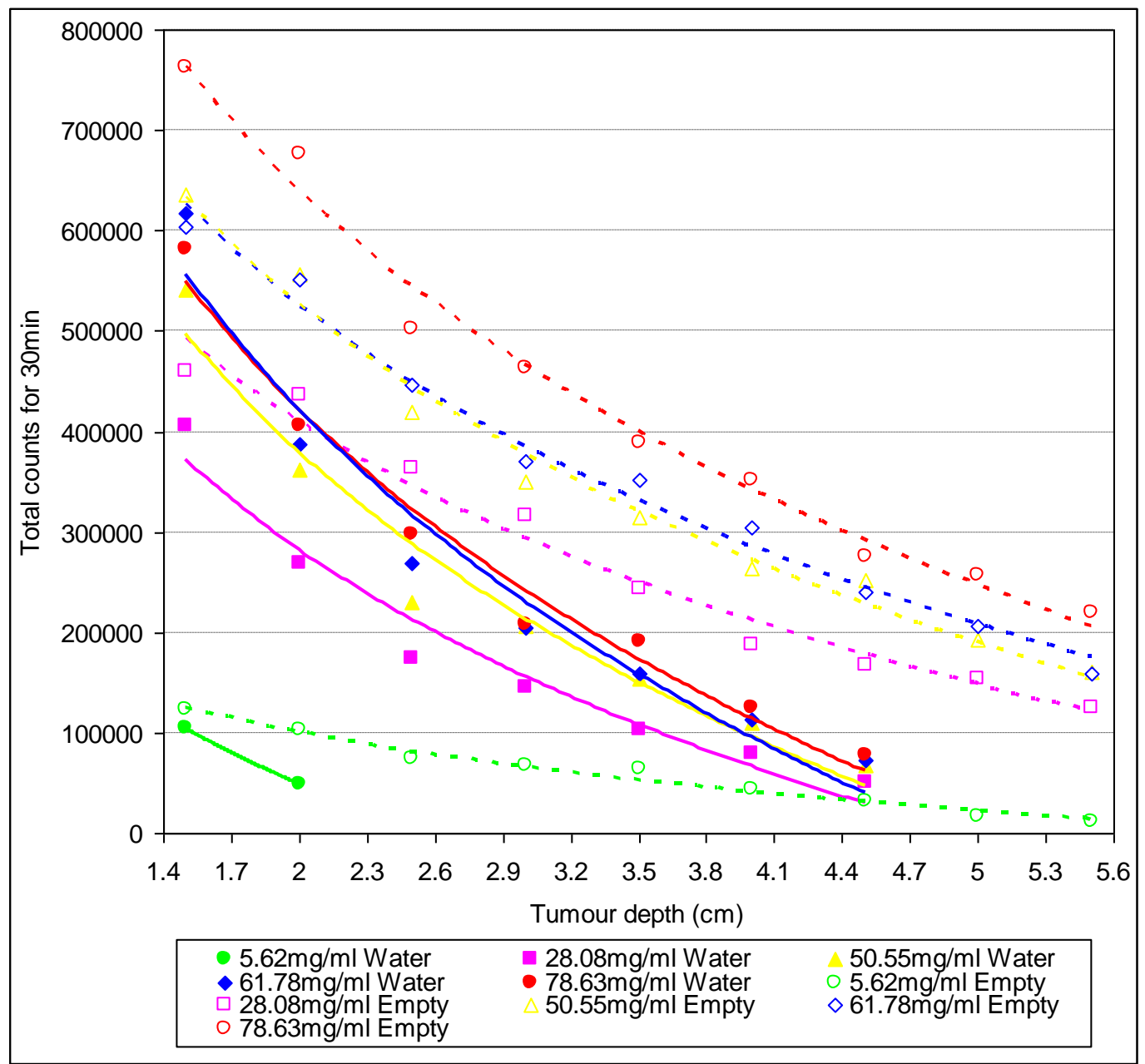

Figure 4.9: Counts versus tumour vessel depth at different concentrations of $\mathrm{Gd}$ for a $3.0 \mathrm{~cm}$ diameter tumour inside a head phantom with and without water in the lateral position. 


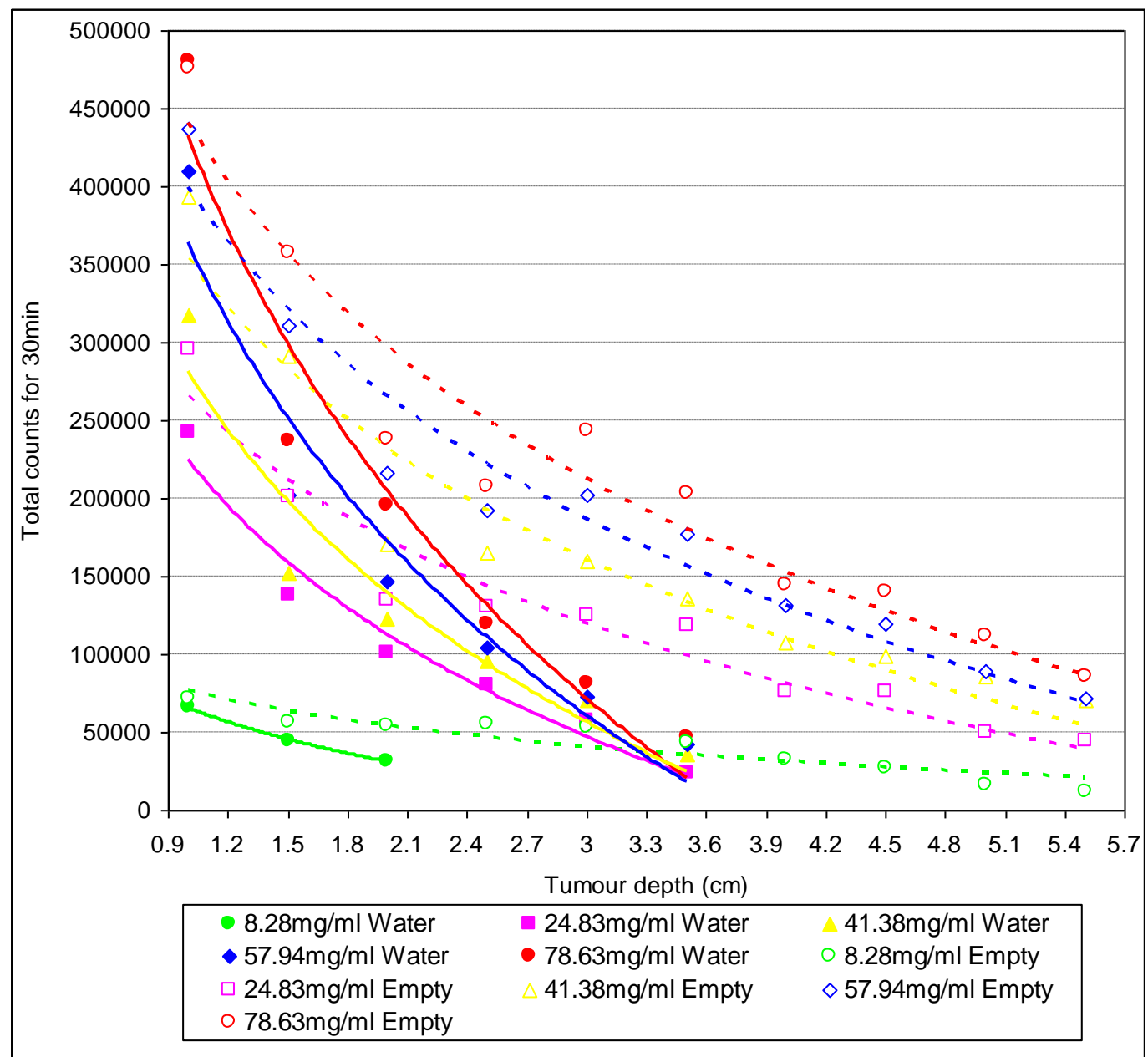

Figure 4.10: Counts versus tumour vessel depth at different concentrations of $\mathrm{Gd}$ for a $2.0 \times 4.0 \mathrm{~cm}$ diameter tumour inside a head phantom with and without water in the lateral position. 
The relationship between the measured attenuation of the water in the skull using the different $\mathrm{Gd}$ concentrations $(\mathrm{mg} / \mathrm{ml})$ and the different tumour depths are shown in Figure 4.11. The line is the predicted attenuation for the known scattering and absorption of water. The incident radiation of $59.5 \mathrm{keV}$ from the source and the emitted characteristic x-ray of $42.98 \mathrm{keV}$ undergo attenuation by the water inside the head phantom in the lateral position. The attenuation of the incoming $59.5 \mathrm{keV}$ gamma ray is given by $\exp [-\mu(59.5 \mathrm{keV}) \mathrm{x}]$, while the attenuation due to the emitted characteristic x-ray of $42.98 \mathrm{keV}$ is $\exp [-$ $\left.\mu(42.98 \mathrm{keV}) \mathrm{x}^{\prime}\right]$, where $\mathrm{x}$ and $\mathrm{x}^{\prime}$ are the distance of the incident radiation and emitted characteristic x-ray respectively, that travels though the water.

The correlation between the experimentally determined attenuation of and the calculated attenuation was observed. 


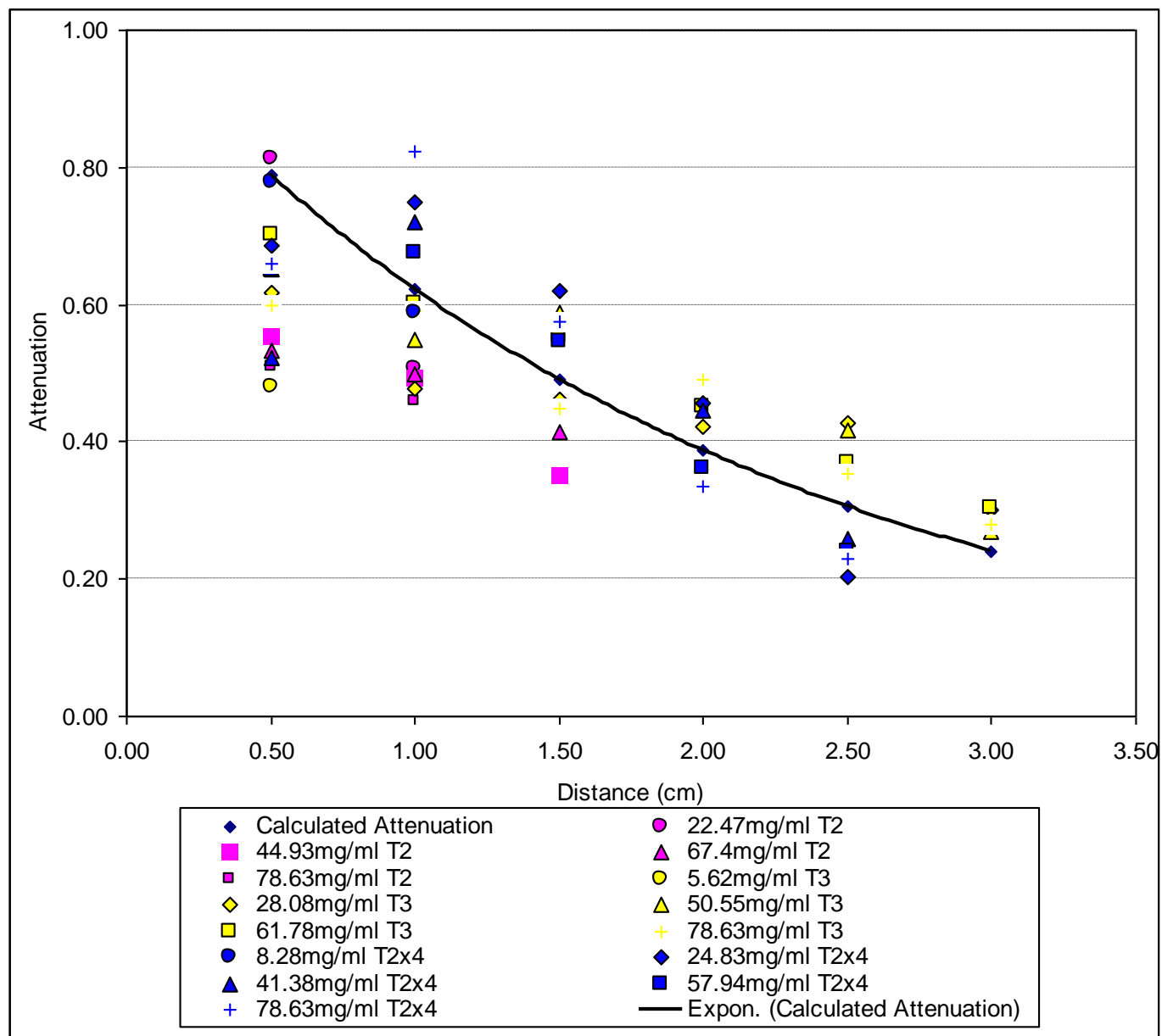

Figure 4.11: Calculated attenuation compared with measured attenuation at different distance $(\mathrm{cm})$ and different concentrations of $\mathrm{Gd}$ on a $2.0 \mathrm{~cm}, 3.0 \mathrm{~cm}$ and $2.0 \times 4.0 \mathrm{~cm}$ diameter tumour, inside the head phantom water, in the lateral position. 
Figure 4.12 shows the total counts versus the concentration of $\mathrm{Gd}$, obtained from the tumour size of $1.0 \mathrm{~cm}, 2.0 \mathrm{~cm}, 3.0 \mathrm{~cm}$ and $2.0 \times 4.0 \mathrm{~cm}$ at a depth of $1.5 \mathrm{~cm}$ in the head phantom without water, in the lateral position. These are drawn in order to show the effect of the tumour size on counts. Clearly, an effect of the tumour size is observed, where increased size of the tumour vessel lead to increases in the total counts. For the $1 \mathrm{~cm}$ tumour, the counts appear to increase linearly with concentration. For each of the larger size tumours, the counts start to increase almost linearly with the amount of Gd for the smallest concentration and then it seems to tend towards a saturation (or the data are nonlinear and seem to approach a plateau). This possibly indicates reabsorption of emitted rays at the higher concentrations of Gd. The highest counts were obtained from the $3.0 \mathrm{~cm}$ diameter of the tumour size. In this case the tumour vessel exposed to the gamma beams has the largest volume and cross sectional area providing higher probability for interaction. 


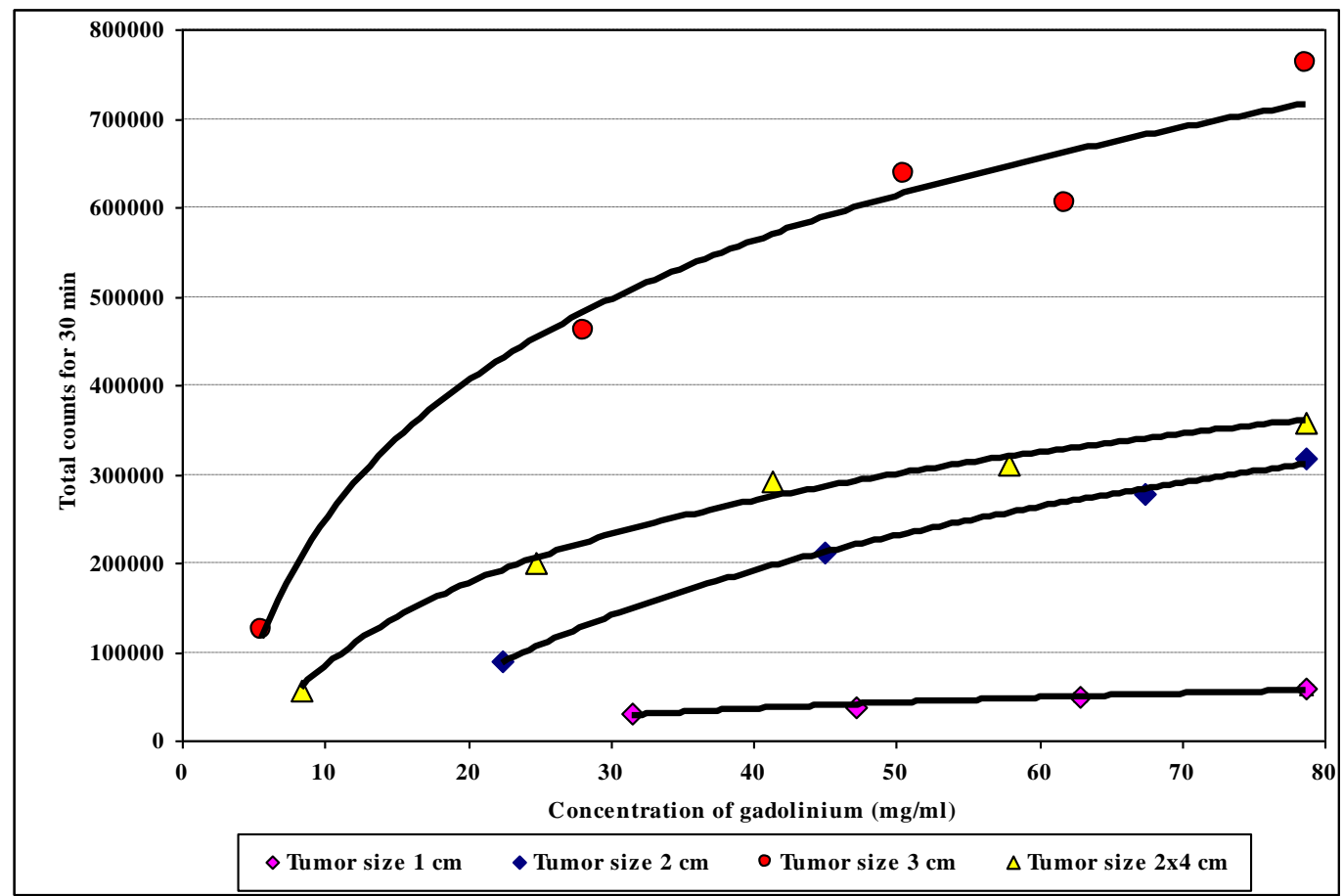

Figure 4.12: Counts versus concentration of Gd in different tumour sizes in the head phantom without water at a depth of $1.5 \mathrm{~cm}$ for all sizes in the lateral position. 
To obtain the size and the shape of the tumour by a radiographic method, a general x-ray machine with radiograph film has been used. Radiographic images are shown in Figure 4.13 to Figure 4.20. In this case the tumour of $3 \mathrm{~cm}$ diameter containing the $\mathrm{Gd}$ agent was placed at a $1.5 \mathrm{~cm}$ depth inside the head phantom containing water. The left lateral of the head phantom was put in contact with the table and the median Sagittal plane was parallel to the film, while the x-ray beam was perpendicular to the film and sagittal plane. The central ray was centred to the right external auditory meatus. Radiographic exposure factors for the experiments were fixed at $73 \mathrm{kVp}, 20 \mathrm{mAs}$, with the source film distance of $105 \mathrm{~cm}$, and the cassette size was a $24 \mathrm{~cm}$ x $30 \mathrm{~cm}$. After the radiographic films were exposed using a conventional x-ray machine (General Eelectric, USA), x-ray films were developed which involved automatic chemical processing where the concentrations of the chemical and the temperature were higher than the usual values used in routine processing in radiology department (Kodak film processing, Japan). These radiographic films showed the $3.0 \mathrm{~cm}$ tumour image in the lateral position with $\mathrm{Gd}$ concentrations of $0.56,2.81,5.62,16.85,28.08$, $39.32,50.55$ and $78.63 \mathrm{mg} / \mathrm{ml}$. The presence of the Gd compound in the tumour vessel inside the head phantom was clearly seen on the radiographic film. The outline of the tumour vessel was apparent.

The differences of optical density in the x-ray films, as shown in Figure 4.21, were obtained when the densities from the centre of the tumour vessels were subtracted from the densities of the darkest point on the $\mathrm{x}$-ray films by using a Victoreen densitometer (Phoenix, USA). That showed that the noise was increased with low concentration of the Gd. Because radiographic film may be 
subjected to different chemical processes where the darkness will be affected, these measurements would be very hard to be quantitative. Accordingly it is difficult to use the film for measuring Gd concentrations.

The main use of radiographic film is to show the size and shape of the tumour. Based on that the appropriate shape of concentration can be selected.

It is obvious that at low concentration, the noise will be much large as seen from the point on the curve, at low concentration.

The value at $5 \mathrm{mg} / \mathrm{ml}$ showed a significant dip. The non-uniformity of the chemical processing across the film can be one reason of this dip. This is not expected to be normal trend of the curve. It is considered an error point and indicative of the amount of scatter that one experiences in the data when the density of film is used to try and quantify concentrations. 


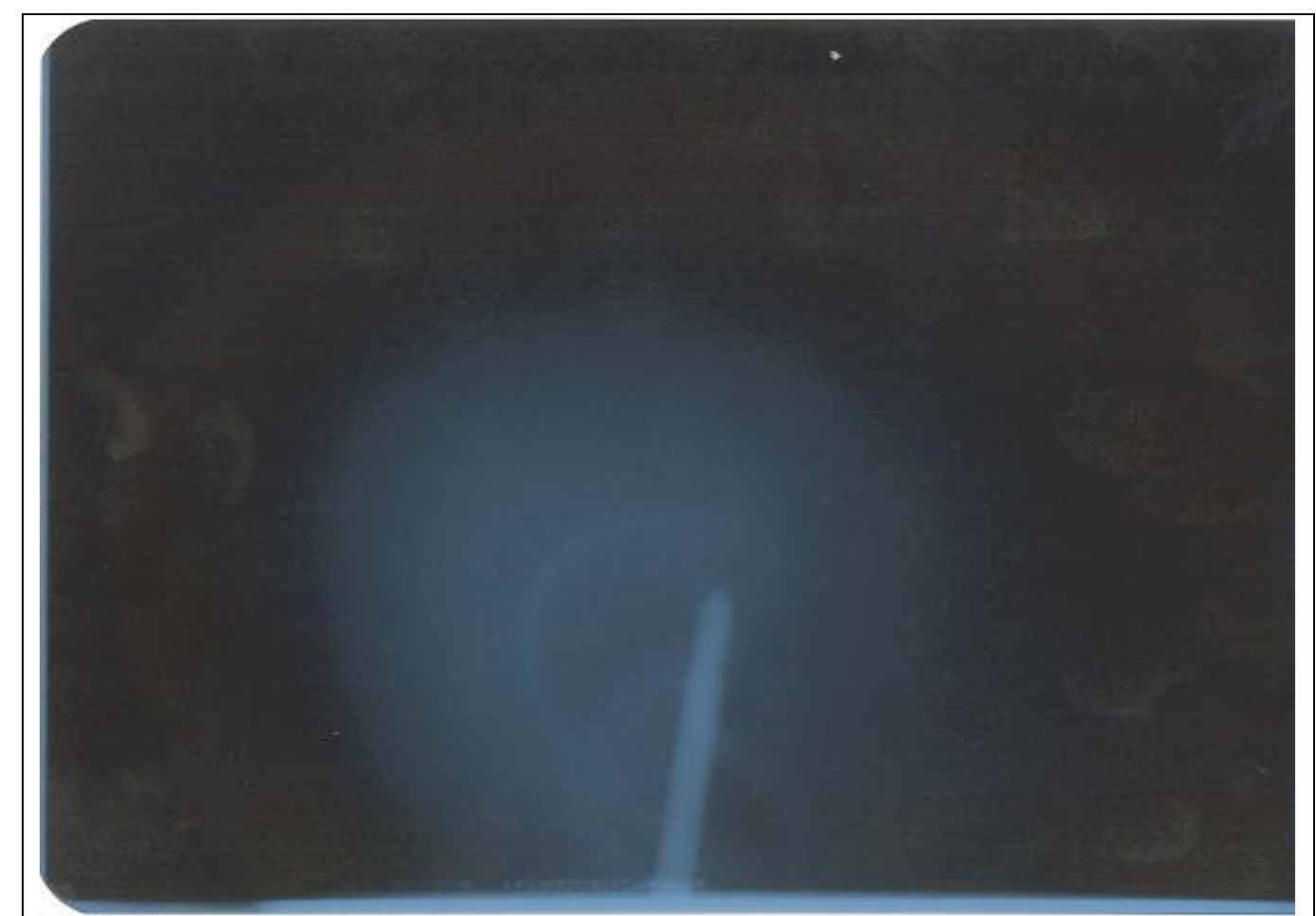

Figure 4.13: Radiograph of the $3 \mathrm{~cm}$ tumour vessel which contains $0.56 \mathrm{mg} / \mathrm{ml}$ of Gd concentration inside the head phantom taken at $73 \mathrm{KVp}, 20 \mathrm{mAs}$, and at 105 cm SFD.

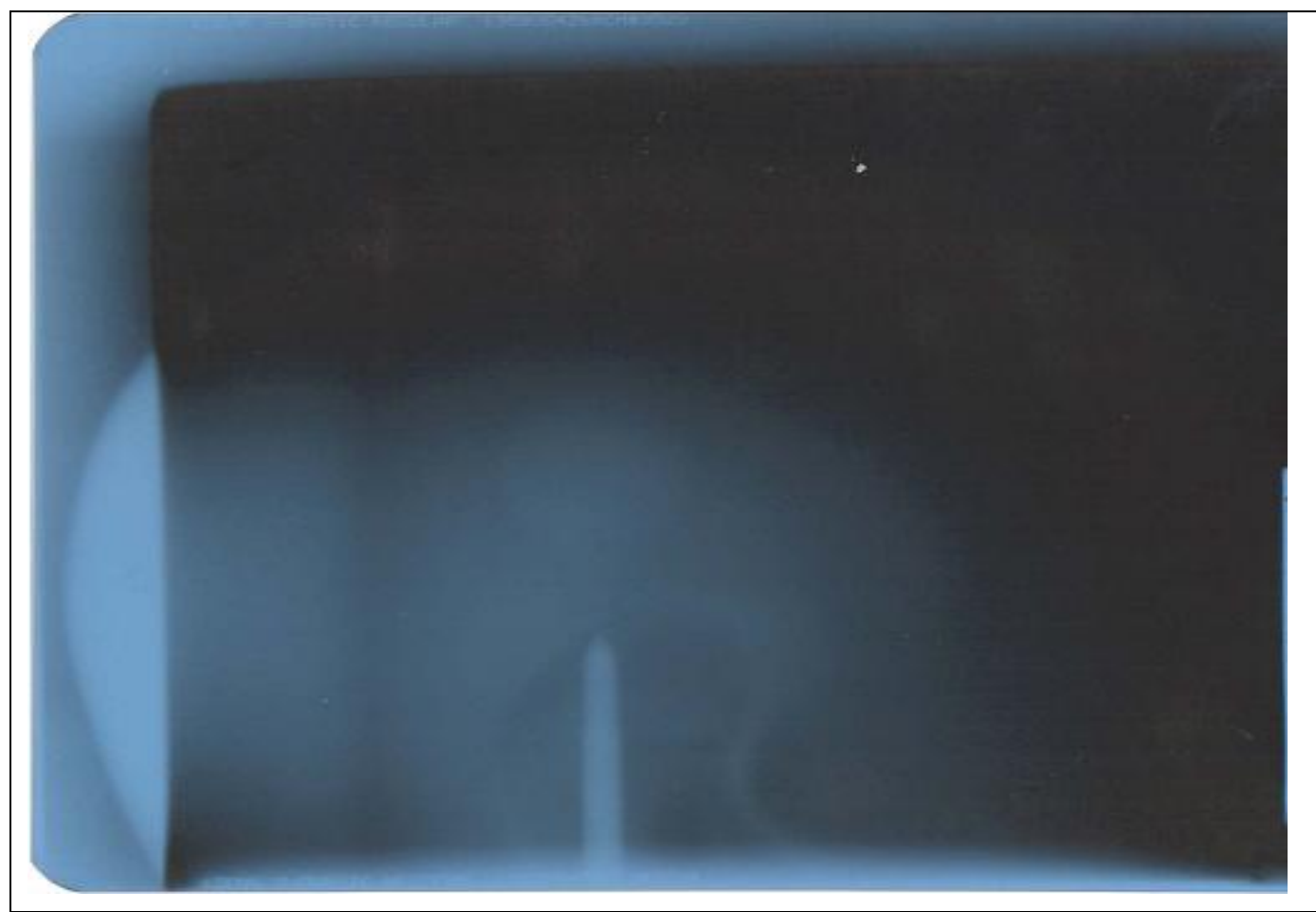

Figure 4.14: Radiograph of the $3 \mathrm{~cm}$ tumour vessel which contains $2.81 \mathrm{mg} / \mathrm{ml}$ of Gd concentration inside the head phantom taken at $73 \mathrm{KVp}, 20 \mathrm{mAs}$, and at 105 cm SFD. 


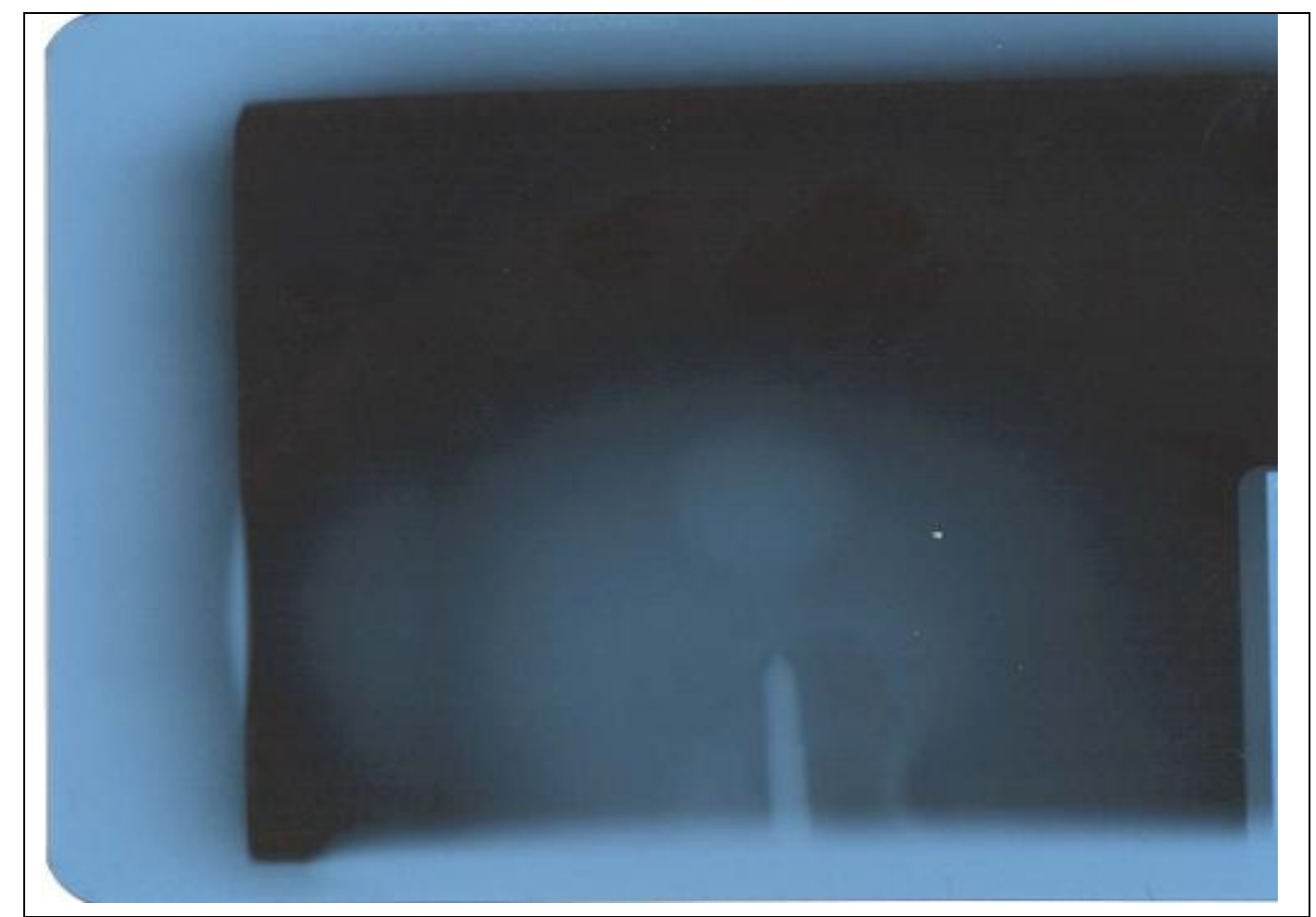

Figure 4.15: Radiograph of the $3 \mathrm{~cm}$ tumour vessel which contains $5.62 \mathrm{mg} / \mathrm{ml}$ of Gd concentration inside the head phantom taken at $73 \mathrm{KVp}, 20 \mathrm{mAs}$, and at 105 cm SFD.

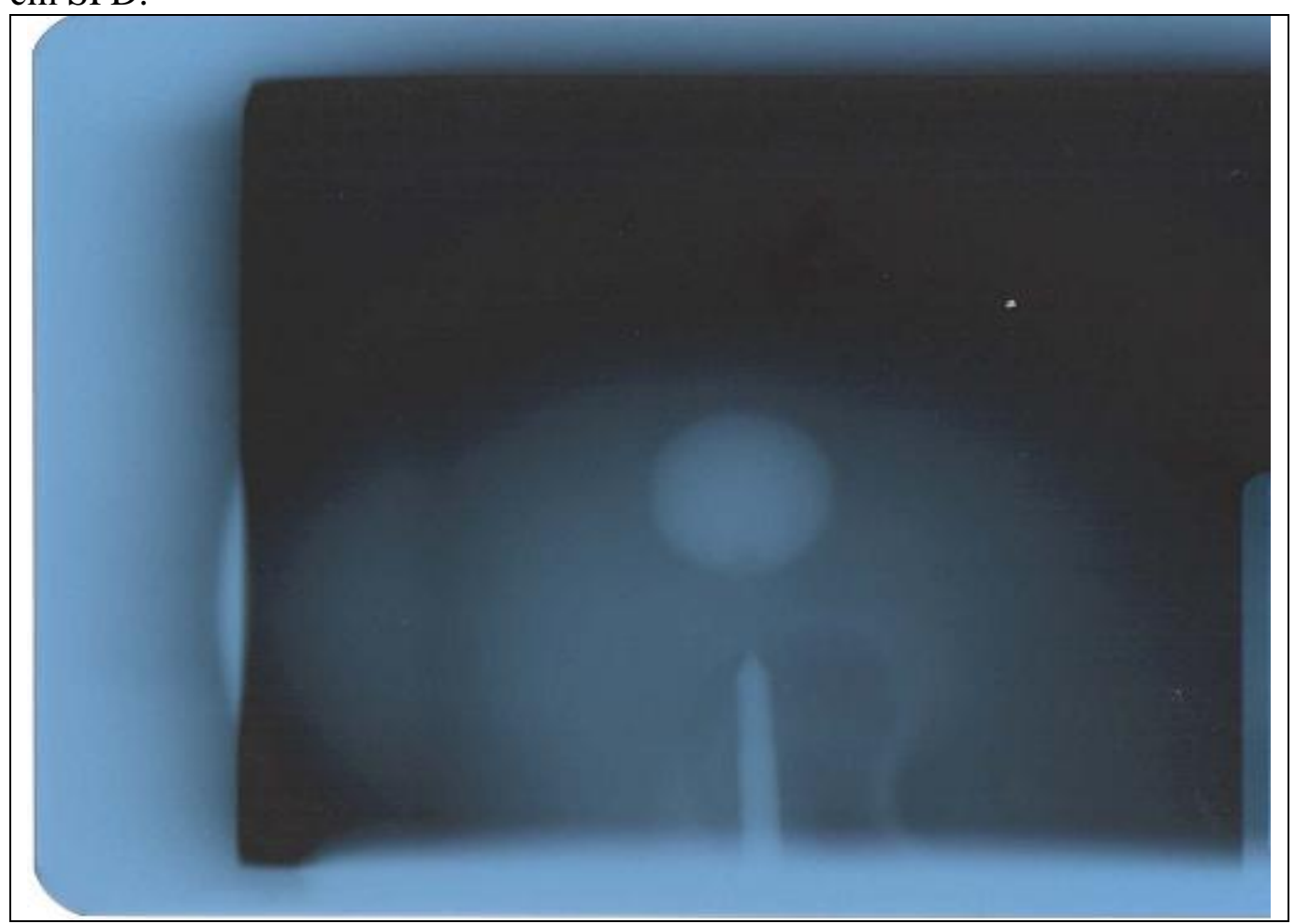

Figure 4.16: Radiograph of the $3 \mathrm{~cm}$ tumour vessel which contains $16.85 \mathrm{mg} / \mathrm{ml}$ of $\mathrm{Gd}$ concentration inside the head phantom taken at $73 \mathrm{KVp}, 20 \mathrm{mAs}$, and at 105 cm SFD. 


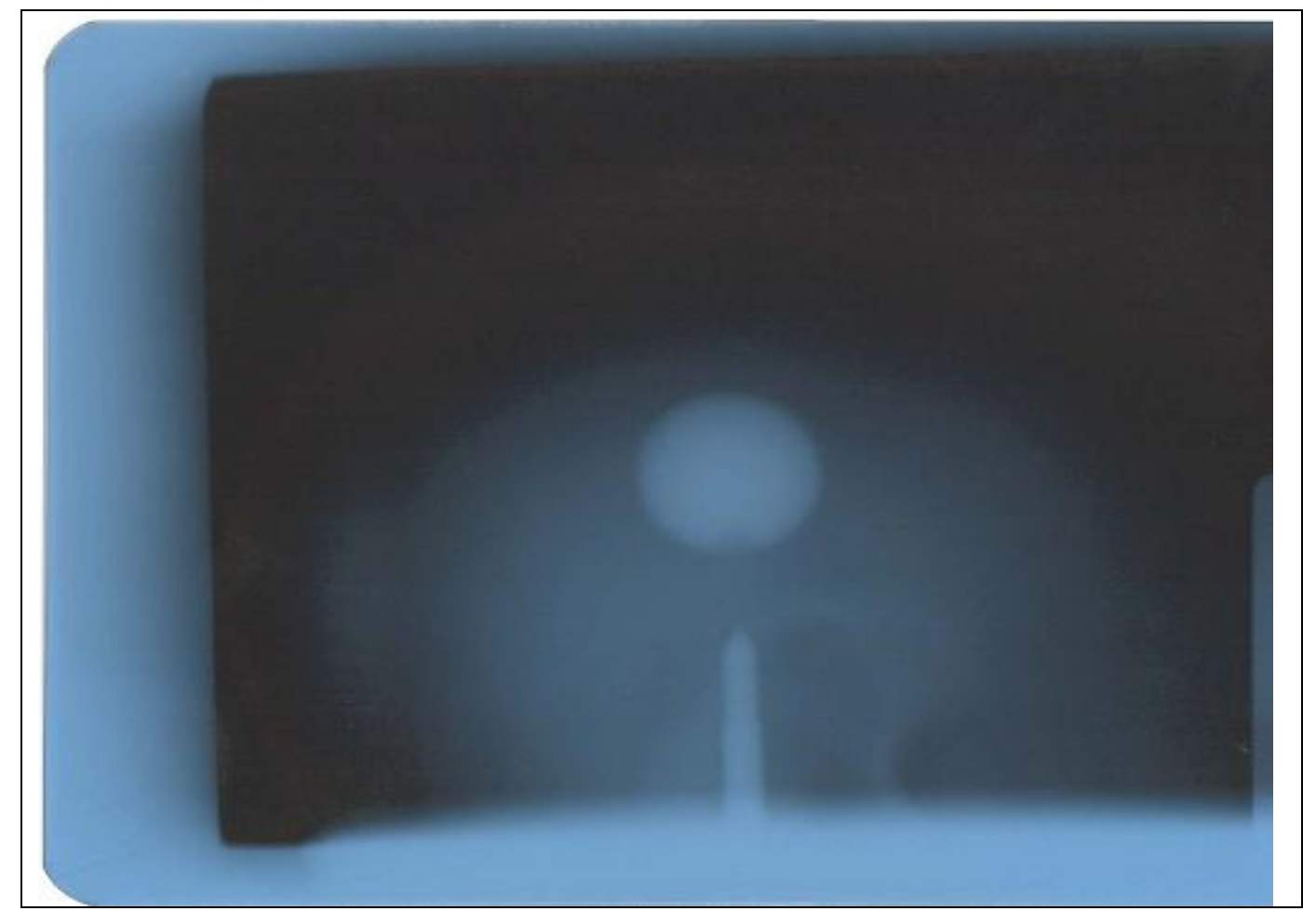

Figure 4.17: Radiograph of the $3 \mathrm{~cm}$ tumour vessel which contains $28.08 \mathrm{mg} / \mathrm{ml}$ of $\mathrm{Gd}$ concentration inside the head phantom taken at $73 \mathrm{KVp}, 20 \mathrm{mAs}$, and at 105 cm SFD.

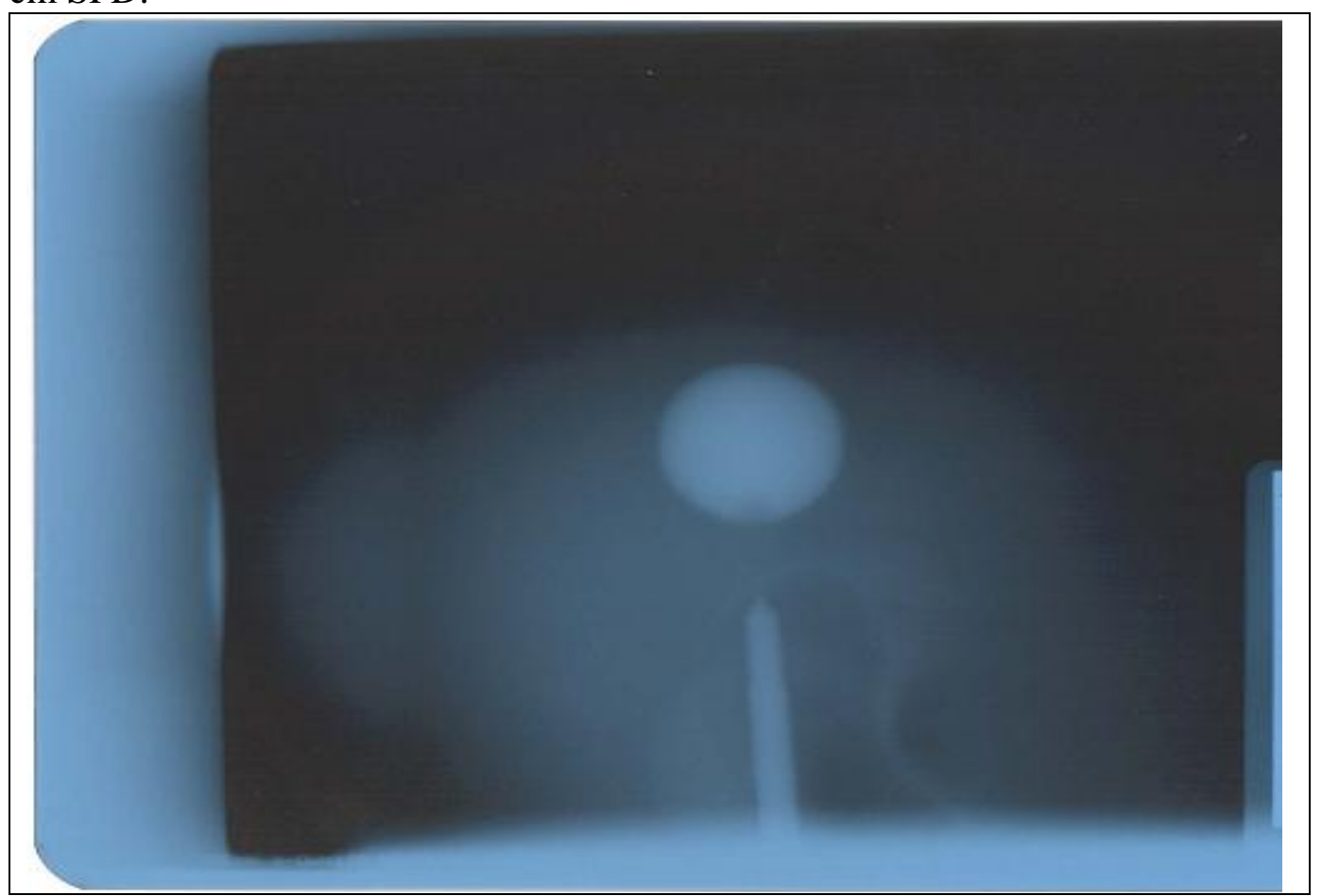

Figure 4.18: Radiograph of the $3 \mathrm{~cm}$ tumour vessel which contains $39.32 \mathrm{mg} / \mathrm{ml}$ of Gd concentration inside the head phantom taken at 73KVp, $20 \mathrm{mAs}$, and at 105 cm SFD. 


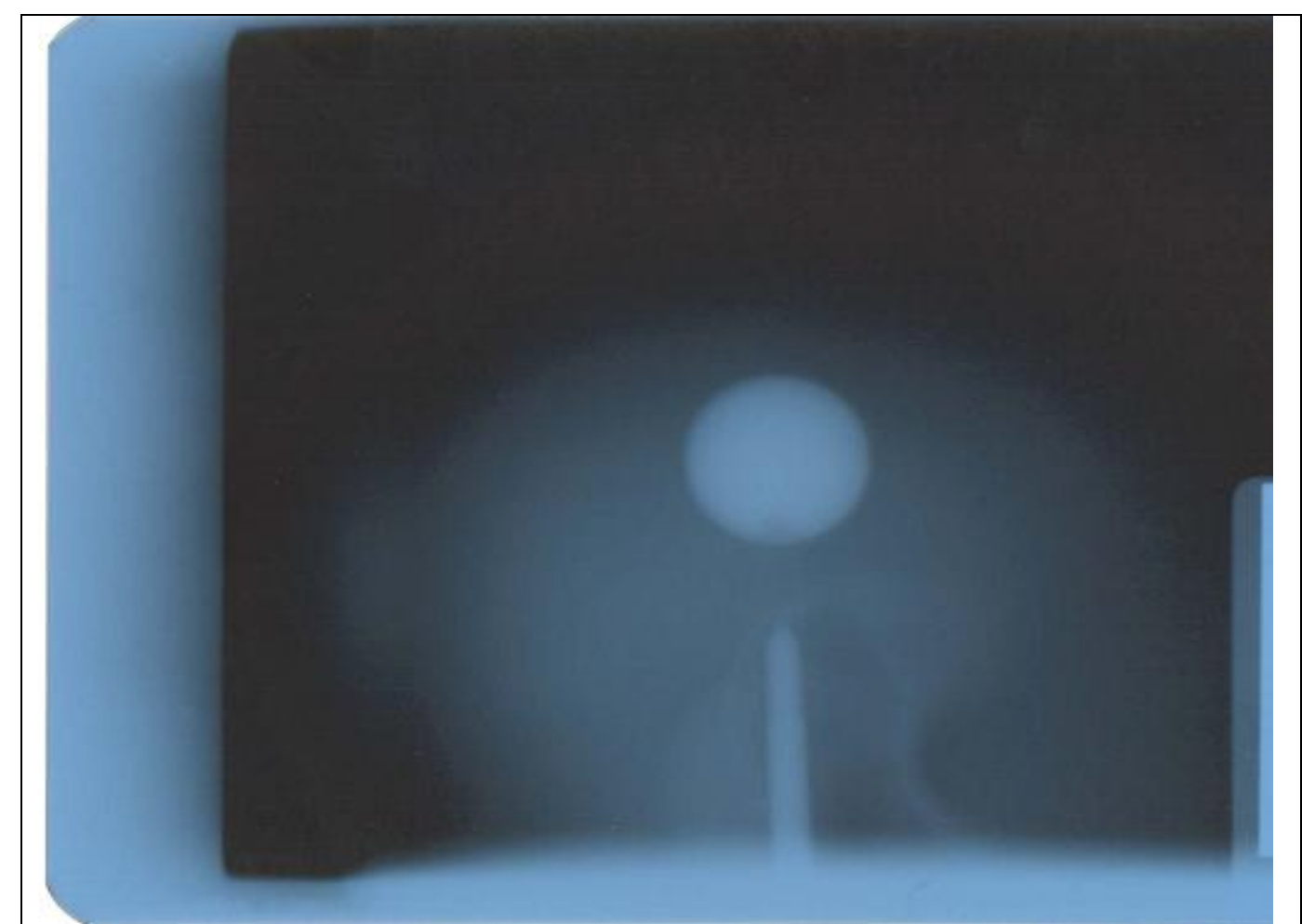

Figure 4.19: Radiograph of the $3 \mathrm{~cm}$ tumour vessel which contains $50.55 \mathrm{mg} / \mathrm{ml}$ of Gd concentration inside the head phantom taken at 73KVp, $20 \mathrm{mAs}$, and at 105 cm SFD.

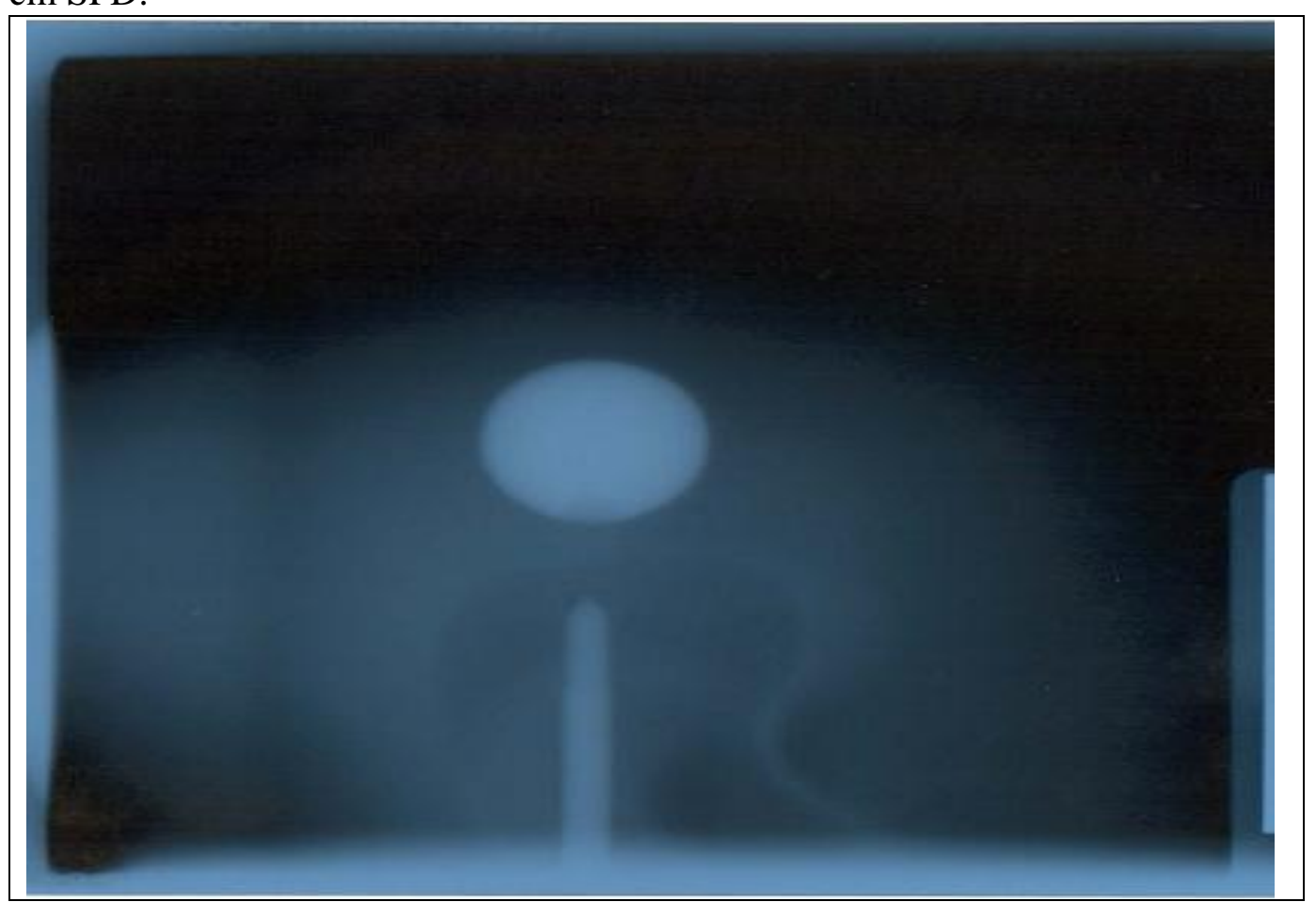

Figure 4.20: Radiograph of the $3 \mathrm{~cm}$ tumour vessel which contains $78.63 \mathrm{mg} / \mathrm{ml}$ of Gd concentration inside the head phantom taken at 73KVp, $20 \mathrm{mAs}$, and at 105 cm SFD. 


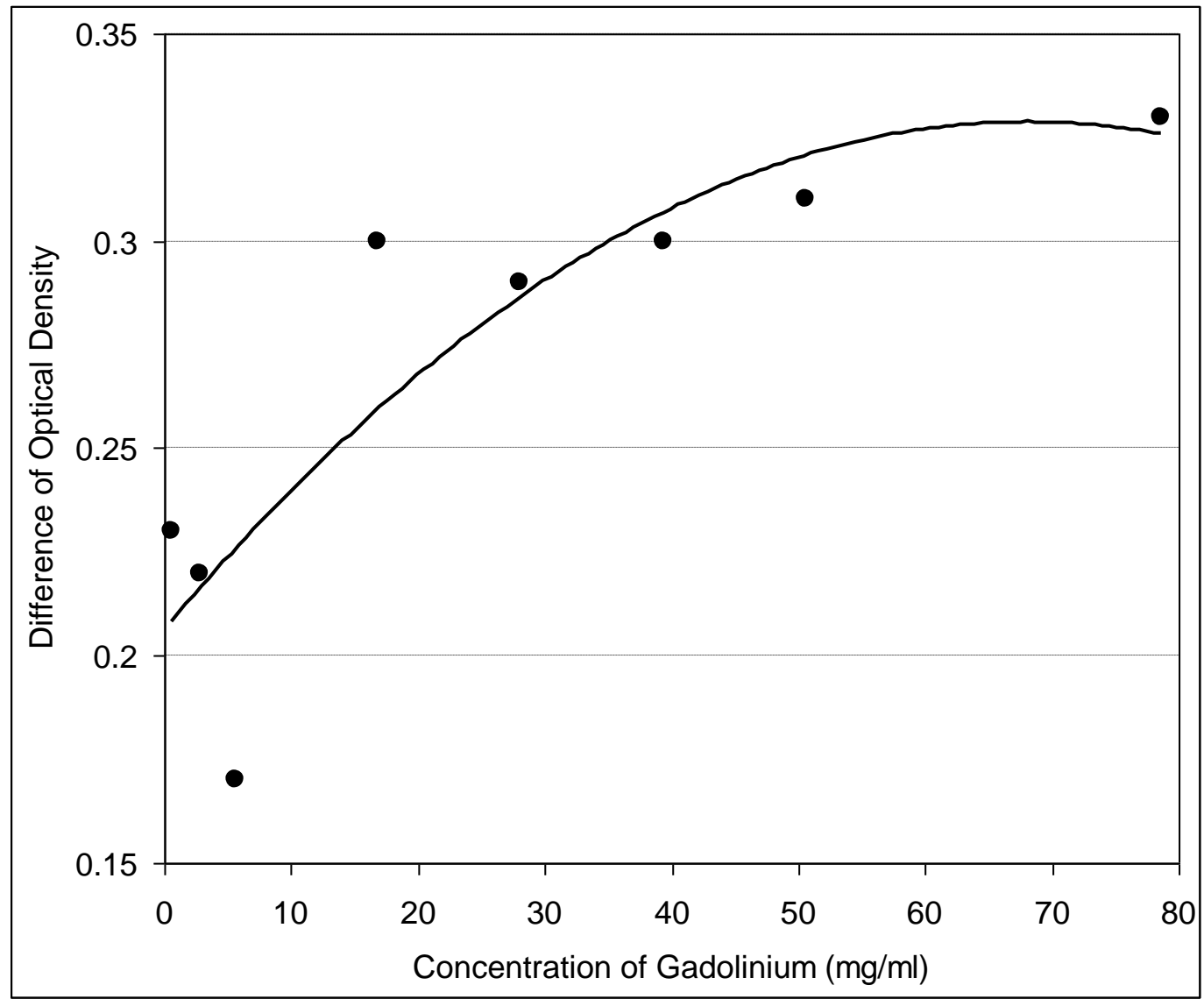

Figure 4.21: Difference of optical density versus concentration of Gd in a $3.0 \mathrm{~cm}$ diameter tumour vessel, at $1.5 \mathrm{~cm}$ depth inside the head phantom, in the lateral position. 


\subsubsection{Measurements of Gd concentration on vertex position}

All of the measurements in this section were taken for the head phantom in the vertex position (see Figure 4.22) as described in chapter 3 section 3.3. The results for the dependence of the total counts of Gd characteristic x-rays (for 30 min) on Gd concentration as a function of the tumour depth are plotted in Figure 4.23 to Figure 4.32 as explained below.

Figure 4.23 to Figure 4.26 show the dependence of the total count on the Gd concentration as a function of the tumour depth for tumour sizes of $1.0 \mathrm{~cm}, 2.0$ $\mathrm{cm}, 3.0 \mathrm{~cm}$, and $2.0 \times 4.0 \mathrm{~cm}$. For each tumour, two sets of data are presented (with and without water) except for the $1.0 \mathrm{~cm}$ tumour (i.e., without water) in Figure 4.23 as explained above. All figures (Figure 4.23 to Figure 4.26) show that the total count increased as the concentration increased and the total count decreased as the tumour depth increased.

In figure 2.24 it is observed that at the region when the tumour was in contact with skull (1 cm depth) higher counts of empty head was obtained. When the tumour is in contact with skull there is insignificant absorption of incident ray in water when head is filled with water. At the same time of the incident radiation that interact with water surrounding the tumour scatter in to the tumour. The scatter radiation still has energy above the excitation energy of Gd. Accordingly the excitation in $\mathrm{Gd}$ and emitted characteristics x-rays are increased compared with empty head.

Figure 4.27 to Figure 4.30 shows the dependence of the total counts on the tumour depth as a function of the Gd concentration for the previous results (Figure 4.23 - Figure 4.26) with and without water. The figures show that the total 
counts decreased as the tumour depth increased and Gd concentration increased. The decrease of counts with depth is not expected to follow exactly the inverse square low because the source is an extended source whose dimension is comparable to the distance from the detector. The inverse square can apply only if the source is a point source, which is not the case here.

The measurements that were taken at depths of $1.0 \mathrm{~cm}$ and $2.0 \mathrm{~cm}$ for tumour sizes of $2.0 \mathrm{~cm}$; at depths of $1.5 \mathrm{~cm}$ and $4.5 \mathrm{~cm}$ for the $3.0 \mathrm{~cm}$ tumour; and at depths of $2.0 \mathrm{~cm}$ and $4.0 \mathrm{~cm}$ for the $2.0 \times 4.0 \mathrm{~cm}$ tumour. They show that the total counts were higher for the phantom head without water for each tumour depth.

Figure 4.31 shows the attenuation versus distance $(\mathrm{cm})$ at different concentrations of Gd for the X-ray beams that undergo attenuation in the water inside the head phantom, in the vertex position. These figures clearly show a good correlation between the experimental and the calculated attenuation.

Figure 4.32 showed the total counts from the tumours of $1.0 \mathrm{~cm}, 2.0 \mathrm{~cm}$, $3.0 \mathrm{~cm}$ and $2.0 \times 4.0 \mathrm{~cm}$ at a depth $2.0 \mathrm{~cm}$ in the head phantom without water in the vertex position. In these Figures, the bigger the tumour, the greater the amount of Gd and the larger the signal detected by the detector. 


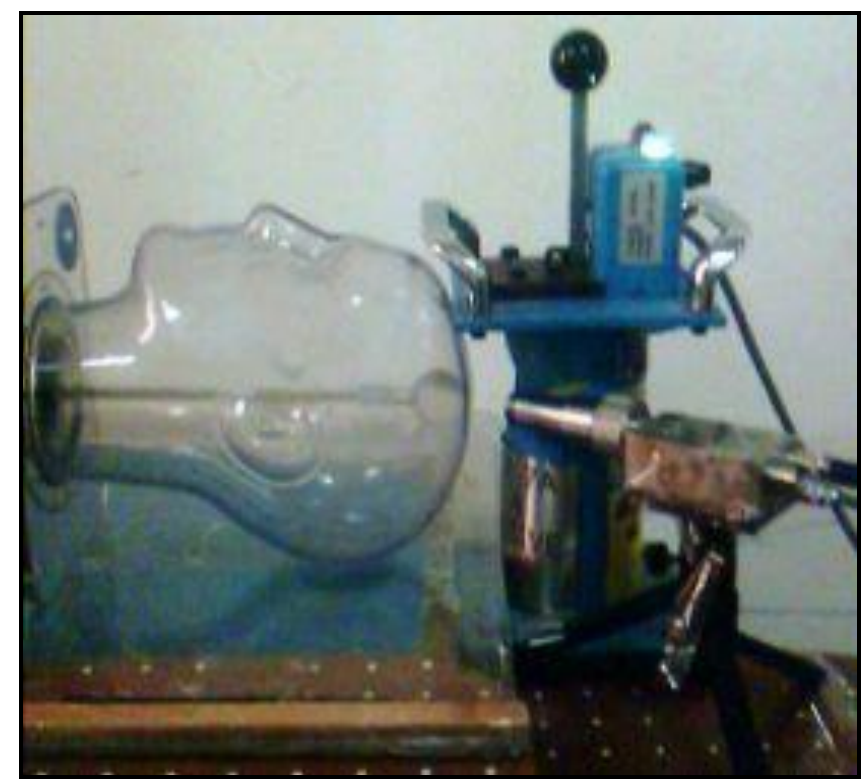

Figure 4.22: Head phantom containing tumour vessel in the vertex position. 


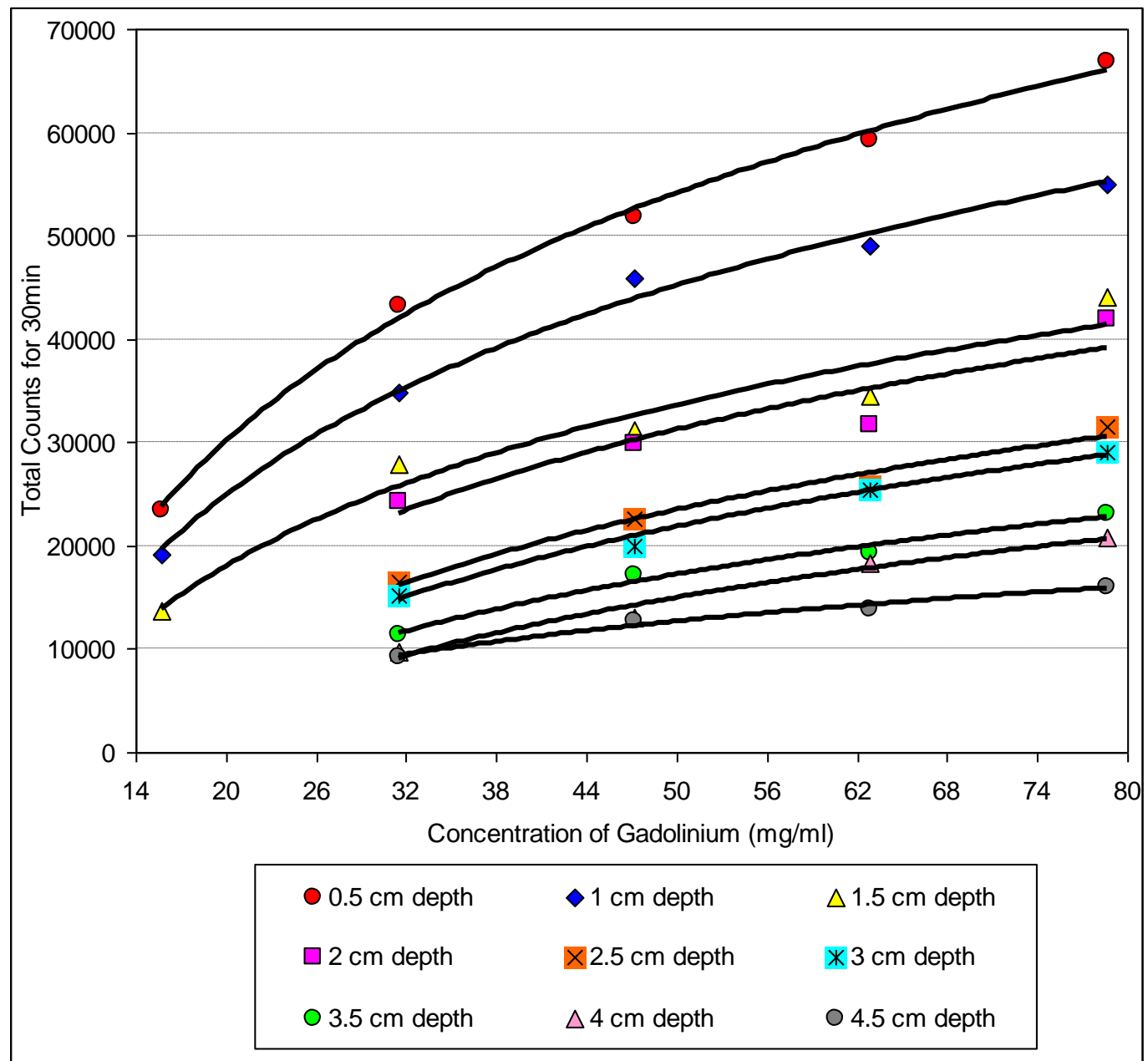

Figure 4.23: Counts versus concentrations of $\mathrm{Gd}$ at different depths for a $1.0 \mathrm{~cm}$ diameter tumour, inside the head phantom in the vertex position. 


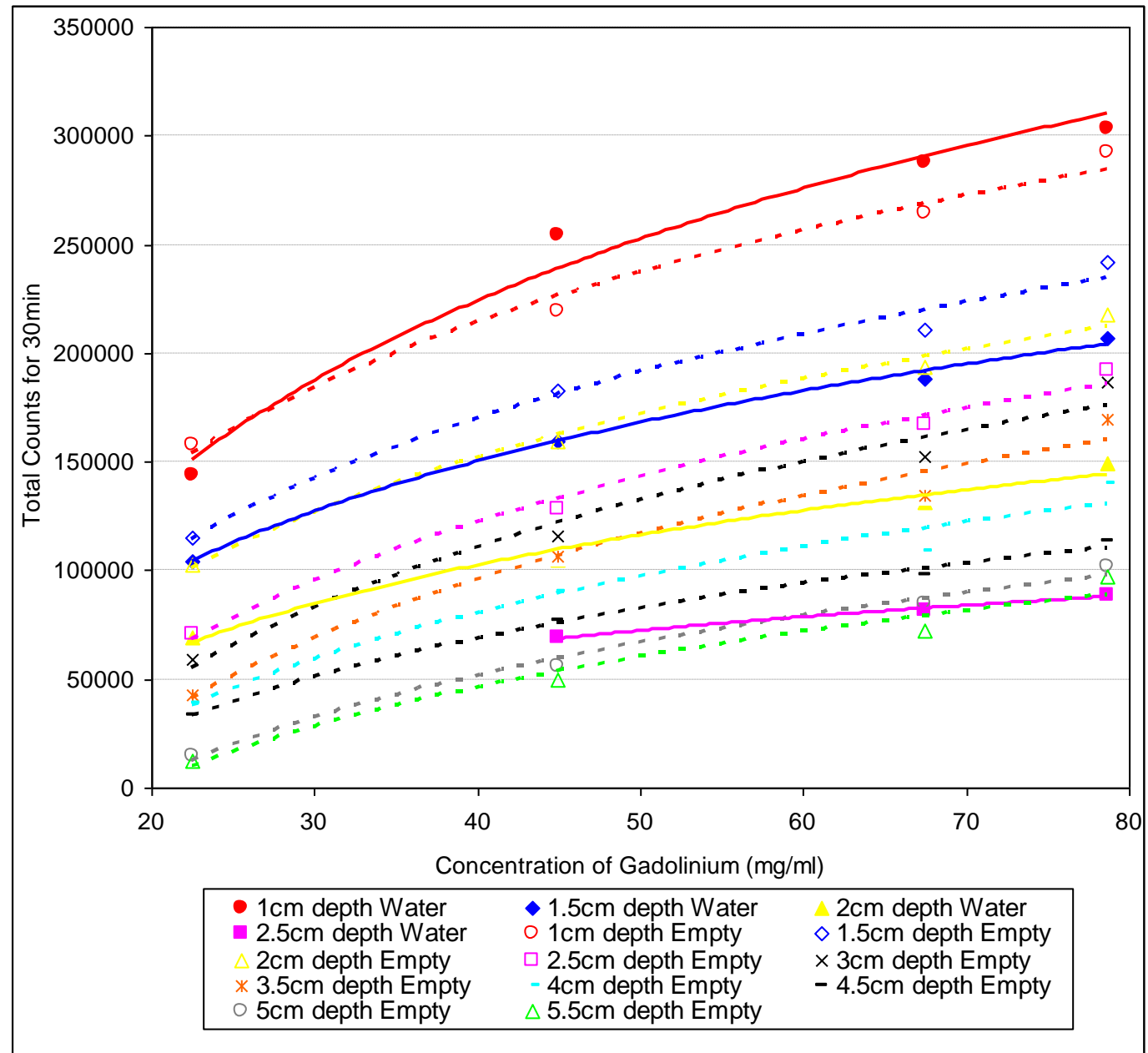

Figure 4.24: Counts versus concentrations of $\mathrm{Gd}$ at different depths for a $2.0 \mathrm{~cm}$ diameter tumour, inside the head phantom with and without water, in the vertex position. 


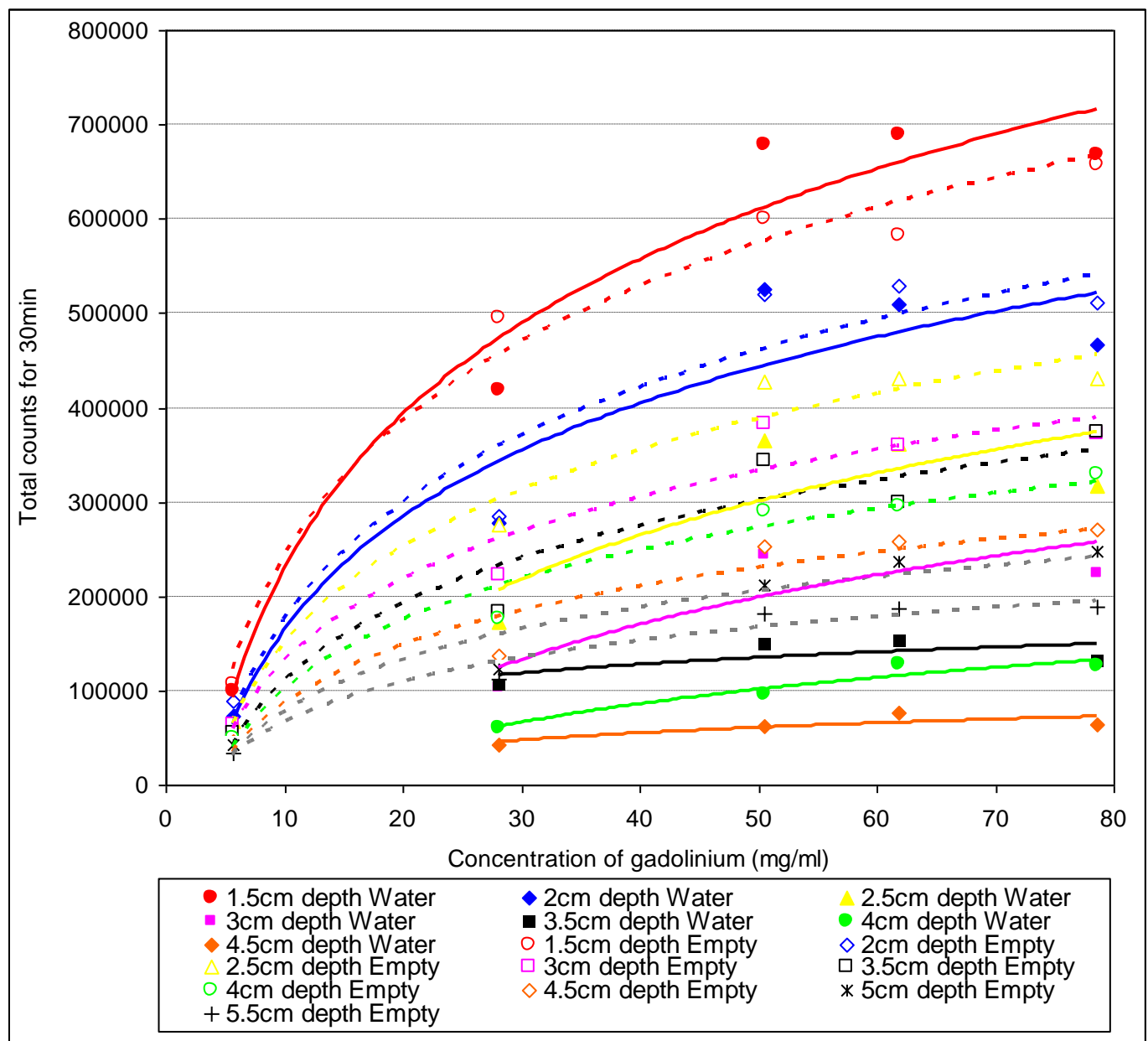

Figure 4.25: Counts versus concentrations of $\mathrm{Gd}$ at different depths for a $3.0 \mathrm{~cm}$ diameter tumour, inside the head phantom with and without water, in the vertex position. 


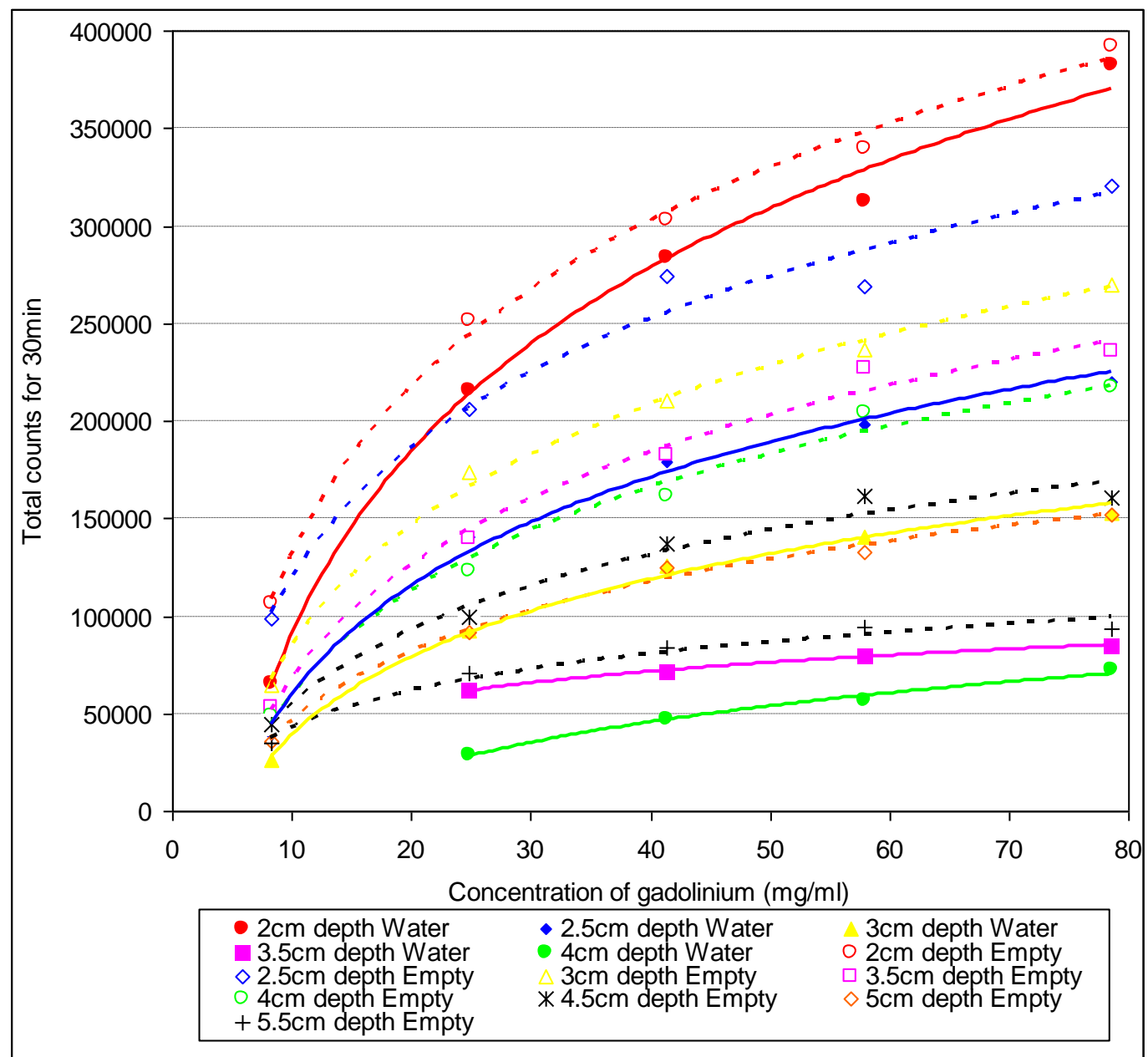

Figure 4.26: Counts versus concentrations of $\mathrm{Gd}$ at different depths for a $2.0 \mathrm{x}$ $4.0 \mathrm{~cm}$ diameter tumour, inside the head phantom with and without water, in the vertex position. 


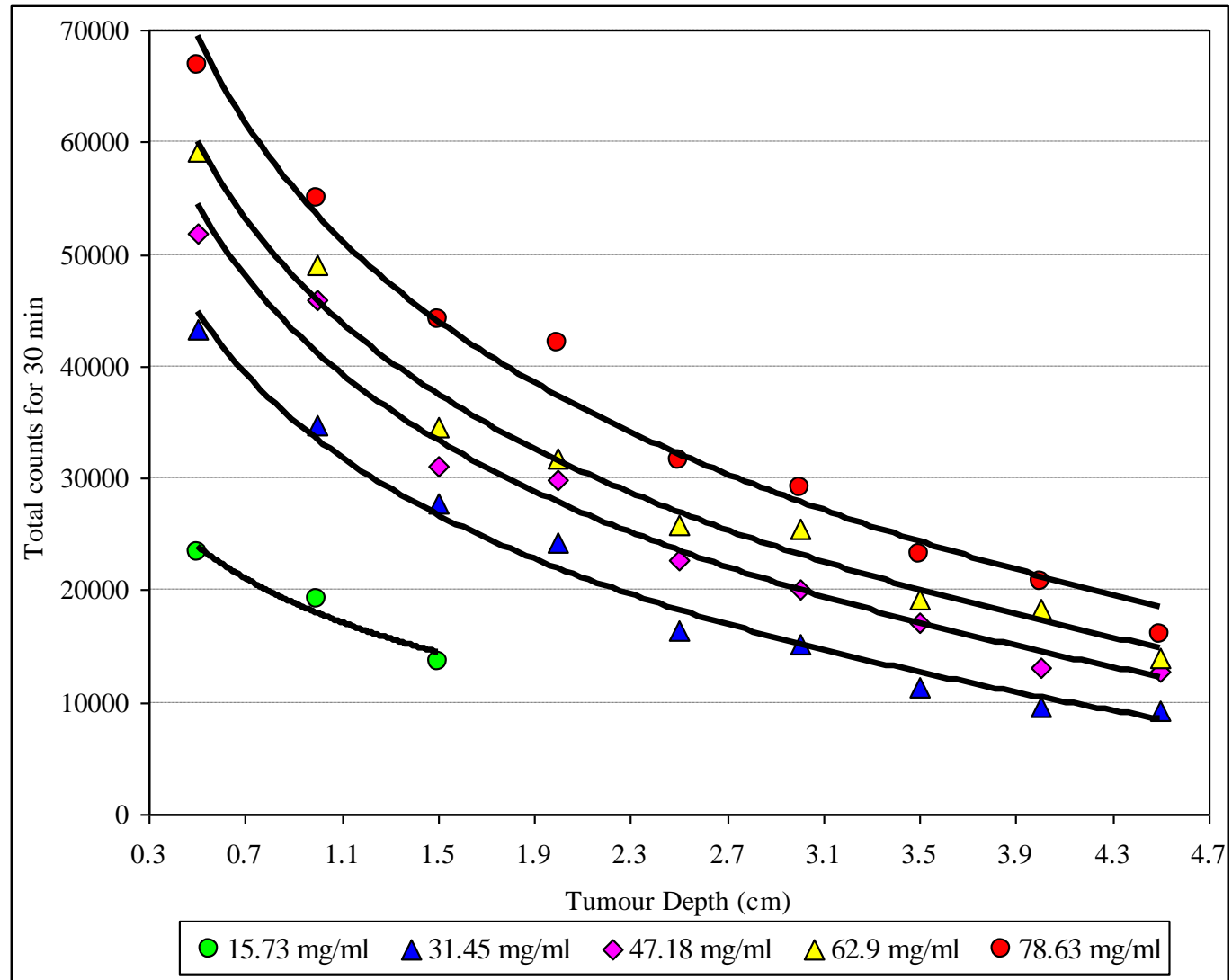

Figure 4.27: Counts versus tumour vessel depth at different concentrations of $\mathrm{Gd}$ for a $1.0 \mathrm{~cm}$ diameter tumour, inside the head phantom in the vertex position. 


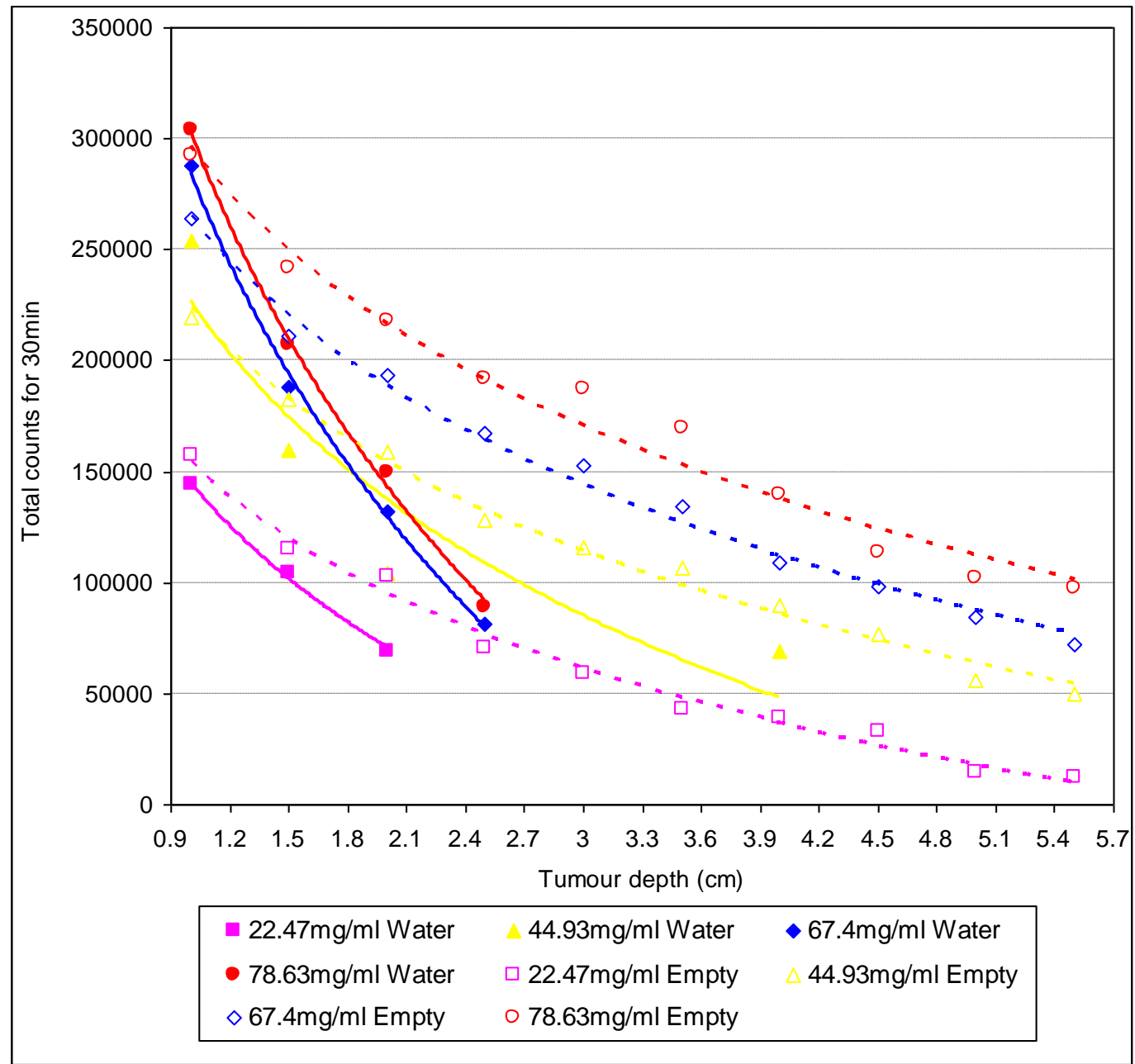

Figure 4.28: Counts versus tumour vessel depth at different concentrations of $\mathrm{Gd}$ for a $2.0 \mathrm{~cm}$ diameter tumour, inside the head phantom with and without water, in the vertex position. 


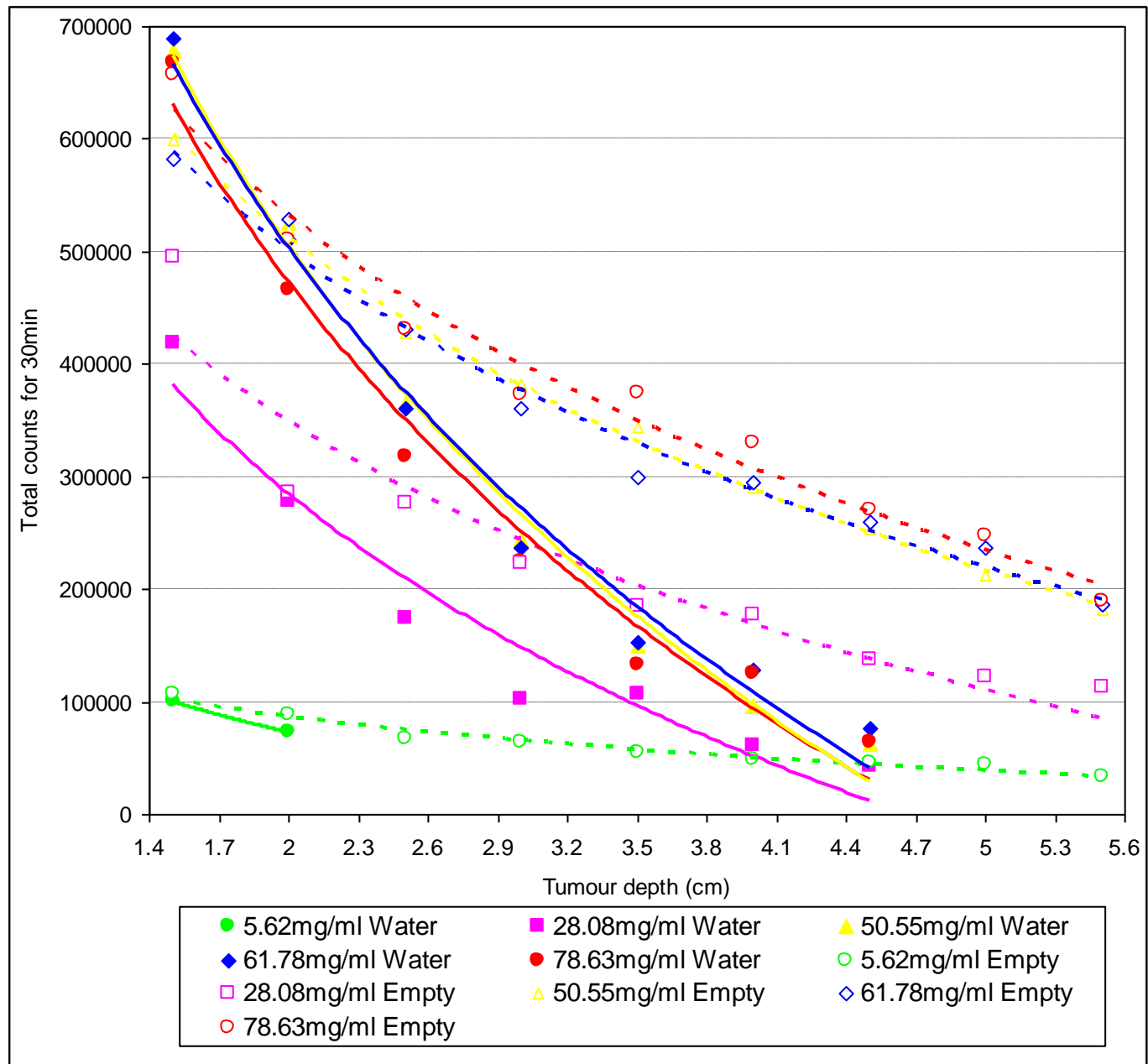

Figure 4.29: Counts versus tumour vessel depth at different concentrations of Gd for a $3.0 \mathrm{~cm}$ diameter tumour, inside the head phantom with and without water, in the vertex position. 


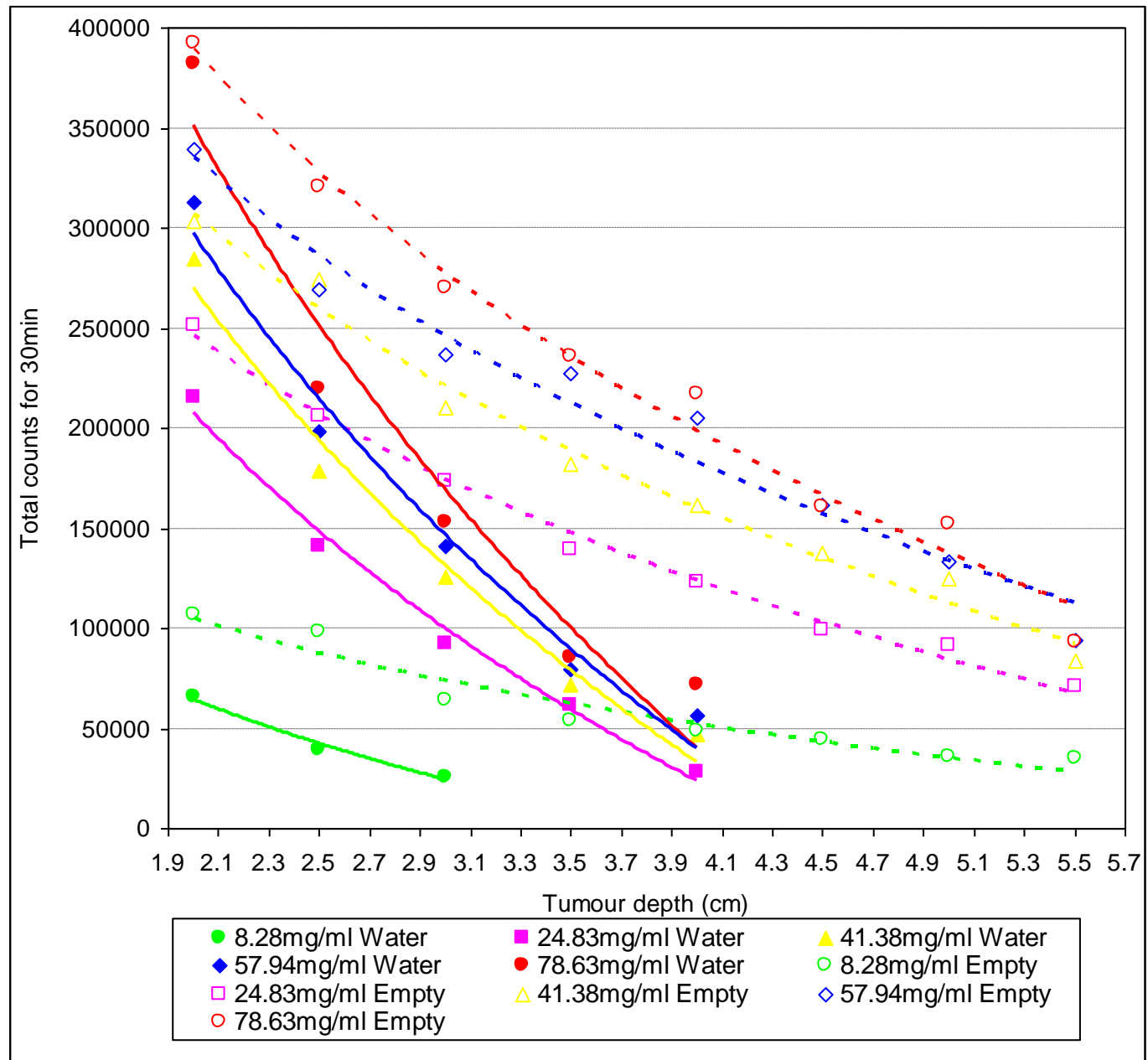

Figure 4.30: Counts versus tumour vessel depth at different concentrations of Gd for a $2.0 \times 4.0 \mathrm{~cm}$ diameter tumour, inside the head phantom with and without water, in the vertex position. 


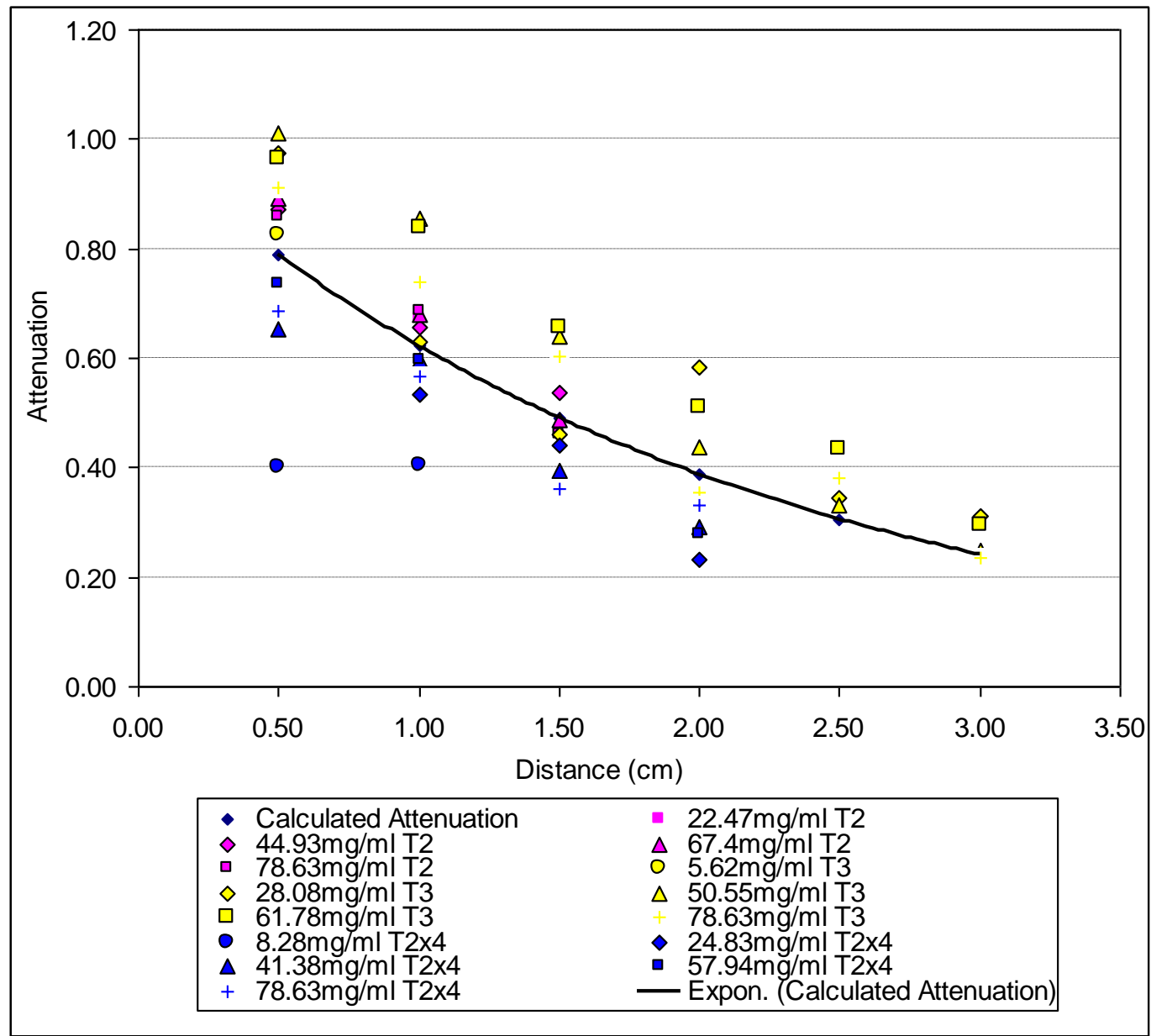

Figure 4.31: Calculated attenuation compared with measured attenuation at different distance $(\mathrm{cm})$ and different concentrations of $\mathrm{Gd}$ for a $2.0 \mathrm{~cm}, 3.0 \mathrm{~cm}$ and $2.0 \times 4.0 \mathrm{~cm}$ diameter tumour, inside the head phantom, in the vertex position. 


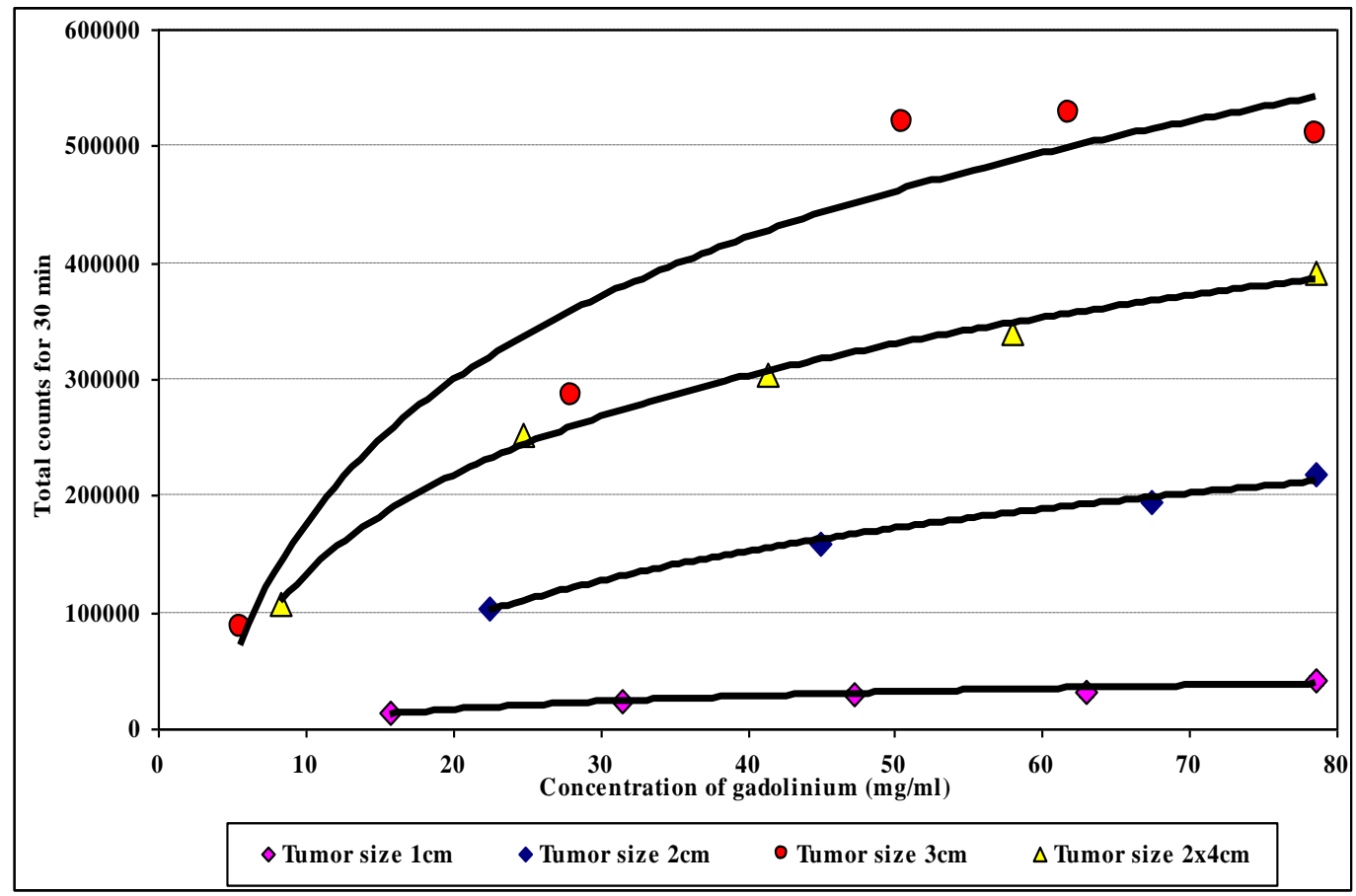

Figure 4.32: Counts versus total amount of Gd in different tumour sizes in the head phantom without water, at a depth of $2.0 \mathrm{~cm}$, for all sizes in the vertex position. 


\subsection{Discussion}

The aim of this research was to develop a technique that measures the amount of Gd in the brain tumour vessel at the same time as a patient is exposed to neutrons or during external beam radiotherapy planning in a NCT treatment. An X-ray fluorescence technique was used. Gadolinium atoms in the tumour vessel were excited by a $36 \mathrm{GBq}(0.97 \mathrm{Ci}){ }^{241} \mathrm{Am}$ source. A cadmium telluride detector measured emitted characteristic fluorescence radiation. The energy of the incident radiation $(59.5 \mathrm{keV})$ was slightly greater than the binding energy of the Gd atom $(50.23 \mathrm{keV})$, therefore the maximum effectiveness of the characteristic x-ray excitation was achieved.

During this process $\mathrm{K}$ shell electrons were ejected with a kinetic energy equal to the difference between the incident photon energy and the $\mathrm{K}$ shell binding energy. Electrons from the L shell immediately occupied the vacancy in the $\mathrm{K}$ shell. This electron transition was accompanied by the emission of a fluorescence $x$-ray whose energy was equal to the difference in binding energy of the electron between its original shell and its new shell as shown in Equation 3.

$$
\mathrm{E}_{\mathrm{x} \text {-ray }}\left(\mathrm{K}_{\alpha}\right)=\mathrm{E}_{\mathrm{B}}(\mathrm{K})-\mathrm{E}_{\mathrm{B}}(\mathrm{L})
$$

$\mathrm{E}_{\mathrm{x} \text {-ray }}\left(\mathrm{K}_{\alpha}\right)$ is the characteristic $\mathrm{x}$-ray energy of the $\mathrm{K}_{\alpha}, \mathrm{E}_{\mathrm{B}}(\mathrm{K})$ is the electron binding energy of the $\mathrm{K}$ shell, and $\mathrm{E}_{\mathrm{B}}(\mathrm{L})$ is the electron binding energy of the L shell. We mention that the fluorescence yield of the K shell is $93.5 \%$ [83, 84]. 
As $\mathrm{K}$ shell electrons of the Gd atoms have a binding energy of $50.23 \mathrm{keV}$, and $\mathrm{L}$ shell electrons are bound by $7.25 \mathrm{keV}$, the characteristic $\mathrm{x}$-ray emitted has an energy of:

$$
50.23 \mathrm{keV}-7.25 \mathrm{keV}=42.98 \mathrm{keV}
$$

According to this result, the characteristic emission of $\mathrm{Gd}$ is $42.98 \mathrm{keV}$ photons. The concentration of Gd in the tumour vessel was obtained by determining the region of interest area under the curve of the $\mathrm{x}$-ray peak. The instrument calculated the net area automatically, where the background counts were subtracted from the integral counts. So, the observed count rate from x-ray peaks of the Gd was dependent on the amount of Gd present in the brain tumour vessel.

Magnevist is a well known agent for MRI tumour imaging and can be readily taken by the body. Magnevist contains $\mathrm{Gd}$; this element has the highest cross section for neutrons and can be readily used for Gd NCT. After neutron absorption, conversion electrons, Auger electrons and characteristic x-rays are emitted that dissipate energy in the tumour, killing tumour cells. Because of the neutrons interaction with Gd nuclei the energy deposited in the dose, depends on the amount of the Gd atoms present. Accordingly, the total number of Gd atoms and the Gd concentration are determine required the dose.

Different sizes of the tumour vessel containing different concentrations of the contrast agent (Magnevist), were placed at different depths inside a head phantom at the lateral and the vertex position, in front of the detector and source for measurements. The tumours with spherical shapes (diameters of $1.0 \mathrm{~cm}, 2.0$ $\mathrm{cm}$ and $3.0 \mathrm{~cm}$ ) and oval shape (two diameters of $2.0 \times 4.0 \mathrm{~cm}$ ) were applied and used. The characteristic x-ray counts were measured from the tumour vessel when 
the head phantom was either full of water or empty. We shall discuss first the results for the tumours when the head phantom was full of water.

The effects of the Gd concentration on the lateral and vertex positions as shown in Figure $\mathbf{4 . 2}$ and Figure 4.22 were investigated and studied. Concentrations of $\mathrm{Gd}$ were assessed using to 30 minutes of detector live time to measure characteristic x-ray emissions from the tumour vessel which contained Gd. Depending on the tumour vessel volume and the detected count rate, the chosen Gd concentrations investigated were different. These concentrations were $15.73,31.45,47.18,62.90$, and $78.63 \mathrm{mg} / \mathrm{ml}$ for the tumour with a diameter of 1.0 $\mathrm{cm}$, while for the tumour with a diameter of $2.0 \mathrm{~cm}$ the concentrations were 22.47 , 44.93, 67.4, and $78.63 \mathrm{mg} / \mathrm{ml}$. The Gd concentrations for the tumour with a diameter of $3.0 \mathrm{~cm}$ were $5.62,28.08,50.55,61.78$, and $78.63 \mathrm{mg} / \mathrm{ml}$. Finally, the concentrations of the $\mathrm{Gd}$ for the $2.0 \times 4.0 \mathrm{~cm}$ tumour were 8.28, 24.83, 41.38, 57.94, and $78.63 \mathrm{mg} / \mathrm{ml}$.

The minimum value of the Gd concentration for each of the above four tumours was limited by the minimum detectable concentration set by the detector. It should be mentioned that the detection of the characteristic x-ray, emitted for a concentration below the minimum value for each of the above tumours, was very difficult even if the detection time was doubled. The maximum Gd concentration was limited by its concentration in the Magnevist, where one millilitre of Magnevist solution contains $469 \mathrm{mg}$ of gadopentetic acid, and dimeglumine salt which corresponds to $78.63 \mathrm{mg}$ of $\mathrm{Gd}$.

The results in Figure 4.3 to Figure 4.6 and Figure 4.23 to Figure 4.26 show that the total counts increased as the concentration of the $\mathrm{Gd}$ in the tumour vessel 
(or the total amounts of $\mathrm{Gd}$ ) increased as expected. The relation between the counts and the concentration for each measurement, does not follow a straight line possibly due to self absorption of the x-ray emissions inside the tumour vessel. This means that attenuation of both incident radiation and characteristic x-ray radiation took place inside the tumour vessel containing Gd. As the Gd concentration (or total amount) increases, the emitted characteristic $\mathrm{x}$-ray is partially absorbed within the tumour because of the effect of the large atomic number of the Gd, which is 64 .

The other factor impacting on the experimental outcome is the location of the tumour vessel inside the head phantom (i.e., the depth of the tumour as measured from the interior wall of the head phantom surface to the centre of the tumour vessel). Measurements showed that at a depth of $2.0 \mathrm{~cm}$ for the tumour vessel with a diameter of $1.0 \mathrm{~cm}$ and also, at a depth of $2.5 \mathrm{~cm}$ for tumours size of $2.0 \mathrm{~cm}, 3.0 \mathrm{~cm}$, and $2.0 \times 4.0 \mathrm{~cm}$ with a minimum concentration of $\mathrm{Gd}$, the total count was not detectable. Furthermore, it was clear that the deeper the tumour was inside the head phantom, the lower the counts were, owing to the increased distance from the CdTe detector and from the Americium source and owing to the attenuated and absorption of incident as well as emitted characteristic x-ray in the water inside the tumour and in the head phantom. This attenuation showed clearly in the highest concentration of Gd that was obtained by a full tumour vessel with $\mathrm{Gd}(78.63 \mathrm{mg} / \mathrm{ml})$ in the lateral position.

The total count obtained from a $2.0 \mathrm{~cm}$ tumour vessel was reduced from $2.58 \times 10^{5} \pm 508$, at a depth of $1.0 \mathrm{~cm}$, to $9.30 \times 10^{4} \pm 305$ counts at a depth of 2.5 cm which was the last depth that Gd concentration was detected. In the tumour 
vessel of $3.0 \mathrm{~cm}$ diameter the counts were reduced from $5.83 \times 10^{5} \pm 763$ at 1.5 $\mathrm{cm}$ depth to $7.74 \times 10^{5} \pm 278$ count at a depth of $4.5 \mathrm{~cm}$. It also occurred in the oval tumour $2.0 \times 4.0 \mathrm{~cm}$. The total count was reduced from $4.81 \times 10^{5} \pm 693$ at $1.5 \mathrm{~cm}$ depth to $4.67 \times 10^{4} \pm 216$ obtained at depth $3.5 \mathrm{~cm}$. Although the tumour is not a point source and counts do not follow exactly the inverse square law, yet attenuation, due to increased distance, is more effective than absorption. As the concentration or total amount of Gd increases, it increases the portion of emitted characteristics x-ray that is absorbed within the tumour vessel. Counts versus tumour depth at different concentrations are shown in Figure 4.7 to Figure 4.10 and from Figure 4.27 to Figure 4.30, clearly the deeper the tumour, the lower the counts.

The effect of water absorption (water is equivalent to biological tissue, as effective atomic number of water and tissue are both 7.4) was found when the experiment was repeated without water inside the head phantom as shown in Figure 4.3 to Figure 4.6. In these figures, the counts are lower for the head phantom containing water, than those of the empty head phantom under the same conditions (i.e., tumour size, tumour depth, and Gd concentration). The results of the characteristic x-ray, between the head phantom with and without water, are shown in Figure 4.24 in the tumour vessel of $2.0 \mathrm{~cm}$ diameter at a depth of $2.0 \mathrm{~cm}$ and containing $78.63 \mathrm{mg} / \mathrm{ml}$ of $\mathrm{Gd}$ concentration at the vertex position.

The total count from the head phantom containing water was $1.50 \times 10^{5} \pm$ 387 compared with $2.18 \times 10^{5} \pm 467$ counts from the head phantom without water. The total count was reduced by factor 1.5 . On the other hand, at a depth of $4.5 \mathrm{~cm}$ in the tumour vessel of $3.0 \mathrm{~cm}$ diameter, the total count, obtained from head 
phantom containing water, was $6.38 \times 10^{4} \pm 253$ compared with $2.71 \times 10^{5} \pm 520$ counts from the empty head phantom (see Figure 4.25). Figure 4.26 showed that counts were reduced by four times when an irregular tumour vessel of $2.0 \times 4.0$ $\mathrm{cm}$ at a depth of $4.0 \mathrm{~cm}$ was used, where counts from head phantom containing water were $7.21 \times 10^{4} \pm 268$ compared with $2.17 \times 10^{5} \pm 466$ from head phantom without water. Generally, at the same conditions (i.e., tumour size, tumour depth, and Gd concentration) the total counts without water were higher. The only effect that is responsible for the difference in total counts, is the presence of water inside the head phantom. This water caused the absorption of the incident $59.5 \mathrm{keV}$ and the x-ray emitted from the tumour vessel.

The relationship between the measured attenuation and the calculated attenuation are shown in Figure 4.11 and Figure 4.31. These figures show clearly the reasonable of the measured attenuation with that calculated.

It should be noted that for the tumour with a diameter of $1.0 \mathrm{~cm}$, it was difficult to measure the characteristics x-rays that were emitted from the tumour vessel containing Gd in the head phantom filled with water because of the small size of the tumour vessel. Therefore, all of the experiments for the $1.0 \mathrm{~cm}$ diameter tumour vessel were conducted in the empty head phantom. Total counts can be measurable for the smallest tumour vessel $(1.0 \mathrm{~cm})$ inside the head phantom containing water by increasing the activity of the source. This also allows getting measurable total counts from the deepest site of the tumour vessel inside the head phantom containing water.

Figure 4.3 to Figure 4.6 and Figure 4.23 to Figure 4.26 also showed that the gaps between each two lines of the dependence of the total counts on the 
concentration for different depths were different but smaller when the head phantom was empty. This occurred because the absorption was greater when water was present inside the head phantom. The results show that it is possible to measure the low concentration of $\mathrm{Gd}$ in the deeper distances inside the head phantom, such as $5.5 \mathrm{~cm}$, when the head phantom is empty.

Total counts from the three types of the tumour size inside the head phantom, in the lateral and vertex positions, showed consistency and a tendency towards saturation at higher concentrations.

In Figure 4.12 and Figure 4.32, the total count measurements were taken for the head phantom without water. The figures also show the results of the 1.0 $\mathrm{cm}$ tumour as they were measurable for this case (unlike the case when the head phantom contained water). This confirms the conclusion that the differences in the counts are due to different tumour size and shape. Increasing the tumour vessel size, increases the total counts for the tumour vessel depths, shown in the figures. It can be observed that for the same total amount of $\mathrm{Gd}$, different counts are obtained by using different shapes. The highest counts were obtained from $3.0 \mathrm{~cm}$ tumour. The $1.0 \mathrm{~cm}$ tumour gave the lowest counts because it contained the least amount of Gd. The same effect was observed for tumours at different depths. This is because a large portion of the tumour vessel was exposed to the gamma radiation emitted from the amercium-241 source.

For example, for about $300 \mathrm{mg}$ of $\mathrm{Gd}$ in the tumour vessel in the vertex position, the number of total counts is higher for the $2.0 \times 4.0 \mathrm{~cm}$ tumour than that of the $2.0 \mathrm{~cm}$. Using $750 \mathrm{mg}$ of $\mathrm{Gd}$, the $3.0 \mathrm{~cm}$ tumour gives higher counts than the $2.0 \times 4.0 \mathrm{~cm}$ as shown in Figure 4.32. This is attributed to the geometrical 
shape of the tumour vessel. Since the distance was taken from the centre of the tumour vessel, the different shapes can have Gd atoms that can be closer or farther away from the detector giving different total counts.

It is clear from the measurements that curves are very consistent in their trend. For example increased concentration show that counts increase before a non-linear trend of the data toward a saturation region is attained. This can be seen in almost all the graphs. For similar trend is observed with an increasing amount of Gd. The counts with increased depth show a decrease that is also similar in all shapes and concentration. This again reveals the consistency of results. No curves show abnormal behaviour which confirms the accuracy of the measurements. Furthermore counts with and without water in the head phantom also show similar trends which physical explanation.

The sizes and the shapes of the tumours in the brain were confirmed by radiographic film of the tumour vessels which contained different concentrations of $\mathrm{Gd}$ inside the head phantom filled with water as shown in Figure 4.13 to Figure 4.20. The radiographic image was taken of a $3.0 \mathrm{~cm}$ diameter tumour vessel in the lateral position at $1.5 \mathrm{~cm}$ depth with different $\mathrm{Gd}$ concentrations such as 0.56 , $2.81,5.62,16.85,28.08,39.32,50.55$ and $78.63 \mathrm{mg} / \mathrm{ml}$. As the $\mathrm{Gd}$ in the tumour vessel has a high atomic number and high density, the incident gamma radiation interaction would be increased, leading to increased photon absorption which in turn made the tumour vessel bright on the x-ray image (i.e., opaque to the x-rays). So, the greater the concentration of Gd, the clearer the tumour image appeared.

The collection time used in this work was 30 minutes. This is too long a time for measuring instantaneous concentration but acceptable for measurements, 
such as this where the skin entrance dose was limited to be less than $10 \mathrm{mGy}$ [85]. On the other hand, the source activity used was $0.97 \mathrm{Ci}\left(3.6 \times 10^{10} \mathrm{~Bq}\right)$. In order to reduce counting time, source activity can be increased. A source activity of about $100 \mathrm{Ci}\left(3.7 \times 10^{12} \mathrm{~Bq}\right)$ is practical and can reduce the collection time to about 0.3 minutes (18 seconds). Even higher activity sources can be used. In industrial radiography, for example, $100 \mathrm{Ci}$ of Iridium $\left({ }^{192} \mathrm{Ir}\right)$ portable sources are used, even though ${ }^{192}$ Ir emits gamma rays of average energy of $400 \mathrm{keV}$, much higher than the $60 \mathrm{keV}$ of ${ }^{241} \mathrm{Am}$.

Reduction of time can also be achieved by using a higher efficiency detector. Our detector of CdTe has about $1 \mathrm{~cm}^{2}$ of cross sectional area while the cylindrical scintillation detector, 5.0 inch in diameter $\mathrm{x} 4.0$ inch height, can have about 125 time higher counts.

The $300 \mu \mathrm{g}{ }^{157} \mathrm{Gd} / \mathrm{g}$ [58] is below the trend towards saturation region; the results fall in the linear region. Error possibility would be small. We had to increase the concentration in order to find where the saturation region would start. It may be possible in the future to develop a chemical pharmaceutical where a higher Gd concentration is possible. By increasing the source activity two orders of magnitude or increasing the detection efficiency or both, counts and the overall efficiency can increase $10^{2}$ times. In this case, the detection limit can be much less than Gd concentration that brain can take.

The energy of $59.5 \mathrm{keV}$ is quite suitable for this application. It is slightly above the $42.98 \mathrm{keV}$ of $\mathrm{Gd}$ characteristics x-rays which make the probability of interaction high. At energy less then $50 \mathrm{keV}$ the interaction is not possible while at higher energy, the probability of interaction will decrease. 
One of the main advantages of ${ }^{241} \mathrm{Am}$, is its long half-life. In such a case the source can be used for a very long time without affecting the sensitivity of the system.

$\mathrm{X}$-rays from an $\mathrm{x}$-ray machine can be used as a radiation source but the continuous spectrum of radiation will make analysis more difficult. For example, with a continuous incident $\mathrm{x}$-ray spectrum, the scattered radiation peak coming from different components will be very wide. The Gd characteristic peak X-rays might be lost in this case. Moreover, the length of the exposure in most diagnostic $\mathrm{x}$-ray generators is small; a fraction of a second. We attempted to use an industrial $\mathrm{x}$-ray machine in which the exposure can last longer. The spectrum was very difficult to analyse. The CdTe detector is most suitable for such applications as it is designed to measure $\mathrm{x}$-rays in the range of $0-100 \mathrm{keV}$. Detectors, such as $\mathrm{NaI}$ (Tl) scintillation detector, can also be used, but the $\mathrm{Gd} 42.98 \mathrm{keV}$ will be close to its lower energy detection limit. A plastic organic scintillation detector of lower limit of about $1 \mathrm{keV}$ will be more suitable. Although a Germanium detector can also be used it is very expensive and needs cooling by liquid nitrogen. 


\section{Possible source of errors:}

Possible errors can be from the following

1. Statistical variation of counts rate. A standard deviation is $\sqrt{N}$, where $N$ is the total counts. The total counts from the $2 \mathrm{~cm}$ diameter tumour in the head phantom containing water at depth $1.5 \mathrm{~cm}$ was 941580 (188316 counts from the signal and 753264 background). Thus the signal is $188316 \pm 970$, where $970=\sqrt{941580}$. Accordingly the ratio of one standard deviation to be the total counts $\sqrt{N_{\text {Total }}} / N_{\text {Signal }}$ will be small.

2. Error from depth measurements. As an example at $2 \mathrm{~cm}$ size tumour inside head containing water, the distance error is within $\pm 0.5 \mathrm{~mm}$ this correspond to counts variation of $2-5 \%$.

3. Error from concentration measurements. Depending on how accurately we observe the volume of liquid added to the Magnevist. We expect this error not to exceed about $2-3 \%$.

4. Error from background subtraction. This is given by the counting system and estimated to be $2 \%$ in general.

5. There might be other errors that are associated with line voltage stability, amplifier stability and computer based multichannel analyzer stability. These are not expected to be more than about $2 \%$.

6. Considering all possible errors we expect the total error should not exceed about $8 \%$. 


\section{Counts due to interaction of radiation with tumour:}

A complete analytical solution of experimental data will be very difficult; but we may reduce the problem into a one dimensional. The model below may present a reasonable explanation of the experimental measured data. It is not expected that this model will fits the experimental data perfectly, but provide a good explanation and a base for future improvement.

For simplicity of the calculations we will assume that the tumour has the following shape shown in Figure 4.33. In this case the problem is reduced to one dimensional instead of three dimensional, which is very complicated to solve analytically.

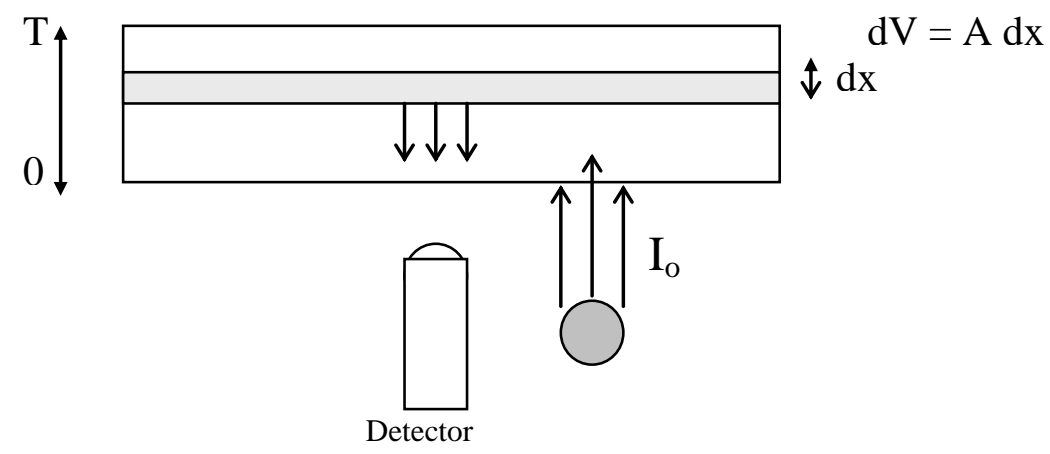

Figure 4.33: Tumour shape. 
Reaction Rate (RR) with a strip of thickness dx within tumour is given by:

$\mathrm{R} R$ (within atoms in strip $\mathrm{dx}$ ) $=\mathrm{I} \sigma \mathrm{dN}$

$\mathrm{I}=$ Incident Radiation intensity $(59.5 \mathrm{keV})$,

$\mathrm{dN}=$ Number of atoms in a volume $\mathrm{dV}$.

$\sigma=$ Cross section of reaction in a volume $\mathrm{dV}$.

$d V=A d x$

The radiation undergoes attenuation given by:

$$
\mathrm{I}=\mathrm{I}_{\mathrm{o}} \mathrm{e}^{-\mu x}
$$

$\mu=$ Linear attenuation coefficient of incident radiation within the tumour with Gd.

$I_{0}=$ Intensity at the surface of the tumour.

$$
d N=(\rho A d x / M) \cdot N_{A}
$$

$\rho=$ Density of tumour with Gd.

$\mathrm{A}=$ Cross sectional area of tumour.

$\mathrm{M}=$ Molecular weight of the tumour.

$\mathrm{N}_{\mathrm{A}}=$ Avogadro number . 
Therefore:

$$
R R=I_{o} e^{-\mu x} \sigma(\rho A d x / M) . N_{A}
$$

After interaction, x-rays are emitted and detected by the detector. The emitted radiation of $42.98 \mathrm{keV}$ will undergo attenuation on its way back to the detector of:

$$
e^{-\mu^{\prime} x}
$$

$\mu^{`}$ is the linear attenuation coefficient of emitted x-rays.

If $\mathrm{K}$ is the detection efficiency, including the geometry factor, the count rate at the detector (dc) due to interaction with the strip is given by:

$$
d c=I_{0} e^{-\mu x} \sigma(\rho A d x / M) \cdot N_{A} \cdot e^{-\mu x} \cdot K
$$

Where $I_{0}, \sigma, A, N_{A}, K$ and $\rho$ are constants.

The total counts rate $(\mathrm{C})$ will be a result of the interaction of all strips.

That is:

$$
\therefore \quad C=\left(N_{A} I_{0} \sigma A \rho K / M\right) \int_{0}^{T} e^{-\left(\mu+\mu^{\prime}\right) x} d x
$$

For simplicity we assumed $\mathrm{K}$ is also a constant

$$
\mathrm{C}=\left(\mathrm{N}_{\mathrm{A}} \mathrm{I}_{\mathrm{o}} \sigma \mathrm{A} \rho \mathrm{K} /\left(\mu+\mu^{\prime}\right) \mathrm{M}\right) \cdot\left[1-\exp \left\{-\left(\mu+\mu^{\prime}\right) \mathrm{T}\right\}\right](10)
$$

Since $\mu=\mu_{\mathrm{m}} \rho, \mu_{\mathrm{m}}$ and $\mu_{\mathrm{m}}{ }^{`}$ are the mass attenuation coefficients. 
$\mathrm{C}=\left(\mathrm{N}_{\mathrm{A}} \mathrm{I}_{\mathrm{o}} \sigma \mathrm{A} \rho \mathrm{K} /\left(\mu_{\mathrm{m}} \rho+\mu_{\mathrm{m}}{ }^{\prime} \rho\right) \mathrm{M}\right) \cdot\left[1-\exp \left\{-\left(\mu_{\mathrm{m}}+\mu_{\mathrm{m}}{ }^{\prime}\right) \rho . \mathrm{T}\right\}\right]$

or

$$
\mathrm{C}=\left(\mathrm{N}_{\mathrm{A}} \mathrm{I}_{\mathrm{o}} \sigma \mathrm{AK} /\left(\mu_{\mathrm{m}}+\mu_{\mathrm{m}}{ }^{\prime}\right) \mathrm{M}\right) \cdot\left[1-\exp \left\{-\left(\mu_{\mathrm{m}}+\mu_{\mathrm{m}}{ }^{\prime}\right) \rho . \mathrm{T}\right\}\right]
$$




\section{Effect of increased concentration:}

The behaviour of the count rate can be explained with reference to equation number 12. Although this system does not exactly represent the real geometry; the derivations can reasonably describe the effect of changing the concentration $(\rho)$ or the volume of the tumour (T. A).

In equation (12), the factor $\left(\mathrm{N}_{\mathrm{A}} \mathrm{I}_{\mathrm{o}} \sigma \mathrm{A} \mathrm{K} /\left(\mu_{\mathrm{m}}+\mu_{\mathrm{m}}{ }^{\prime}\right) \mathrm{M}\right)$ is a constant, the variation in count rate can be explained in terms of the factor

$$
1-\exp \left\{-\left(\mu_{\mathrm{m}}+\mu_{\mathrm{m}}{ }^{\prime}\right) \rho . \mathrm{T}\right\}
$$

Since the concentration of Magnevist is directly proportional to the density ( $\rho$ ) the effect of changing concentration can be explained in terms of $\rho$. The count rate (C) for constant thickness, will increase gradually and exponentially, reaching a saturation count of

$$
\mathrm{N}_{\mathrm{A}} \mathrm{I}_{\mathrm{o}} \mathrm{AK} / \mu_{\mathrm{m}}+\mu_{\mathrm{m}}{ }^{`} \mathrm{M}
$$

This exponential increase in counts was observed in our experiments as can be seen in the lateral position from Figure 4.3 to Figure 4.6. It can also be seen in the vertex position from Figure 4.23 to Figure 3.26. The above equation provides reasonable explanation for self absorption. 
Effect of self absorption with increased concentration on count rate for constant volume:

The effect of self absorption is clear from equation (7) and (9). Incident as well as emitted radiation undergoes attenuation in different layers of the tumour. Accordingly, the count rate will not increase linearly with concentration reaching the upper value limit.

\section{Effect of increased volume at constant concentration:}

The effect of changing volume can be explained with reference to equation (10). If the concentration is constant, $\mu$ and $\mu$ are constant. In the above model only $\mathrm{T}$ will change. Clearly, the count rate will increase in similar fashion as the change in concentration. If $\mathrm{T}$ increases, the count rate increases, reaching an upper value limit. As the volume increases, the fraction of radiation that reaches the deeper layers will be small, according to equation (8). Similarly, the emitted radiation from the deeper layers undergoes attenuation on its way to the detector. An insignificant amount of radiation, emitted from deeper layers of the tumour, will reach the detector if the volume is large. 


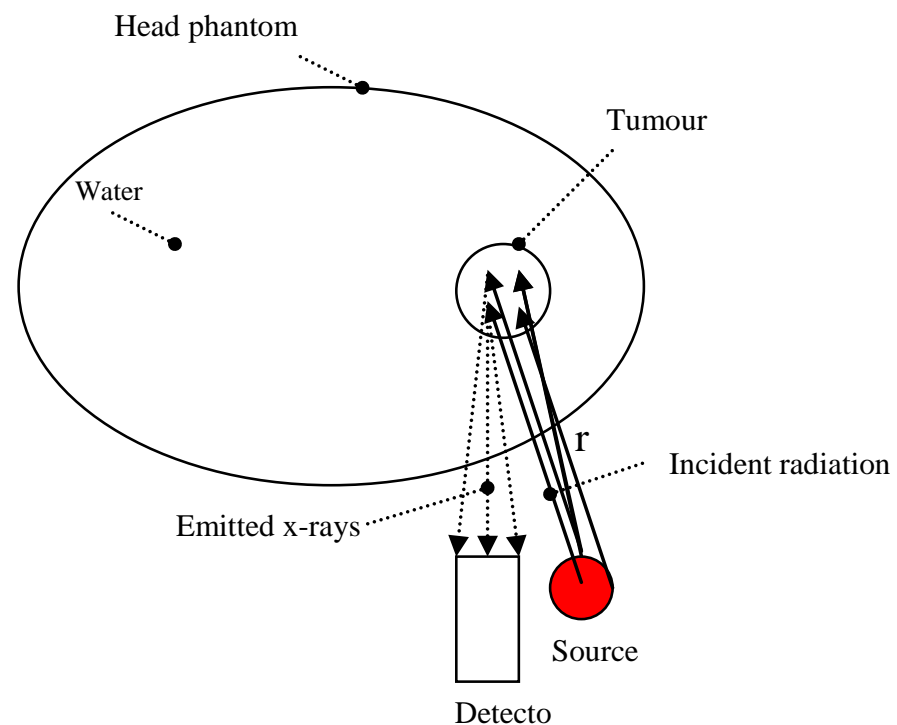

Figure 4.34: Schematic of radiation interaction inside head phantom.

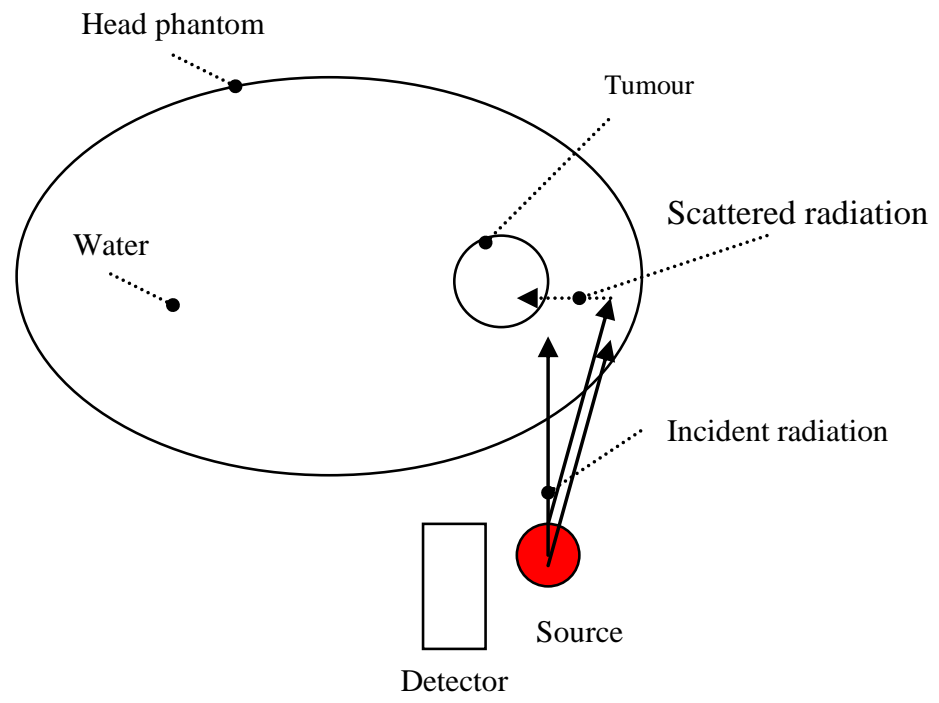

Figure 4.35: Schematic of affect of scattered radiation inside head phantom. 


\section{Effect of tumour position inside head phantom on count rate:}

Referring to Figure 4.34 above, the factors that affect the count rate are:

\section{Attenuation of incident radiation:}

The incident radiation of $59.5 \mathrm{keV}$ from the source, will undergo attenuation in water before reaching the tumour. The attenuation is given by $\mathrm{e}^{-\mu \mathrm{r}}$ where $\mu$ is the linear attenuation coefficient in water of $59.5 \mathrm{keV}$ gamma rays.

\section{Scattered radiation within water:}

Referring to Figure 4.35 part of the scattered radiation within the water, whose energy was greater than $42.98 \mathrm{keV}$ reaches the tumour thereby increasing the reaction rate. This is not a significant interaction because the fraction of scattered radiation, whose energy is greater than $42.98 \mathrm{keV}$, is very small.

\section{Attenuation of emitted radiation:}

Referring to Figure 4.34, the emitted radiation will undergo attenuation given by $\mathrm{e}^{-\mu^{\prime} \mathrm{r}}$ where $\mu^{\prime}$ is the linear attenuation coefficient in water of $42.98 \mathrm{keV}$ X-rays.

4. Distance between source and tumour:

The distance ( $\mathrm{r}$ ) between the source and the tumour, is approximately the same between the tumour and the detector. The larger the distance the more the divergence will be of incident and emitted radiation and the less will be the count rate and vice versa. Because the source and the tumour dimensions are not very 
small compared to the distance (r), the inverse square relation will not apply perfectly here.

The effect of distance (r) only alone can be seen with references to Figure 4.7, Figure 4.8, Figure 4.9 and Figure 4.10 in the lateral position, and Figure 4.27, Figure 4.28, Figure 3.29 and Figure 4.30 in the vertex position. In which there is not water in the phantom and according no attenuation of the incident or emitted X-rays.

In order to correlate the derived equation of the modelling with the empirical equation we use expansion series, as follows

$$
1-\exp [-(x-1)]=(x-1)-\frac{1}{2 !}(x-1)^{2}+\frac{1}{3 !}(x-1)^{3}-\cdots
$$

and

$$
\ln [x]=(x-1)-\frac{1}{2}(x-1)^{2}+\frac{1}{3}(x-1)^{3}-\cdots \quad(B)
$$

$\mathrm{x}$ near 1.0 , of an equation (B)

Neglecting the constants, the similarity between equation (A) and (B) is clear, especially at low concentrations. As the concentration increases the deviation between the two equations increases in the derived model neither the distance between the tumour and detector in the equation nor the absorption in water of incident and emitted rays were not taken as a parameter. Accordingly we do not expect the derived model can explain the experimental all data. 


\section{Empirical fitting data equation:}

In order to develop empirical equations from the experimental measurements to determine the concentration when the counts; the size of the tumour and the depth are given.

The equation is in the form of

$$
\mathrm{Y}=\mathrm{A} \operatorname{Ln}(\mathrm{x})+\mathrm{B}
$$

was utilised

\begin{tabular}{|l|l|l|}
\hline where & $Y=$ & Counts measured from the experiment \\
\hline & $\mathrm{X}=$ & Concentration of the Gd in a brain tumour vessel \\
\hline & A and B & $\begin{array}{l}\text { Are the equation's parameters given by the curve fitting } \\
\text { tools for each depth (ranges from } 0.5 \mathrm{~cm} \text { to } 4.5 \mathrm{~cm} \text { ), tumour } \\
\text { size, and shape }\end{array}$ \\
\hline
\end{tabular}

Table 4.1 shows the experiment results for a $1 \mathrm{~cm}^{3}$ brain tumour at several depths. Also, Figure 4.3 shows the counts for a fixed tumour volume.

The Gd concentration varies with depth. From this a relationship between the depth the concentration can be deduced as discussed below. 
Table 4.1: Counts for $30 \mathrm{~min}$ of $\mathrm{Gd}$ characteristic $\mathrm{X}$-rays at different concentrations of $\mathrm{Gd}$ and different depths inside the head phantom of a $1.0 \mathrm{~cm}$ diameter tumour in the lateral position.

\begin{tabular}{|c|c|c|c|c|c|}
\hline \multirow{2}{*}{$\begin{array}{c}\text { Distance from } \\
\text { Skull surface to } \\
\text { Tumour centre } \\
(\mathrm{cm})\end{array}$} & \multicolumn{5}{|c|}{ Concentration of $\mathbf{G d}(\mathrm{mg} / \mathrm{ml})$} \\
\hline & 15.73 & 31.45 & 47.18 & 62.9 & 78.63 \\
\hline 0.5 & $\begin{array}{c}2.89 \times 10^{4} \\
\pm 170\end{array}$ & $\begin{array}{c}5.72 \times 10^{4} \\
\pm 239\end{array}$ & $\begin{array}{c}7.09 \times 10^{4} \\
\pm 266\end{array}$ & $\begin{array}{c}7.89 \times 10^{4} \\
\pm 281\end{array}$ & $\begin{array}{c}8.17 \times 10^{4} \\
\pm 286\end{array}$ \\
\hline 1 & $\begin{array}{c}1.98 \times 10^{4} \\
\pm 141\end{array}$ & $\begin{array}{c}3.80 \times 10^{4} \\
\pm 195\end{array}$ & $\begin{array}{c}4.98 \times 10^{4} \\
\pm 223\end{array}$ & $\begin{array}{c}6.50 \times 10^{4} \\
\pm 255\end{array}$ & $\begin{array}{c}7.42 \times 10^{4} \\
\pm 272\end{array}$ \\
\hline 1.5 & $\begin{array}{c}6.36 \times 10^{3} \\
\pm 80\end{array}$ & $\begin{array}{c}3.03 \times 10^{4} \\
\pm 174\end{array}$ & $\begin{array}{c}3.85 \times 10^{4} \\
\pm 196\end{array}$ & $\begin{array}{c}4.86 \times 10^{4} \\
\pm 220\end{array}$ & $\begin{array}{c}5.82 \times 10^{4} \\
\pm 241\end{array}$ \\
\hline 2 & - & $\begin{array}{c}2.08 \times 10^{4} \\
\pm 144\end{array}$ & $\begin{array}{c}3.13 \times 10^{4} \\
\pm 177\end{array}$ & $\begin{array}{c}3.79 \times 10^{4} \\
\pm 195\end{array}$ & $\begin{array}{c}4.77 \times 10^{4} \\
\pm 218\end{array}$ \\
\hline 2.5 & - & $\begin{array}{c}1.81 \times 10^{4} \\
\pm 135\end{array}$ & $\begin{array}{c}2.78 \times 10^{4} \\
\pm 167\end{array}$ & $\begin{array}{c}3.15 \times 10^{4} \\
\pm 177\end{array}$ & $\begin{array}{c}3.77 \times 10^{4} \\
\pm 194 \\
\end{array}$ \\
\hline 3 & - & $\begin{array}{c}1.56 \times 10^{4} \\
\pm 125\end{array}$ & $\begin{array}{c}2.20 \times 10^{4} \\
\pm 148\end{array}$ & $\begin{array}{c}2.80 \times 10^{4} \\
\pm 167\end{array}$ & $\begin{array}{c}3.11 \times 10^{4} \\
\pm 176\end{array}$ \\
\hline 3.5 & - & $\begin{array}{c}1.10 \times 10^{4} \\
\pm 105\end{array}$ & $\begin{array}{c}1.78 \times 10^{4} \\
\pm 134\end{array}$ & $\begin{array}{c}2.21 \times 10^{4} \\
\pm 149\end{array}$ & $\begin{array}{c}2.44 \times 10^{4} \\
\pm 156\end{array}$ \\
\hline 4 & - & $\begin{array}{c}8.75 \times 10^{3} \\
\pm 94\end{array}$ & $\begin{array}{c}1.28 \times 10^{4} \\
\pm 113 \\
\end{array}$ & $\begin{array}{c}1.76 \times 10^{4} \\
\pm 133 \\
\end{array}$ & $\begin{array}{c}1.92 \times 10^{4} \\
\pm 139 \\
\end{array}$ \\
\hline 4.5 & - & $\begin{array}{c}7.67 \times 10^{3} \\
\pm 88\end{array}$ & $\begin{array}{c}1.08 \times 10^{4} \\
\pm 104\end{array}$ & $\begin{array}{c}1.44 \times 10^{4} \\
\pm 120\end{array}$ & $\begin{array}{c}1.59 \times 10^{4} \\
\pm 126\end{array}$ \\
\hline
\end{tabular}




\section{Step one:}

Using the Excel curve fitting tools a general equation can be developed as follows.

Using the counts versus concentrations for a $1.0 \mathrm{~cm}$ diameter tumour at different depths, curves of the fitting equations, as shown in Figure 4.3 are given by:

$$
\begin{array}{ll}
\mathrm{Y}_{0.5}=33623 \operatorname{Ln}(\mathrm{x})-61329 & \mathrm{R}^{2}=0.9811 \\
\mathrm{Y}_{1.0}=33595 \operatorname{Ln}(\mathrm{x})-75385 & \mathrm{R}^{2}=0.9778 \\
\mathrm{Y}_{1.5}=31025 \operatorname{Ln}(\mathrm{x})-78816 & \mathrm{R}^{2}=0.9914 \\
\mathrm{Y}_{2.0}=28389 \operatorname{Ln}(\mathrm{x})-77779 & \mathrm{R}^{2}=0.9832 \\
\mathrm{Y}_{2.5}=20540 \operatorname{Ln}(\mathrm{x})-52404 & \mathrm{R}^{2}=0.9858 \\
\mathrm{Y}_{3.0}=17295 \operatorname{Ln}(\mathrm{x})-44155 & \mathrm{R}^{2}=0.9957 \\
\mathrm{Y}_{3.5}=14855 \operatorname{Ln}(\mathrm{x})-39890 & \mathrm{R}^{2}=0.9917 \\
\mathrm{Y}_{4.0}=11922 \operatorname{Ln}(\mathrm{x})-32512 & \mathrm{R}^{2}=0.9838 \\
\mathrm{Y}_{4.5}=9301 \operatorname{Ln}(\mathrm{x})-24562 & \mathrm{R}^{2}=0.9885
\end{array}
$$




\section{Step Two:}

Table 4.2 lists the constant value (A and B) obtained from the curve fitting for each depth obtained from Figure 4.3.

Table 4.2: List of A \& B constant values.

\begin{tabular}{|c|c|c|}
\hline Depth $(\mathbf{c m})$ & A & B \\
\hline $\mathbf{0 . 5}$ & 33623 & 61329 \\
\hline $\mathbf{1 . 0}$ & 33595 & 75385 \\
\hline $\mathbf{1 . 5}$ & 31025 & 78816 \\
\hline $\mathbf{2 . 0}$ & 28389 & 77779 \\
\hline $\mathbf{2 . 5}$ & 20540 & 52404 \\
\hline $\mathbf{3 . 0}$ & 17295 & 44155 \\
\hline $\mathbf{3 . 5}$ & 14855 & 39890 \\
\hline $\mathbf{4 . 0}$ & 11922 & 32512 \\
\hline $\mathbf{4 . 5}$ & 9301 & 24562 \\
\hline
\end{tabular}

Equations of $\mathrm{A}$ and $\mathrm{B}$ constant are obtained by drawing the constant, versus depth, as is clear in Figure 4.36 and Figure 4.37. 


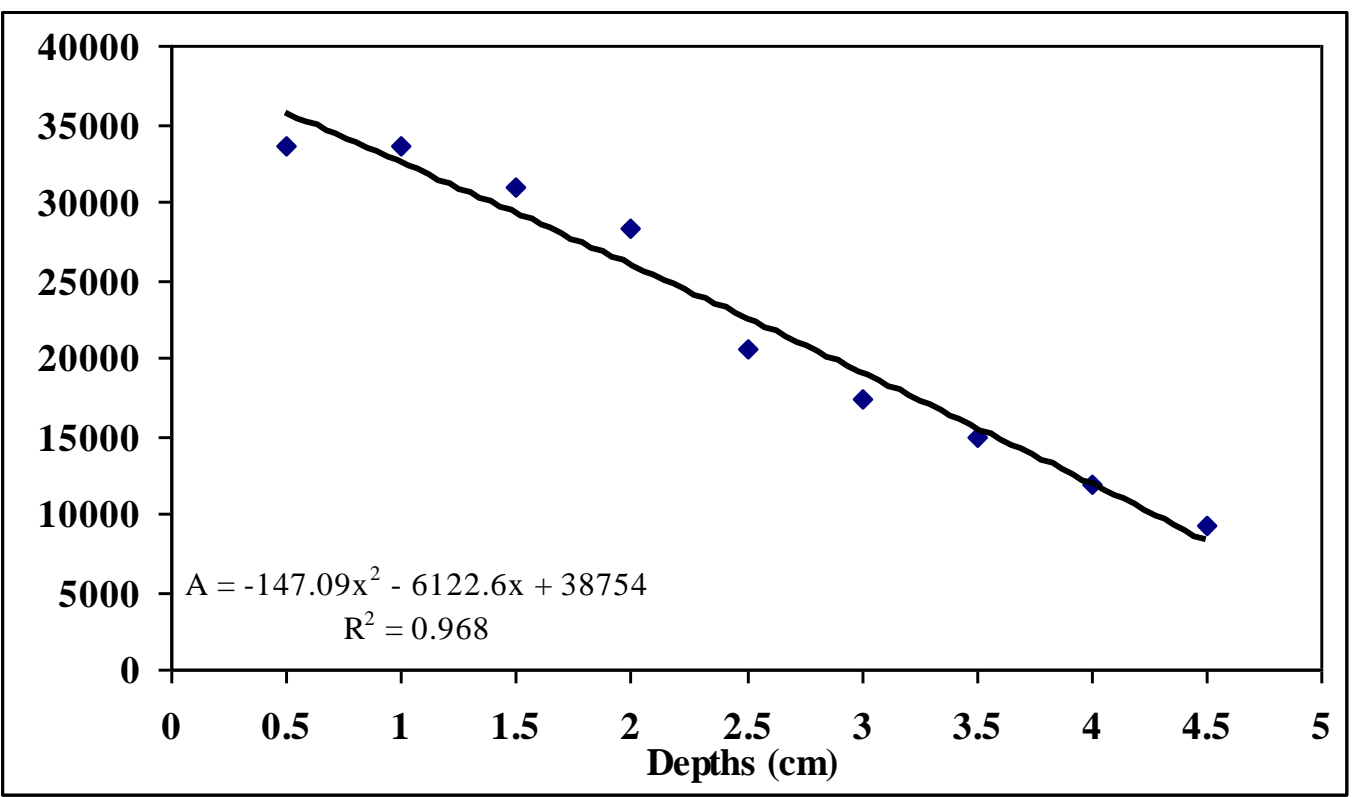

Figure 4.36: Value of A parameter versus depth.

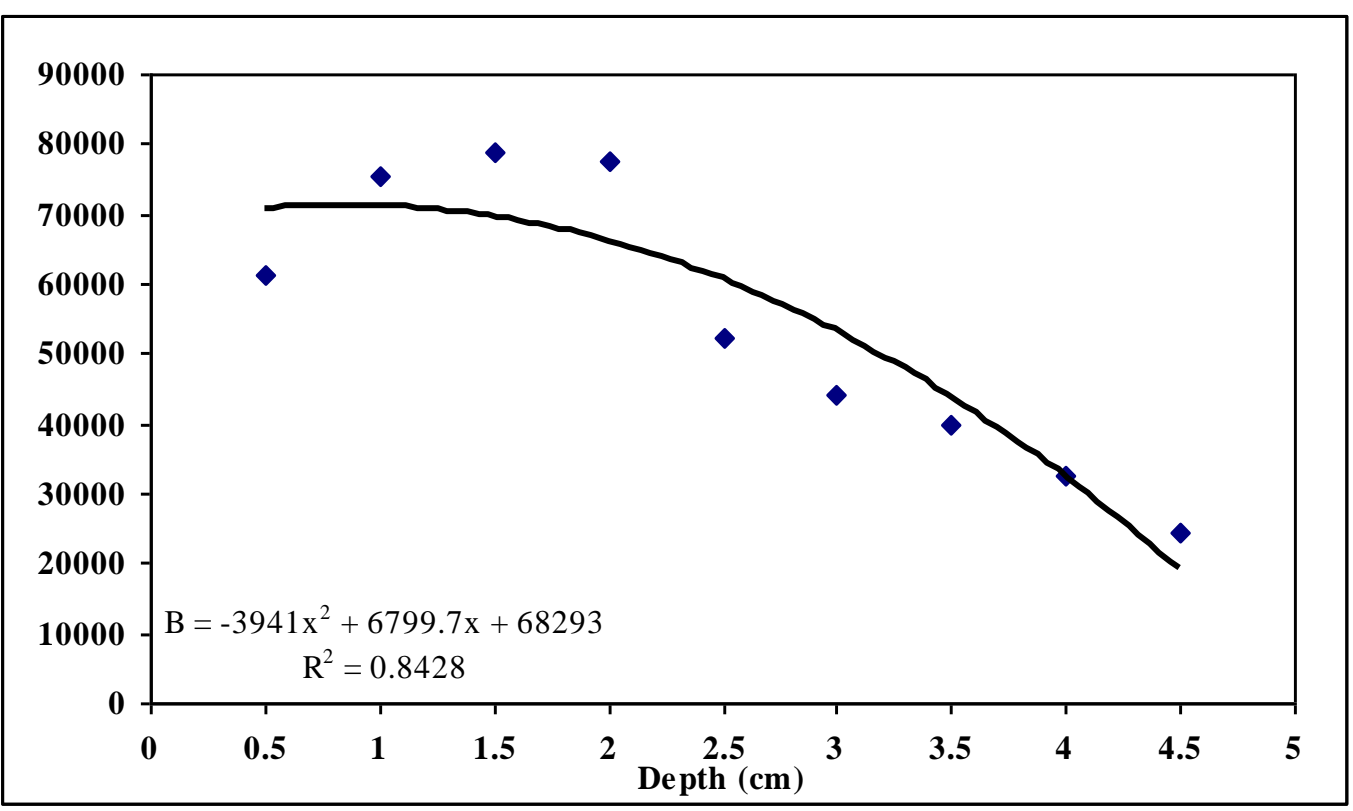

Figure 4.37: Value of B parameter versus depth. 
The above equation (13) was developed for a $1.0 \mathrm{~cm}^{3}$ tumour.

In order to generalise these equations with other tumours, of different volumes and shapes, we allowed the parameters $\mathrm{A}$ and $\mathrm{B}$ to be a function of depth. A power series fitting equation was utilised. If depth is the fitting equation for $\mathrm{A}$ and $\mathrm{B}$ :

$$
\begin{aligned}
& A=-147.09 \times \text { Depth }^{\wedge 2}-6122 \times \text { Depth }+38754 \\
& B=-3941 \times \text { Depth }^{\wedge 2}+6799.7 \times \text { Depth }+68293
\end{aligned}
$$

The reason for equations $15 \& 16$ being of a second degree order, is mainly decided by the curve fitting tool function. Different fitting techniques, such as linear or exponential fitting, do not provide a good match for the original curve. The R- squared as shown in Figure 4.36 and Figure 4.37 for A and B constants are 0.968 and 0.8428 , respectively. R-squared is defined as a number from 0 to 1 which shows how closely the estimated value for the trendline corresponds with the actual data. A fitting is most accurate when its R-squared value is near to 1 .

Putting equations (15) and (16) in equation (10), we have:

$$
\begin{aligned}
Y=( & \left.-147.09 \times \text { Depth }^{\wedge}-6122 \times \text { Depth }+38754\right) \operatorname{Ln}(X)+\left(-3941 \times \text { Depth }^{\wedge 2}\right. \\
& +6799.7 \times \text { Depth }+68293)
\end{aligned}
$$


We find the solution for $\mathrm{X}$ :

$$
\begin{gathered}
\mathrm{Y}=\mathrm{A} \operatorname{Ln}(\mathrm{X})+\mathrm{B} \\
\operatorname{Ln}(\mathrm{X})=\frac{Y-B}{A} \\
\mathrm{X}=\mathrm{e}^{(\mathrm{Y}-\mathrm{B}) / \mathrm{A}}
\end{gathered}
$$

Substituting the values of $\mathrm{A}$ and $\mathrm{B}$ in from the fitting equations yields the equations listed in Table 4.3, for different sizes with and without water in the head phantom. 
Table 4.3: List of general equations for each tumour case.

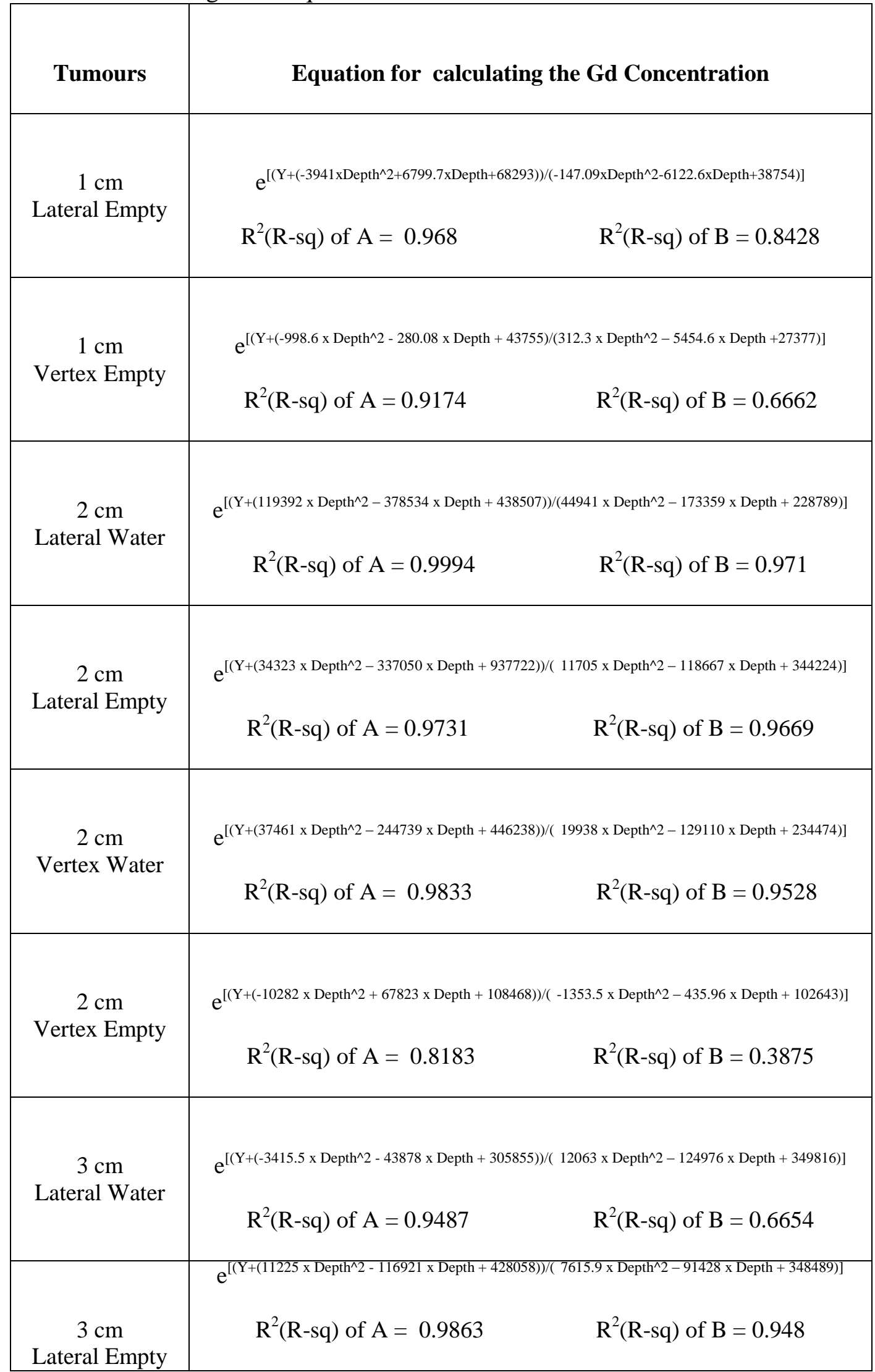




\begin{tabular}{|c|c|}
\hline $\begin{array}{c}3 \mathrm{~cm} \\
\text { Vertex Water }\end{array}$ & $\begin{array}{l}\mathrm{e}^{[(\mathrm{Y}+(-22709 \times \mathrm{Depth} \wedge 2+45210 \times \mathrm{Depth}+292154)) /(10022 \times \text { Depth } 2-129398 \times \mathrm{Depth}+406331)]} \\
\mathrm{R}^{2}\left(\mathrm{R} \text {-sq) of } \mathrm{A}=0.9127 \quad \mathrm{R}^{2}(\mathrm{R}-\mathrm{sq}) \text { of } \mathrm{B}=0.5668\right.\end{array}$ \\
\hline $\begin{array}{c}3 \mathrm{~cm} \\
\text { Vertex Empty }\end{array}$ & $\begin{array}{l}\mathrm{e}^{[(\mathrm{Y}+(396.1 \times \mathrm{D} \text { Depth^2 }-41190 \times \text { Depth }+298212)) /(4685 \times \text { Depth^2-66208 x Depth }+290691)]} \\
\mathrm{R}^{2}(\mathrm{R}-\mathrm{sq}) \text { of } \mathrm{A}=0.987 \quad \mathrm{R}^{2}(\mathrm{R}-\mathrm{sq}) \text { of } \mathrm{B}=0.9626\end{array}$ \\
\hline $\begin{array}{c}2 \times 4 \mathrm{~cm} \\
\text { Lateral Water }\end{array}$ & $\begin{array}{l}\mathrm{e}^{[(\mathrm{Y}+(81895 \times \mathrm{Depth} \wedge 2-477240 \times \text { Depth }+706859)) /(36012 \times \text { Depth } 2-220451 \times \text { Depth }+354437)]} \\
\mathrm{R}^{2}(\mathrm{R}-\mathrm{sq}) \text { of } \mathrm{A}=0.9587 \quad \mathrm{R}^{2}(\mathrm{R}-\mathrm{sq}) \text { of } \mathrm{B}=0.9511\end{array}$ \\
\hline $\begin{array}{c}2 \times 4 \mathrm{~cm} \\
\text { Lateral Empty }\end{array}$ & $\begin{array}{c}\mathrm{e}^{[(\mathrm{Y}+(17127 \times \mathrm{Depth} \wedge 2-153841 \times \mathrm{Depth}+410260)) /(8402.6 \mathrm{x} \text { Depth^2 }-81492 \times \mathrm{Depth}+237969)]} \\
\mathrm{R}^{2}(\mathrm{R}-\mathrm{sq}) \text { of } \mathrm{A}=0.9021 \quad \mathrm{R}^{2}(\mathrm{R}-\mathrm{sq}) \text { of } \mathrm{B}=0.8686\end{array}$ \\
\hline $\begin{array}{c}2 \times 4 \mathrm{~cm} \\
\text { Vertex Water }\end{array}$ & $\begin{array}{l}\mathrm{e}^{[(\mathrm{Y}+(77621 \times \text { Depth^2 }-535582 \times \text { Depth }+983429)) /(36843 \times \text { Depth^2 }-272599 \times \text { Depth }+533931)]} \\
\mathrm{R}^{2}\left(\mathrm{R} \text {-sq) of } \mathrm{A}=0.9712 \quad \mathrm{R}^{2}(\mathrm{R}-\mathrm{sq}) \text { of } \mathrm{B}=0.9562\right.\end{array}$ \\
\hline $\begin{array}{c}2 \times 4 \mathrm{~cm} \\
\text { Vertex Empty }\end{array}$ & $\begin{array}{l}\mathrm{e}^{[(\mathrm{Y}+(-10167 \times \text { Depth } 2+47188 \times \text { Depth }+77641)) /(-941.14 \times \text { Depth} \wedge 2-16795 \times \text { Depth }+152994)]} \\
\mathrm{R}^{2}(\mathrm{R}-\mathrm{sq}) \text { of } \mathrm{A}=0.9572 \quad \mathrm{R}^{2}(\mathrm{R}-\mathrm{sq}) \text { of } \mathrm{B}=0.8335\end{array}$ \\
\hline
\end{tabular}




\section{Minitab Regression Equation}

Another method was used to calculate the Gd concentration in the tumour vessel inside a head phantom, with and without water. This method was regression equation determined by using the Minitab programme.

Minitab is a statistical software programme used for data analysis capabilities.

The regression equation is

$$
\mathrm{Y}=\beta 1+\beta 2 * \log \mathrm{G}+\beta 3 * \text { Depth }
$$

\begin{tabular}{|l|l|l|}
\hline Where & $\mathrm{Y}=$ & Counts measured from the experiment \\
\hline & $\mathrm{G}=$ & Gadolinium concentration $/(\mathrm{mg} / \mathrm{ml})$ \\
\hline & $\mathrm{B}_{1,2,3}$ & Parameters given by regression tools \\
\hline
\end{tabular}


Table 4.4: $\log \mathrm{G}$ and counts measurement at different concentrations and depths inside a head phantom of $1 \mathrm{~cm}^{3}$, in the lateral position.

\begin{tabular}{|c|c|c|c|}
\hline $\begin{array}{l}\text { Tumour depth } \\
\text { (cm) }\end{array}$ & $\begin{array}{l}\text { Gadolinium concentration } \\
\qquad(\mathrm{mg} / \mathrm{ml})\end{array}$ & Counts & $\log G$ \\
\hline 0.50 & 15.70 & 28852.00 & 2.75 \\
\hline 1.00 & 15.70 & 19775.00 & 2.75 \\
\hline 1.50 & 15.70 & 6361.00 & 2.75 \\
\hline 0.50 & 31.50 & 57233.00 & 3.45 \\
\hline 1.00 & 31.50 & 38027.00 & 3.45 \\
\hline 1.50 & 31.50 & 30260.00 & 3.45 \\
\hline 2.00 & 31.50 & 20776.00 & 3.45 \\
\hline 2.50 & 31.50 & 18126.00 & 3.45 \\
\hline 3.00 & 31.50 & 15635.00 & 3.45 \\
\hline 3.50 & 31.50 & 10958.00 & 3.45 \\
\hline 4.00 & 31.50 & 8750.00 & 3.45 \\
\hline 4.50 & 31.50 & 7670.00 & 3.45 \\
\hline 0.50 & 47.20 & 70920.00 & 3.85 \\
\hline 1.00 & 47.20 & 49774.00 & 3.85 \\
\hline 1.50 & 47.20 & 38477.00 & 3.85 \\
\hline 2.00 & 47.20 & 31259.00 & 3.85 \\
\hline 2.50 & 47.20 & 27817.00 & 3.85 \\
\hline 3.00 & 47.20 & 21992.00 & 3.85 \\
\hline 3.50 & 47.20 & 17847.00 & 3.85 \\
\hline 4.00 & 47.20 & 12829.00 & 3.85 \\
\hline
\end{tabular}




\begin{tabular}{|c|c|c|c|}
\hline 4.50 & 47.20 & 10804.00 & 3.85 \\
\hline 0.50 & 62.90 & 78862.00 & 4.14 \\
\hline 1.00 & 62.90 & 64980.00 & 4.14 \\
\hline 1.50 & 62.90 & 48550.00 & 4.14 \\
\hline 2.00 & 62.90 & 37937.00 & 4.14 \\
\hline 2.50 & 62.90 & 31460.00 & 4.14 \\
\hline 3.00 & 62.90 & 28012.00 & 4.14 \\
\hline 3.50 & 62.90 & 22072.00 & 4.14 \\
\hline 4.00 & 62.90 & 17644.00 & 4.14 \\
\hline 4.50 & 62.90 & 14407.00 & 4.14 \\
\hline 0.50 & 78.60 & 81666.00 & 4.36 \\
\hline 1.00 & 78.60 & 74184.00 & 4.36 \\
\hline 1.50 & 78.60 & 58218.00 & 4.36 \\
\hline 2.00 & 78.60 & 47700.00 & 4.36 \\
\hline 2.50 & 78.60 & 37686.00 & 4.36 \\
\hline 3.00 & 78.60 & 31148.00 & 4.36 \\
\hline 3.50 & 78.60 & 24401.00 & 4.36 \\
\hline 4.00 & 78.60 & 19206.00 & 4.36 \\
\hline 4.50 & 78.60 & 15908.00 & 4.36 \\
\hline
\end{tabular}


The data shown in Table 4.4 were used to obtain the regression equation which is:

$$
\text { Counts }=-35396+26271 \operatorname{LogG}-13942 \text { Depth }
$$

From the equation (15) the amount of concentration is solved for G:

$$
\begin{gathered}
\mathrm{Y}=\beta 1+\beta 2 * \log \mathrm{G}+\beta 3 * \text { Depth } \\
\log \mathrm{G}=\frac{Y-\beta 1+\beta 3 * \text { Depth }}{\beta 2} \\
\mathrm{G}=\mathrm{e}^{(\mathrm{Y}-\beta 1+\beta 3 \text { Depth }) / \beta 2}
\end{gathered}
$$

By using Regression Analysis: Counts versus LogG, and Depth, different equations are obtained for different tumour vessel positioning, as shown in Table 4.5 . 
Table 4.5: List of Gd concentration equations for each tumour case using Minitab software.

\begin{tabular}{|c|c|}
\hline Tumours case & Equation for calculating the Gd concentration \\
\hline $\begin{array}{l}1 \mathrm{~cm} \\
\text { Lateral Empty }\end{array}$ & $\begin{array}{l}\mathrm{e}^{((\mathrm{Y}+35396+13942 \text { Depth }) / 26271)} \\
\mathrm{R}^{2}(\mathrm{R}-\mathrm{sq})=0.904\end{array}$ \\
\hline $\begin{array}{c}1 \mathrm{~cm} \\
\text { Vertex Empty }\end{array}$ & $\begin{array}{l}\mathrm{e}^{((\mathrm{Y}+19074+9926 \mathrm{Depth}) / 18370)} \\
\mathrm{R}^{2}(\mathrm{R}-\mathrm{sq})=0.917\end{array}$ \\
\hline $\begin{array}{c}2 \mathrm{~cm} \\
\text { Lateral Water }\end{array}$ & $\begin{array}{l}\mathrm{e}^{((\mathrm{Y}+11672+104230 \text { Depth }) / 80687)} \\
\mathrm{R}^{2}(\mathrm{R}-\mathrm{sq})=0.931\end{array}$ \\
\hline $\begin{array}{l}2 \mathrm{~cm} \\
\text { Lateral Empty }\end{array}$ & $\begin{array}{l}\mathrm{e}^{((\mathrm{Y}+109906+50993 \text { Depth }) / 106328)} \\
\mathrm{R}^{2}(\mathrm{R}-\mathrm{sq})=0.838\end{array}$ \\
\hline $\begin{array}{c}2 \mathrm{~cm} \\
\text { Vertex Water }\end{array}$ & $\begin{array}{l}\mathrm{e}^{((\mathrm{Y}-23766+125175 \text { Depth }) / 87997)} \\
\mathrm{R}^{2}(\mathrm{R}-\mathrm{sq})=0.952\end{array}$ \\
\hline $\begin{array}{c}2 \mathrm{~cm} \\
\text { Vertex Empty }\end{array}$ & $\begin{array}{l}\mathrm{e}^{((\mathrm{Y}+79639+36751 \text { Depth }) / 84138)} \\
\mathrm{R}^{2}(\mathrm{R}-\mathrm{sq})=0.958\end{array}$ \\
\hline $\begin{array}{c}3 \mathrm{~cm} \\
\text { Lateral Water }\end{array}$ & $\begin{array}{l}\mathrm{e}^{((\mathrm{Y}-125209+139420 \text { Depth }) / 133741)} \\
\mathrm{R}^{2}(\mathrm{R}-\mathrm{sq})=0.876\end{array}$ \\
\hline $\begin{array}{l}\qquad 3 \mathrm{~cm} \\
\text { Lateral Empty }\end{array}$ & $\begin{array}{l}\mathrm{e}^{((\mathrm{Y}-198421+99569 \mathrm{Depth}) / 131741)} \\
\mathrm{R}^{2}(\mathrm{R}-\mathrm{sq})=0.877\end{array}$ \\
\hline $\begin{array}{c}3 \mathrm{~cm} \\
\text { Vertex Water }\end{array}$ & $\begin{array}{l}\mathrm{e}^{((\mathrm{Y}-144282+175695 \text { Depth }) / 164329)} \\
\mathrm{R}^{2}(\mathrm{R}-\mathrm{sq})=0.870\end{array}$ \\
\hline $\begin{array}{c}3 \mathrm{~cm} \\
\text { Vertex Empty }\end{array}$ & $\begin{aligned} \mathrm{e}^{((\mathrm{Y}-114655+78347 \text { Depth }) / 124162)} \\
\mathrm{R}^{2}(\mathrm{R}-\mathrm{sq})=0.883\end{aligned}$ \\
\hline
\end{tabular}




\begin{tabular}{|c|c|}
\hline $\begin{array}{l}2 \times 4 \mathrm{~cm} \\
\text { Lateral Water }\end{array}$ & $\mathrm{R}^{2}(\mathrm{R}-\mathrm{sq})=0.80$ \\
\hline $\begin{array}{l}2 \times 4 \mathrm{~cm} \\
\text { Lateral Empty }\end{array}$ & $\begin{array}{l}\mathrm{e}^{((\mathrm{Y}-40555+51403 \text { Depth }) / 79201)} \\
\mathrm{R}^{2}(\mathrm{R}-\mathrm{sq})=0.808\end{array}$ \\
\hline $\begin{array}{c}2 \times 4 \mathrm{~cm} \\
\text { Vertex Water }\end{array}$ & $\begin{array}{l}\mathrm{e}^{((\mathrm{Y}-169009+115071 \text { Depth }) / 83709)} \\
\mathrm{R}^{2}(\mathrm{R}-\mathrm{sq})=0.892\end{array}$ \\
\hline $\begin{array}{c}2 \times 4 \mathrm{~cm} \\
\text { Vertex Empty }\end{array}$ & $\begin{array}{l}\mathrm{e}^{((\mathrm{Y}-105323+54294 \mathrm{Depth}) / 75542)} \\
\mathrm{R}^{2}(\mathrm{R}-\mathrm{sq})=0.921\end{array}$ \\
\hline
\end{tabular}

The above equations in Table 4.3 and Table 4.5 provide a good indication of the Gd concentration as obtained from the practical measurements with slight differences. This is contributed to the accuracy of the curve fitting method.

The problem with the above approach is that the above equation is only valid for the specific case study (i.e. e. $1.0 \mathrm{~cm}^{3}$, lateral position of the head phantom empty) and cannot be implemented in other cases $\left(e . g ., 1.0 \mathrm{~cm}^{3}\right.$ vertex position of the head phantom empty). Each case requires its own equation driven by the same steps as above. Refer to Table 4.3 and Table 4.5 for a list of the equations for different sized tumours with and without water, inside the head phantom. 


\section{Application of this work in treatment:}

1. Neutron capture therapy with maximum Gd concentration:

This work has an immediate application in the real treatment of NCT. Using a geometry similar to the one used here, measurements (count rate) can be taken at several times during exposure to incident gamma radiation, for the purpose of finding the time of maximum Gd concentration. At maximum $\mathrm{Gd}$ concentration, neutron treatment can start and maximum dose will be delivered to the tumour. The concentration or the total amount of $\mathrm{Gd}$ in the tumour will determine the dose delivered. This is significant for any radiation therapy treatment.

\section{Diagnostic Imaging:}

This method can be used for tumour imaging purposes. Again, the count rate can be measured continuously, until the maximum value is reached. At this stage imaging by $x$-ray radiography, from different projects can take place. This accurately locates the tumour position. This can be easier than the MRI process which usually takes much longer time ( $20-60 \mathrm{~min})$. The patient is expected to stay without any movement; a process that is of discomfort to patients. Moreover, Gd may start to be eliminated from the tumour, if the process is too long. 


\section{CHAPTER 5}

\section{CONCLUSIONS}

An analysis of $\mathrm{Gd}$ concentration in the brain tumour vessel by XRF provided very useful information. It suggested the effective dose delivery to the tumour and what preventive measures should be taken to reduce the dose to the healthy tissue.

The dose delivered to the tumour is of prime interest to therapists. Because the Gd compounds gradually build up in the tumour, followed by elimination, it is important to know the time when the highest concentration is reached, in order to give the highest dose.

Measuring the concentration of Gd leads to dose assessment as well as to the time it takes to reach the highest concentration at which treatment can start. It should be mentioned that the time needed for the concentration to reach a maximum value, depends on each individual human body and can differ from one patient to another. Individual measurement of Gd concentration is therefore vital.

Other techniques, such as MRI, are qualitative and do not provide concentration values. Moreover, it is time consuming and impractical for detecting when the highest concentration is reached. The best time to use this technique is immediately prior to the treatment procedure. It is also useful to measure the concentration immediately after treatment, in order to know how much Gd has been eliminated. Measurement during treatment is also possible. 
The purpose of this research was to provide a method for analysis of the amount of Gd that was in the brain tumour vessel, where the Gd atoms, in the tumour vessel, were excited by a $36 \mathrm{GBq}(0.97 \mathrm{Ci}){ }^{241} \mathrm{Am}$ source that emits gamma rays of $59.54 \mathrm{keV}$, in $35.7 \%$ of it's decays causing the Gd atoms, to emit a characteristic fluorescence at $42.98 \mathrm{keV}$ in the resulting $\mathrm{X}$-ray fluorescence spectrum. The intensity of the XRF radiation was proportional to the amount of Gd present in the brain tumour vessel. A Cadmium Telluride (CdTe) detector was used to evaluate and make an analysis of the Gd concentration. Determinations of the Gd content were obtained directly from the detector measurements of XRF from the exposed tumour vessel. Depending on the size of the tumour vessel, a depth was chosen from the skull surface to the centre of the tumour vessel. The positioning of the head phantom was selected to be either in the lateral and vertex positions. Different sizes of tumour vessels, such as spherical tumour vessels of $1.0,2.0,3.0 \mathrm{~cm}$ and an oval tumour vessel of $2.0 \mathrm{~cm}$ diameter and $4.0 \mathrm{~cm}$ length, containing the Gd agent were used. They were placed at different depths inside a head phantom at different positions in front of the detector and the source for the measurements. Different concentrations of $\mathrm{Gd}$ were subjected to 30 minutes of detector live time, and the characteristic x-ray emission was measured. The Gd concentrations which were investigated started from 5.62 and ranged up to 78.63 $\mathrm{mg} / \mathrm{ml}$.

These levels were selected because the lowest concentration used, detected by the detector, corresponded to $5.62 \mathrm{mg}$ of Gd per millilitre of the brain tumour volume. The highest concentration used was $78.63 \mathrm{mg} / \mathrm{ml}$. Different parameters impact on the experiment outcome, in terms of the total counts. The first 
parameter was the amount of the Gd in the tumour vessel. Increasing the amount of $\mathrm{Gd}$ in the tumour vessel leads to increases in the total counts detectable. Total counts proportionally increased as the concentration and total amounts of Gd increased which as one would expect. The relation is not a straight line, possibly due to self absorption of the characteristics x-rays inside the tumour. As the concentration or the total amount of Gd increased, a portion of emitted characteristics X-rays were absorbed within the tumour containing Gd which has a much higher attenuation compared to that containing water and that because Gd is a chemical element in the periodic table that has atomic number 64 which therefore would increase photon absorption leading to a reduction in the detected total counts.

The second effect, which impacted on the experimental outcome, was the location of the tumour inside the head phantom. This effect was studied at different distances from the surface of the head phantom to the centre of the tumour vessel. These depths, ranged from $0.5 \mathrm{~cm}$ to $5.5 \mathrm{~cm}$ between the centre of the tumour and interior wall of the head phantom surface. The results showed it was possible to measure the lower concentration of the $\mathrm{Gd}$, for deeper distances inside the head phantom, such as the case of a depth of $5.5 \mathrm{~cm}$. Furthermore, it was clear, that the deeper the tumour inside the head phantom, the lower the counts, due to the increased distance from the detector. Because of the size of the tumour vessel of $1.0 \mathrm{~cm}$ diameter, it was difficult to measure the characteristic $\mathrm{x}$ rays that were emitted from the tumour, containing $\mathrm{Gd}$ in the head phantom which was filled with water to equivalent biological tissue. Consequently, all the experiments were conducted in empty head phantoms. 
The study showed that it is possible to measure Gd in the brain tumour vessel by using XRF. It also provided information concerning those aspects of radiotherapy planning that need the most attention to optimise the dose treatment in radiotherapy. One more advantage of this method can be understanding the tumour Gd uptake, where the blood supply in the vessels of the cancer tumour is very limited. A benign tumour has more blood supply. Therefore, this study may give some information about the pathology of the tumour.

The activity of the source directly affects the count rate. In this work 30 minutes counting time was required. In order to reduce the count rates the source activity needs to be increased. At $100 \mathrm{Ci}$ source the same counts can be obtained in 0.3 minutes (18 seconds). This is a very practical and fast measurement and can provide instantaneous concentration values of $\mathrm{Gd}$ during the build-up in the tumour or the elimination from it.

Our work suggests that a total collected count depends not only on the total amount of Gd present, but also on the shape, size and depth of the tumour. Fortunately these parameters can be found by using ordinary and rapid radiography which gives instantaneous data, as shown in this work. It should be mentioned a radiographic film was used in this work. If digital radiography (DR) or computerised radiography had been used, a better image could have been obtained.

The gamma rays emitted from the source are of energy $59.5 \mathrm{keV}$. This is adequate energy for such an application. The absorption by the Gd atom for a lower energy close to that of the binding energy of Gd $(50.23 \mathrm{keV})$ can be higher. But by using lower energy the attenuation in the head phantom contain water will 
be higher as well. For a higher energy source the attenuation in water is lower but the absorption cross section by Gd will be lower as well. We recommend that the lower energy require should be investigated. Unfortunately, there are not many sources of lower energy with a long enough half life to make them practical for such applications. Most available sources that emit $40-60 \mathrm{keV}$ have a short half life.

Total numbers of examinations were 478; at the vertex position were 232 comparing the following cases: 39 were for the $1.0 \mathrm{~cm}$ spherical tumour, 55 were for the $2.0 \mathrm{~cm}$ spherical tumour, 75 were for the $3.0 \mathrm{~cm}$ spherical tumour and 63 were for the $2.0 \times 4.0 \mathrm{~cm}$ ellipsoid tumour. While the total numbers of examinations in the lateral position were 246 comparing the following cases: 39 were for the $1.0 \mathrm{~cm}$ spherical tumour, 55 were for the $2.0 \mathrm{~cm}$ spherical tumour, 75 were for the $3.0 \mathrm{~cm}$ spherical tumour and 77 were for the $2.0 \times 4.0 \mathrm{~cm}$ ellipsoid tumour. 


\section{REFERENCES}

1. Zizzari., A., Automatic Definition of Planning Target Volume in Computer-Assisted Radiotherapy.

2. R. K. Ten Haken, et al., A quantitative assessment of the addition of MRI to $C T$ - bases, 3D treatment planning of brain tumors. Radiotherapy Oncol., 1992. 25: p. 121-133.

3. Association, T.A.B.T., Central brain tumor registry of the United States. 1997.

4. C. K. Bomford, S. B. Sherriff, and I. H. Kunkler, Textbook of Radiotherapy, Radiation Physics, Therapy and Oncology. 1993: Churchill Livingstone.

5. S. Vynkier, Dosimetry of clinical neutron and proton beams: an overview of

recommendation. Radiation Protection Dosimetry, 2004. 110: p. 565-572.

6. Wheldon, T.E., Radiation physics and genetic targeting: new directions for radiotherapy. Phys. Med. Biol 2000. 45 R77-R95.

7. O. A. Pettersson, et al., A facility for Biomedical experiments with thermal neutrons. Phys Med Biol, 1993. 38: p. 1081-1088.

8. V. M. Runge and J.R. Parker, Worldwide clinical safety assessment of gadoteridol injection: an update. Eur. J. Radiol, 1997. 7: p. S243-S245.

9. H. J. Weinmann, et al., Characteristics of Gadolinium-DTPA Complex: A Potential NMR Contrast Agent. Am .J. Roentgenol 1984. 142: p. 619-624.

10. B. Hofmann, et al., Gadolinium Neutron Capture Therapy (GdNCT) of Melanoma Cells and Solid Tumors With the Magnetic Resonance Imaging Contrast Agent Gadobutrol. INVESTIGATIVE RADIOLOGY, 1999. 34(2): p. 126-133.

11. B. J. Allen, B.J. MeGregor, and R.F. Martin, Neutron capture therapy with gadolinium-157. Strahlentherapie and onkologie, 1989. 165: p. 156-157.

12. R. F. Martin, et al., Induction of DNA Double-Strand Breaks by $157 \mathrm{Gd}$ Neutron Capture. Pigment Cell Research, 1989. 2: p. 330-332. 
13. G. V. Miloshevsky, et al., Elastic scattering of electrons by gadolinium and barium atoms. Nuclear Instruments and Methods in Physics Research B, 2000. 168(4): p. 467-472.

14. M. Flego, K. Nicolay, and P. Watkins, Three dimensional back-projection reconstruction methods for Magnetic Resonance Imaging (MRI) of nuclei with short relaxation times. Advances in Neutron Capture Therapy, Medicin and Physics, 1997. 1: p. 289-293.

15. K. Yoshida, et al., Assessment of T1 time course changes and tissue blood ratios after Gd-DTPA administration in brain tumors. Magnetic Resonance Imaging, 1989. 7: p. 9-15.

16. A. A. Harms and G.R. Norman, The Role of Internal Conversion Electrons in Gadolinium-Exposure Neutron Imaging. J. Appl. Phys, 1972. 43(7): p. 3209-3212.

17. T. Zhang, et al., A Comparison of In Vivo Gd-NCT Trial by Using Two Targeting Compounds: Gd-BOPTA and Gd-DTPA. Research and Development in Neutron Capture Therapy: Proc. 10th Congress on Neutron Capture Therapy, 2002: p. 807-812.

18. G. V. Miloshevsky, et al., Calculated gadolinium atomic electron energy levels and Auger electron emission probability as a function of atomic number Z. Nuclear Instrumment and Methods in Physics Research B, 2002. 192: p. 360-364.

19. H. Ichikawa and Y. Fukumori, Formulation Considerations of Gadolinium Lipid-Nanoemulsion for Intraveneous Delivery to Tumor in Neutron Capture Therapy. Research and Development in Neutron Capture Therapy: Proc. 10th Congress on Neutron Capture Therapy, Medimond S.R.L, Bologna, Italy, 2002: p. 797-801.

20. J. Carlsson, et al., Radiation Therapy Through Activation of Stable Nuclides. Acta Oncological, 2002. 41: p. 629-634.

21. Eileen M. Skelly Frame and E.E. Uzgiris, Gadolinium determination in tissue samples by inductively coupled plasma mass spectrometry and inductively coupled plasma atomic emission spectrometry in evaluation of the action of magnetic resonance imaging contrast agents. Analyst, 1998. 123: p. 675-679.

22. Eric J. Bernhard, et al., Re-Evaluating Gadolinium(III) Texaphyrin as a Radiosensitizing Agent. Cancer Research, 2000. 60: p. 86-91. 
23. George A. Miller, et al., Gadolinium Neutron Capture Therapy. Nuclear Technology, 1993. 103: p. 320-331.

24. S. A. Klykov, et al., Tissue absorbed dose from a gadolinium layer irradiated with neutrons. Atomic Energy, 2004. 96(6): p. 430-433.

25. M. E. Bartolini, et al., An investigation of the toxicity of gadolinium based MRI contrast agents using neutron activation analysis. Magnetic Resonance Imaging, 2003. 21(5): p. 541-544.

26. A. A. Burlon, et al., In-phantom dosimetry for the $13 C(d, n) 14 N$ reaction as a source for accelerator-based BNCT. Medical Physics, 2001. 28(5): p. 796-803.

27. G. W. Kabalka, et al., Evaluation of Fluorine-18-BPA-Fructose for Boron Neutron Capture Treatment Planning. The Journal of Nuclear Medicine, 1997. 38(11): p. 1762-1767.

28. H. F. Arlinghaus, et al., Imaging of Boron in Tissue at the Cellular Level for Boron Neutron Capture Therapy. Analytical Chemistry, 1997. 69(16): p. 3169-3176.

29. D. A. Allen, T. D. Beynon, and J. Perks, In vivo on-line $10 B(n, \alpha)$ three dimensional dosimetry using binary Gabor zone plate encoded $\gamma$-ray holography. Advances in Neutron Capture Therapy, Medicine and Physics, 1997. 1: p. 229-236.

30. K. M. Bradshaw, et al., BSH Distribution in the Canine Head and a Human Patient Using 11B MRI. Magn Reson Med, 1995. 34: p. 48-56.

31. G. Strgliotto, et al., Biodistribution of Boron Sulfhydryl (BSH) in Humans: A Quality Control of Analytical Methods. Progress in Neutron Capture Therapy for Cancer. New York, Plenum Press, 1992: p. 545-547.

32. W. A. Ausserer, et al., Quantitative Imaging of Boron, Calcium, Magnesium, Potassium, and Sodium Distributions in Cultured Cells with Ion Microscopy. Analytical Chemistry, 1989. 61(24): p. 2690-2695.

33. T. Matsumoto and O. Aizawa, Head phantom experiment and calculation for boron neutron capture therapy. Phys. Med. Biol., 1988. 33(6): p. 671686.

34. D. Gabel, S. Foster, and R. Fairchild, The Monte Carlo Simulation of the Biological Effects o the 10B $(n, \alpha) 7 L i$ Reaction in Cells and Tissue and its 
Implications for Boron Neutron Capture Therapy. Radiation Research, 1987. 111: p. 14-25.

35. D. Gabel, et al., Quantitative Neutron Capture Radiography for Studying the Biodistribution of Tumor-seeking Boron-containing Compounds. Cancer Research, 1987. 47: p. 5451-5454.

36. T. Kobayashi and K. Kanda, Analytical Calculation of Boron-10 Dosage in Cell Nucleus for Neutron Capture Therapy. Radiation research, 1982. 91: p. 77-94.

37. G. Stragliotto and H. Fankhauser, Biodistribution of Boron Sulfhydryl for Boron Neutron Capture Therapy in Patients with Intracranial Tumors. Neurosurgery, 1995. 36(2): p. 285-293.

38. B. H. Laster, et al., The Biological Effects of Auger Electrons Compared to $\alpha$-Particles and Li Ions. Acta Oncologica, 1996. 35(7): p. 917-923.

39. Y. Zhao, et al., A combination of gadolinium and boron compounds for use in Gd-BNCT. Advance Neutron Capture Therapy, Chemistry and Biology, 1997. 11: p. 451-455.

40. R. M. Brugger and J. A. Shih, Evaluation of Gadolinium-57 as a neutron capture therapy agent. Strahlentherapie and onkologie,, 1989. 165(Nr. 2/3): p. 153-156.

41. J. A. Shih and R. M.Brugger, Gadolinium as a neutron capture therapy agent. Progress in Neutron Capture Therapy for Cancer, Plenum Publishing Corp. New York, 1992: p. 183-186.

42. G.R. Moran, et al., An investigation of the toxicity of gadolinium based MRI contrast agents. Proc. Intl. Soc. Mag. Reson. Med., 2002. 10.

43. Jing-Luen A. Shih and Robert M. Brugger, Neutron Autoradiography of Trace Amount of Gadolinium. Nuclear Technology, 1992. 98: p. 217-223.

44. Chr. Reiners, et al., X-ray fluorescence analysis (XFA) of thyroidal iodine content (TIC) with an improved measuring system. Experimental and Clinical Endocrinol Diabetes, 1998. 106(3): p. S31-S33.

45. T. Gronberg, et al., Non-invasive estimation of kidney function by x-ray fluorescence analysis. Method for in vivo measurements of iodinecontaining contrast media in rabbits. Phys. Med. Biol., 1981. 26(3): p. 501-506. 
46. J. Borjesson, S. Mattsson, and M. Alpsten, Trace Element Concentrations Studied In Vivo Using X-ray Fluorescence Analysis. Appl. Radiat. Isot., 1998. 49(5/6): p. 437-445.

47. L. Gerhardsson, et al., In Vivo XRF as a Means to Evaluate the Risk of Kidney Effects in Lead and Cadmium Exposed Smelter Workers. Appl. Radiat. Isot., 1998. 49(5/6): p. 711-712.

48. V. Zaichick and N. Ovchjarenko, In Vivo X-ray Fluorescence for Estimation of Essential and Toxic Trace Elements in Teeth. Appl. Radiat. Isot., 1998. 49(5/6): p. 721 - 722.

49. Ulf Nilsson and S. Skerfving, In vivo x-ray fluorescence measurements of cadmium and lead. Scand J work Environ Health, 1993. 19(1): p. 54-58.

50. A. Tartari, et al., X-ray fluorescence analysis of $C d$ and tissue characterization via scattered radiation evaluation: A feasibility study for in vivo applications. Appl. Radiat. Isot., 1995. 46(6/7): p. 605-606.

51. Brian J. Thoms, Equipment Design Issues for the In Vivo X-Ray Fluorescence Analysis of Bone Lead. Environmental Health Perspectives, 1991. 91: p. 39-43.

52. L. Wielopolski, et al., Feasibility of noninvasive analysis of lead in the human tibia by soft x-ray fluorescence. Med. Phys., 1983. 10(2): p. 248251.

53. P. J. Mountford, et al., Tibial lead determination by $99 m T c$ radiopharmaceutical x-ray fluorescence. Physics in Medicine and Biology, 1994. 39(4): p. 773-779.

54. Gelsomina De Stasio, et al., Gadolinium in Human Glioblastoma Cells for Gadolinium Neutron Capture Therapy. Cancer Research, 2001. 61: p. 4272-4277.

55. Alicia T. Tatham, et al., Relaxation Properties of a Dual-Labeled Probe for MRI and Neutron Capture Therapy. Magnetic Resonance in Medicine, 1999. 42: p. 32-36.

56. Tim Goorley and Hooshang Nikjoo, Electron and Photon Spectra for Three Gadolinium-Based Cancer Therapy Approaches. Radiation Research, 2000. 154: p. 556-563. 
57. Jevremovice., C.N.C.a.T., Computational assessment of improved cell-kill by gadolinium-supplemented boron neutron capture therapy. Physics in Medicine and Biology., 2003. 48: p. 3943-3959.

58. Jing-luen A. Shih and Robert M. Brugger, Gadolinium as a neutron capture therapy agent. Medical Physics, 1992. 19(3): p. 733-744.

59. Matsumoto, T., Evaluation of depth-dose distributions for gadolinium neutron captures therapy. Advance in Neutron Capture Therapy, Plenum Press, New York, 1993: p. 235-239.

60. K. Kagehira, et al., Physical Dose Evaluation on Gadolinium Neutron Capture Therapy. Annu. Rep. Res. Reactor Inst. Kyoto Univ., 1994. 27: p. 42-56.

61. T. Maeda, et al., Calculation of the Electron Energy Spectrum for Gadolinium Capture Therapy. Annu. Rep. Res. Reactor Inst. Kyoto Univ., 1995. 28: p. 39-43.

62. J. T. Masiaskowski, J. L. Horton, and L. J. Peters, Gadolinium neutron capture therapy for brain tumors: A computer study. Med. Phys., 1992. 19(5): p. 1277-1284.

63. Shirin A. Enger, et al., Gadolinium Neutron Capture Brachytherapy (GdNCB), A New Treatment Method for Intravascular Brachytherapy. Med. Phys., 2006. 33(1): p. 46-51.

64. S. M. Lombard and T. L. Isenhour, Determination of Samarium and Gadolinium in Rare Earth Ores by Neutron Capture Gamma-Ray Activation Analysis. Analytical Chemistry, 1969. 41(8): p. 1113-1116.

65. LND, I.D.M.o.N.R.D., 2022 Cylindrical Bf3 Neutron Detector Manual, 3230 LAWSON BLVD., OCEANSIDE, NEW YORK 11572.

66. Messtechnik, A.u., Teletctor 6112B Manual, Ladenberg, Germany.

67. Technology, N.E., NM2B Neutron Monitor Manual, United Kingdom.

68. Chung, Z.B.A.a.C., Prompt Gamma Neutron Activation Analysis. 1995: CRC Press.

69. Lamarsh, J.R., Interoduction to Nuclear Engineering. 2nd Edition ed. 1983: Addison- Wesley Publishing Company, Inc. 
70. Churchin Association LTD, U., The Phantom Laboratory Manual. 1997.

71. Amptek Inc, U., XR - 100T - Cadmium Telluride Detector Manual.

72. Firestone., E.B.a.R.B., Table of radioactive isotopes. 1986.

73. A. Martin and S. Harbison, An introduction to radiation protection. Fifth edition ed. Vol. Chapter 2. 2006: Hodder Aronold. 11-12.

74. Cember, H., Introduction to health physics. Third edition ed. Vol. Chapter 4. 1996: McGraw-Hill companies, Inc. 87-91.

75. David J. Spinosa, J.A.K., and Gary D., Hartwell Gadolinium Chelates in Angiography and Interventional Radiology: A Useful Alternative to Iodinated Contrast Media for Angiography. University of Virginia, Health System, 2002. 223: p. 319-325.

76. Nyman Ulf., B.E., Peter Leander, Mats Nilsson, Klaes Golman, and Torsten Almén . Are Gadolinium-based Contrast Media Really Safer than Iodinated Media for Digital Subtraction Angiography in Patients with Azotemia. Radiology, 2002. 223: p. 311-318.

77. Vivian S. Lee, M.H., Cardiovascular MRI: Physical Principles to Practical Protocols. Vol. Chapter 3. 2005: Lippincott Williams \& Wilkins. 44.

78. S. Fine and C.F. Hendee, X-Ray Critical-Absorption and Emission Energies in $\mathrm{keV}$.

79. R.D. Deslattes, et al., X-Ray Transition Energies Database. 2003.

80. Laboratory, N.P., X-ray adsorption edges and characteristic X-ray line energies $(\mathrm{keV})$.

81. Faiz M. Khan, The physics of radiation therapy. Third edition ed. Vol. Chapter 5. 2003: Lippncott Williams \& Wiilkins. 66-67.

82. Shapiro, J., Radiation protection, A guide for scientists, regulators, and physicians. Fourth edition ed. 2002: Harvard university press. 39-43.

83. Bushberg T., a.S.J., The Essential Physics Of Medical Imaging. Second edition ed. Vol. Chapter 5. 2002: Lippincott Williams \& Wilkins. 100-102. 
84. Stewart C., B., Radiologic science for technologist. Fourth edition ed. Vol. Chapter 8. 1988, Washington: The C.V. Company. 141-142.

85. Lucian Wielopolski, Design consideration for an EDXRF system for in vivo elemental analysis. Adv. X-Ray Anal, 1999. 41: p. 892-897. 